\title{
Clean Option: An Alternative Strategy for Hanford Tank \\ Waste Remediation
}

\author{
Volume 2: Detailed Description \\ of First Example Flowsheet
}

J. L. Swanson

September 1993

Prepared for the U.S. Department of Energy under Contract DE-AC06-76RLO 1830

Pacific Northwest Laboratory

Operated for the U.S. Department of Energy by Battelle Memorial Institute 


\title{
DISCLAIMER
}

This report was prepared as an account of work sponsored by an agency of the United States Government. Neither the United States Government nor any agency thereof, nor Battelle Memorial Institute, nor any of their employees, makes any warranty, expressed or implied, or assumes any l gal liability or responsibility for the accuracy, completeness, or usefulness of any information, apparatus, product, or process disclosed, or represents that its use would not infringe privately owned rights. Reference herein to any specific commercial product, process, or service by trade name, trademark, manufacturer, or otherwise does not necessarily constitute or imply its endorsement, recommendation, or favoring by the United States Government or any agency thereof, or Battelle Memorial Institute. The views and opinions of authors expressed herein do not necessarily state or reflect those of the United States Government or any agency thereof.

\author{
PACIFIC NORTHWEST LABORATORY \\ operated by \\ BATTELLE MEMORIAL INSTITUTE \\ for the \\ UNITED STATES DEPARTMENT OF ENERGY \\ under Contract DE-AC06-76RLO 1830
}

Printed in the United States of America

Available to DOE and DOE contractors from the

Office of Scientific and Technical Information, P.O. Box 62, Oak Ridge, TN 37831;

prices available from (615) 576-8401, FTS 626-8401.

Available to the public from the National Technical Information Service,

U.S. Department of Commerce, 5285 Port Royal Rd., Springfield, VA 22161. 
Clean Option: An Alternative Strategy for Hanford Tank Waste Remediation

\section{Volume 2. Detailed Description of First Example Flowsheet}

J. L. Swanson

September 1993

Prepared for

the U.S. Department of Energy

under Contract DE-AC06-76RLO 1830

Pacific Northwest Laboratory

Richland, Washington 99352 


\section{Summary}

Plans for remediation of the Hanford underground storage tanks are currently being reevaluated. As part of this process, many options are being considered for the Tank Waste Remediation System (TWRS). The "clean option" described in the Volume 1, Overview, report proposes an aggressive waste processing strategy to achieve the three major objectives:

- greatly reduce the volume of high-level waste (HLW) to lessen demands on geologic repository space

- decrease by several orders of magnitude the amount of radioactivity and toxicity now in the waste tanks that will be left permanently onsite as low-level solid waste (LLW)

- accomplish the first two objectives without significantly increasing the total amount of waste for disposal.

This study has focused on process chemistry, as it provides the foundation for achieving the clean option objectives. Because demonstrated separation steps have been identified and connected in a flowsheet that meets these objectives, the study concludes that the process chemistry rests on a firm technical basis. However, it should be remembered that the clean option is a set of goals, rather than a flowsheet.

This Volume 2 report contains additional detail regarding the process steps and the material balance considerations of the example flowsheet that was first used to illustrate the technical feasibility of the clean option approach. This first flowsheet uses chemical processes that had been demonstrated on a plant or laboratory scale as of mid-1992; it may not represent the final processes recommended for achieving the clean option goals, but it is an example of how the goals can be met.

The flowsheet described here is based on processing all portions of the tank wastes in a concurrent manner in a large, central facility. Alternative processing approaches would require some flowsheet modifications. Two such alternatives that have received considerable attention since this flowsheet was developed are 1) a "decoupled" or "phased implementation" approach in which processing of the supernate and salt cake portions of the waste would begin before processing of the sludge, and 2) the use of a number of small, field-deployed processing units instead of a single large, central processing facility.

This report also contains much of the information on the development of the clean option goals that was presented in the Volume 1, Overview, report. However, the information contained here is more extensive and some is presented in a different manner. 


\section{Acknowledgments}

The assistance of the other authors of the Volume 1, Overview, report in advancing the clean option concept is gratefully acknowledged. They are Jerry L. Straalsund, Eddie G. Baker, Evan O. Jones, and William L. Kuhn of Pacific Northwest Laboratory and James J. Holmes of Westinghouse Hanford Company. Dr. Straalsund deserves special recognition as the driving force for the development of this concept.

Special thanks are due to David O. Campbell for several valuable discussions and for identification of some technical errors in the draft of this report, and to Wallace W. Schulz who questioned the need for some steps in the initial draft flowsheet and thus contributed to some flowsheet simplification. Valuable discussions with Georget F. Vandegrift and Gregg J. Lumetta are also greatly appreciated. The assistance received from the other national technical experts identified below who contributed their time to reviewing the draft of this report, especially those who also attended the review meeting at PNL in November 1992, is also gratefully acknowledged. Subsequent to that meeting, helpful discussions were also held with Allyn L. Boldt and Scott A. Colby of Westinghouse Hanford Company.

Contributing experts:

Moses Attrep, Jr.

Steven A. Barker

Walter D. Bond

David O. Campbell

Emory D. Collins

Harry J. Dewey

E. Philip Horwitz

George Jansen, Jr.

Gregg J. Lumetta

Wallace W. Schulz

Major C. Thompson

George F. Vandegrift
Los Alamos National Laboratory

Westinghouse Hanford Company

Oak Ridge National Laboratory

Consultant

Oak Ridge National Laboratory

Los Alamos National Laboratory

Argonne National Laboratory

Westinghouse Hanford Company

Pacific Northwest Laboratory

Consultant

Westinghouse Savannah River Company

Argonne National Laboratory 


\section{Contents}

Summary $\ldots \ldots \ldots \ldots \ldots \ldots \ldots \ldots \ldots \ldots \ldots \ldots \ldots \ldots \ldots \ldots \ldots \ldots \ldots$

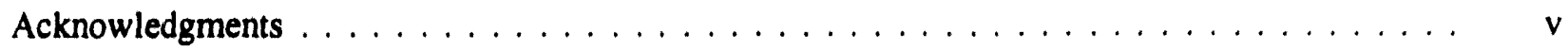

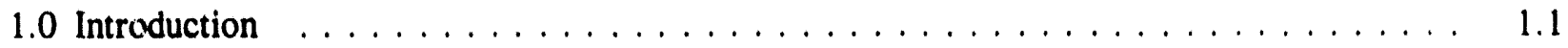

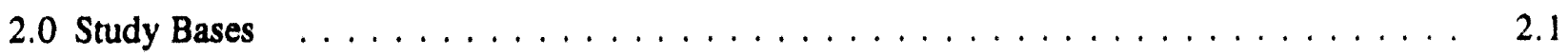

2.1 Clean Option Objectives $\ldots \ldots \ldots \ldots \ldots \ldots \ldots \ldots \ldots \ldots \ldots \ldots$

2.1.1 Specific Goals for First Example Clean Option Flowsheet $\ldots \ldots \ldots \ldots \ldots$

2.1.2 Assumptions and Rationale for Selection of Goals $\ldots \ldots \ldots \ldots . \ldots . . .2$

2.2 Wastes to be Treated $\ldots \ldots \ldots \ldots \ldots \ldots \ldots \ldots \ldots \ldots$

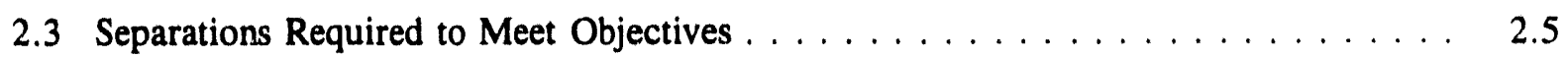

2.3.1 HLW-driven Separations Requirements $\ldots \ldots \ldots \ldots \ldots \ldots \ldots$

2.3.2 LLW-driven Separations Requirements $\ldots \ldots \ldots \ldots \ldots \ldots \ldots$

2.3.3 ALARA-driven Separations Requirements $\ldots \ldots \ldots \ldots \ldots \ldots \ldots . \ldots .11$

2.3.4 Disposition of Tank Waste Constituents . . . . . . . . . . . . . 2.11

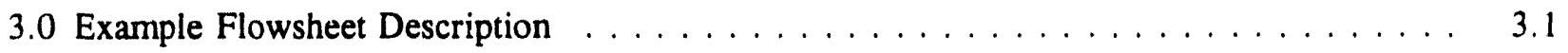

3.1 Sludge Washing and Dissolution $\ldots \ldots \ldots \ldots \ldots \ldots \ldots$

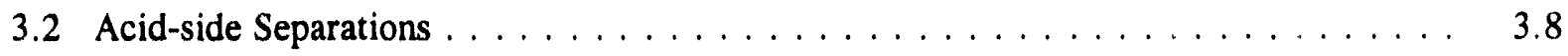

3.2.1 TBP Solvent Extraction for Removal of Uranium, Plutonium, Neptunium, and Thorium . . . . . . . . . . . . . . . 3.11

3.2.2 CMPO Solvent Extraction and Americium/Lanthanide Ion Exchange . . . . . 3.16

3.2.3 Crown Ether Solvent Extraction for Strontium and Technetium Removal and Strontium/Barium Ion Exchange . . . . . . . . . . . . . . . . 3.20

3.2.4 Ammonium Phosphomolybdate (APM) Ion Exchange for Cesium Removal . . . . . . . . . . . . . . . . . . . . . . . . . 3.24 


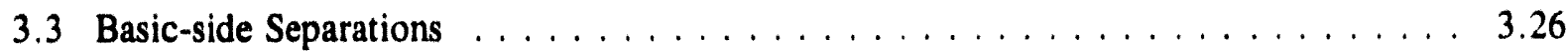

3.3.1 Resorcinol-Formaldehyde Ion Exchange for Cesium Removal . . . . . . . . 3.26

3.3.2 Chelating Ion Exchange for Strontium Removal $\ldots \ldots \ldots \ldots \ldots \ldots$

3.3.3 Anion Exchange Removal of Technetium . . . . . . . . . . . . . 3.30

3.4 Treatment of LLW Streams Resulting from Separations $\ldots \ldots \ldots \ldots$

3.4.1 LLW Streams from Acid-side Separations $\ldots \ldots \ldots \ldots \ldots \ldots$

3.4.2 LLW Stream from Basic-side Separations . . . . . . . . . . . . . 3.35

3.4.3 Sodium Hydroxide Reuse and Disposal $\ldots \ldots \ldots \ldots \ldots \ldots . \ldots \ldots$

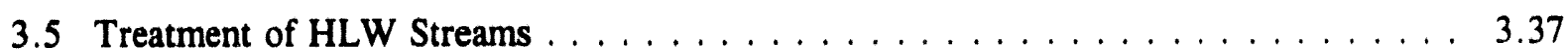

3.6 Recycling of Nitric Acid and Water $\ldots \ldots \ldots \ldots \ldots \ldots \ldots$

4.0 Results of Flowsheet Implementation $\ldots \ldots \ldots \ldots \ldots \ldots \ldots \ldots \ldots$

4.1 Quantity of HLW Glass $\ldots \ldots \ldots \ldots \ldots \ldots \ldots \ldots \ldots \ldots$

4.2 LLW Grout Quantity Considerations $\ldots \ldots \ldots \ldots \ldots \ldots \ldots \ldots \ldots$

4.2 .1 LLW Volume Comparison $\ldots \ldots \ldots \ldots \ldots \ldots \ldots \ldots \ldots \ldots$

4.2.2 Effect of Process Chemical Additions on LLW Volume . . . . . . . . . 4.3

4.3 Radionuclide Content of LLW Grout $\ldots \ldots \ldots \ldots \ldots \ldots$

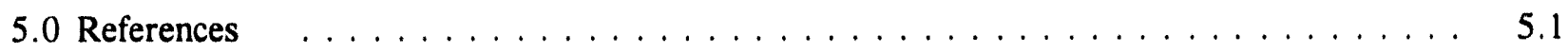




\section{Figures}

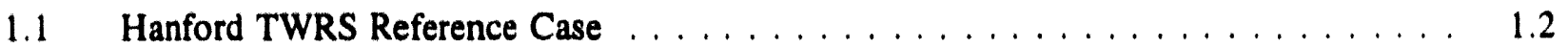

3.1 Example Clean Option Overall Flowsheet $\ldots \ldots \ldots \ldots \ldots \ldots \ldots \ldots$

3.2 Sludge Washing and Caustic Leaching Portion of Flowsheet $\ldots \ldots \ldots \ldots \ldots$

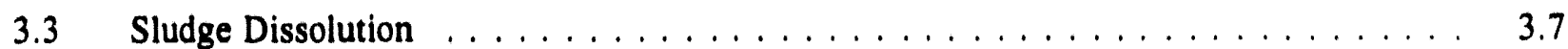

3.4 Typical Distribution Coefficients for TBP and CMPO Extractions $\ldots \ldots \ldots \ldots \ldots$

3.5 TBP Solvent Extraction for Removal of Uranium, Plutonium, Neptunium,

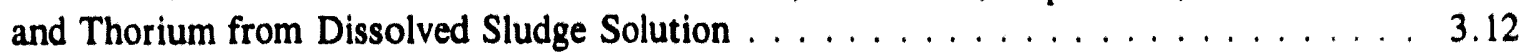

3.6 Second TBP Extraction Cycle for Purification of Uranium $\ldots \ldots \ldots \ldots \ldots \ldots$

3.7 CMPO Solvent Extraction Cycle for Removal of Americium (and Lanthanides) from First TBP Cycle Raffinate . . . . . . . . . . . . . . . . . . . . 3.17

3.8 Band Displacement Cation Exchange for Separation of Americium and Heavy Lanthanides from Light Lanthanides . . . . . . . . . . . . . . . . . . . 3.19

3.9 Crown Ether Solvent Extraction Cycle for Removal of Technetium and Strontium (and Barium) from CMPO Cycle Raffinate . . . . . . . . . . . . . . . 3.21

3.10 Separation of Technetium, Strontium, and Barium by Cation Exchange $\ldots \ldots \ldots \ldots .23$

3.11 Ammonium Phosphomolybdate Ion Exchange for Removal of Cesium from

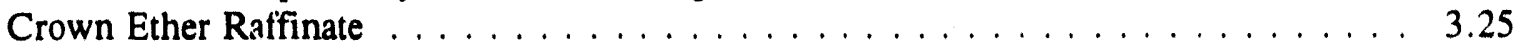

3.12 Preparation of Feed for Basic-side Processing of Supernate, Dissolved Salt Cake, and Caustic Leach Solutions

3.13 Resorcinol-Formaldehyde Ion Exchange for Removal of Cesium from Basic-side Feed . . . . . . . . . . . . . . . . . . . . . . . . . . . . . . . . 3.29

3.14 Chelating Cation Exchange for Removal of Strontium from Resorcinol-

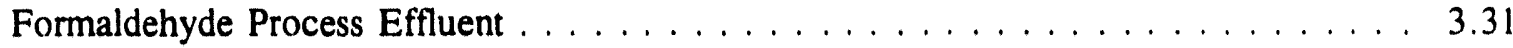

3.15 Strong-base Anion Exchange for Removal of Technetium from Chelating

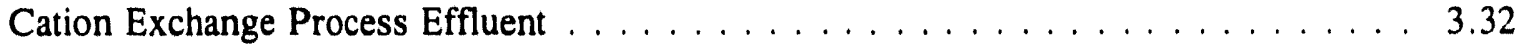

3.16 Initial Treatment of Acidic Low-Level Waste Streams $\ldots \ldots \ldots \ldots \ldots \ldots$ 
3.17 Treatment of Low-Level Waste Streams $\ldots \ldots \ldots \ldots$

3.18 Caustic Treatment and Grout Formation $\ldots \ldots \ldots \ldots \ldots \ldots$

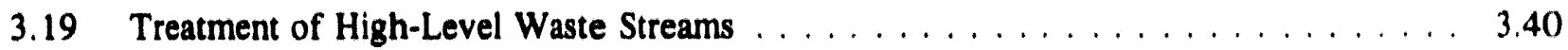

3.20 Nitric Acid Recovery $\ldots \ldots \ldots \ldots \ldots \ldots \ldots \ldots \ldots \ldots \ldots$ 


\section{Tables}

2.1 Bulk Constituents of Total SST Waste $\ldots \ldots \ldots \ldots \ldots \ldots \ldots \ldots \ldots \ldots$

2.2 Allowable Additions to Glass in Waste Feed $\ldots \ldots \ldots \ldots \ldots$

2.3 Effect of Important Constituents on Canister Count $\ldots \ldots \ldots \ldots \ldots \ldots$

2.4 NRC LLW Limits for Radionuclides Present in SST Waste $\ldots \ldots \ldots \ldots \ldots$

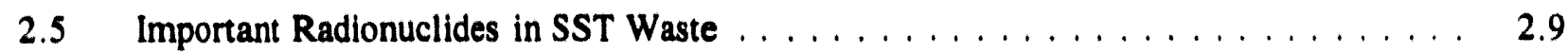

2.6 Disposition of Tank Waste Constituents $\ldots \ldots \ldots \ldots \ldots \ldots \ldots \ldots$

4.1 Number of HLW Canisters Required for Radionuclides Separated

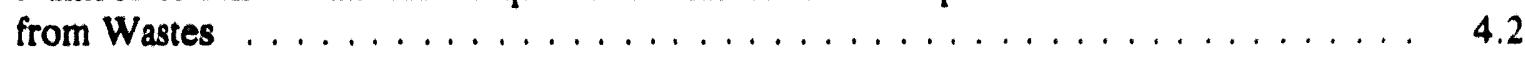

4.2 Additions to LLW Caused By Processing SST Wastes $\ldots \ldots \ldots \ldots \ldots$

4.3 Radionuclides in Clean Option LLW from SST Wastes $\ldots \ldots \ldots \ldots \ldots$ 


\subsection{Introduction}

Disposal of high-level tank wastes at the Hanford Site is currently envisioned to divide the waste between two principal waste forms: glass for the high-level waste (HLW) and grout for the low-level waste (LLW). The draft flow diagram shown in Figure 1.1 was developed as part of the current planning process for the Tank Waste Remediation System (TWRS), which is evaluating options for tank cleanup. The TWRS has been established by the U.S. Department of Energy (DOE) to safely manage the Hanford tank wastes. It includes tank safety and waste disposal issues, as well as the waste pretreatment and waste minimization issues that are involved in the "c ean option" discussed in this report.

The "reference case" illustrated in Figure 1.1 is similar to the system described by Grygiel et al. (1991), and will be used in this report as a basis for comparison with the "clean option" presented here. In the reference case, chemical separations have been proposed for the tank wastes that are sufficient to prevent the grout from becoming a transuranic (TRU) waste form according to U.S. Nuclear Regulatory Commission (NRC) Class C LLW limits (10 CFR 61) However, in this case, tens of megacuries of other radioactive isotopes would become part of the grout. In addition to total radioactivity, some mobile and long-lived radionuclides and the high nitrate content contribute to the long-term risks associated with the grout disposal. For the HLW fraction, nonradioactive waste constituents would lead to HLW glass volumes of over 10,000 canisters. These canisters would cost several billion dollars to produce and dispose of in a geologic repository. When combined with canisters expected from other sites, the total volume would seriously impact the space presently planned for DOE defense wastes at the Nevada repository.

This report describes the results of a study led by Pacific Northwest Laboratory(a) to determine if a more aggressive separations scheme could be devised which could mitigate concerns over the quantity of the HLW and the toxicity of the LLW produced by the reference system. This more aggressive scheme, which would meet NRC Class A restrictions (10 CFR 61), would fit within the overall concept depicted in Figure 1.1; it would perform additional and/or modified operations in the areas identified as interim storage, pretreatment, and LLW concentration. Additional benefits of this scheme might result from using HLW and LLW disposal forms other than glass and grout, but such departures from the reference case are not included at this time.

The evaluation of this aggressive separations scheme addressed institutional issues such as:

- radioactivity remaining in the Hanford Site LLW grout

- volume of HLW glass that must be shipp ad ofsite

- disposition of appropriate waste constituents to nonwaste forms

(a) Pacific Northwest Laboratory is operated for the U.S. Department of Energy by Battelle Memorial Institute under Contract DE-AC06-76RLO 1830. 


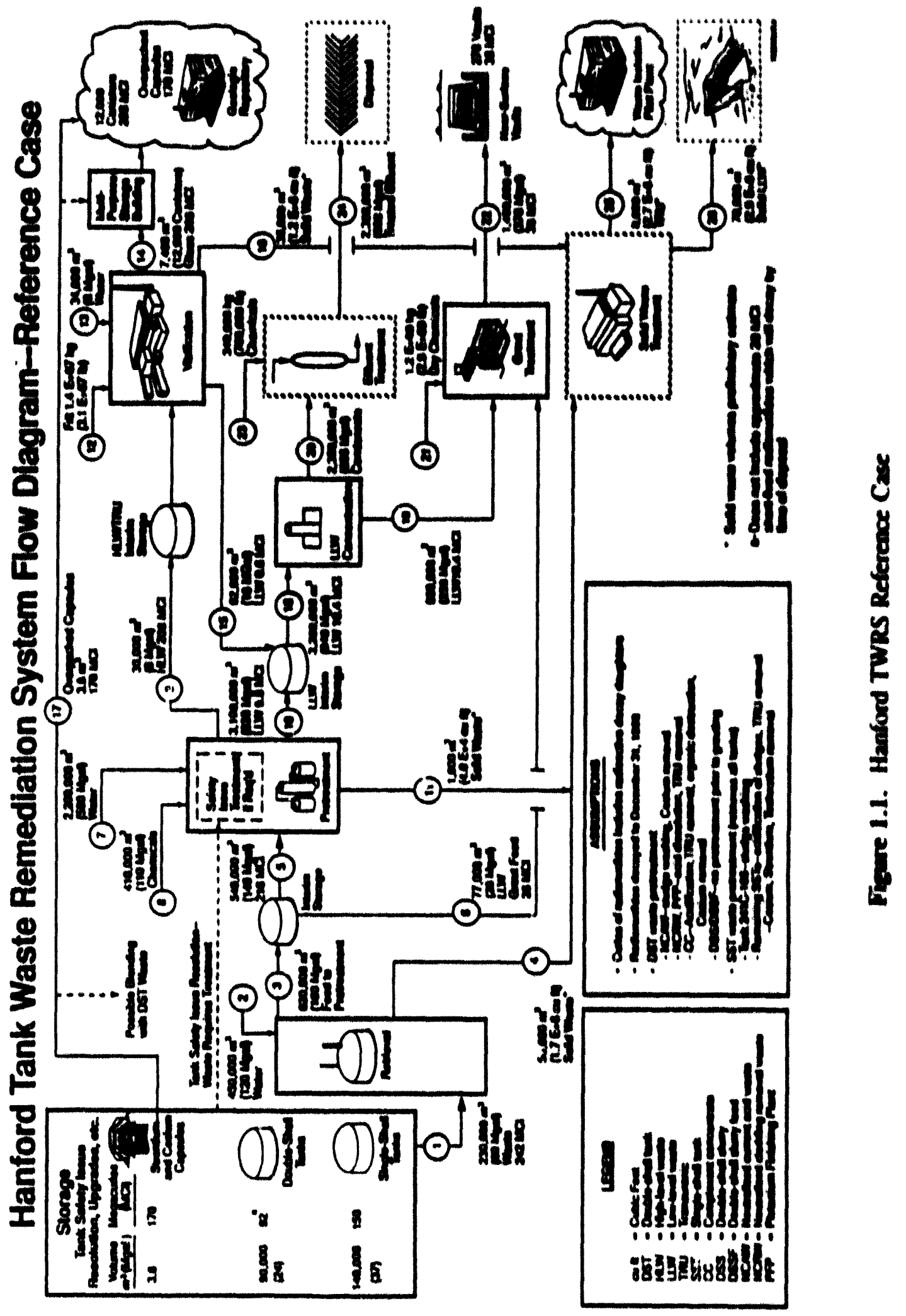


- generation and disposition of secondary wastes

- emisalons.

Specific goals for an aggressive separations scheme were developed based on these issues. These goals comprise the clean option. Once the specific goals were defined, a chemical process nowsheet for a separations scheme was developed as an example of how the clean option could be achieved. The flowsheet was used as a basis to assess waste volumes, to consider the feasibility of the process chemistry, and to identify technical issues that must be resolved to achieve the clean option goals. Although the specific example flowsheet was used to guide the identification of technology issues, alternative flowsheet and technology approaches were considered sufficiently to determine that the issues would be the same for a range of approaches.

This report (Voiume 2) contains a detailed description of the flowsheet and mass balance assessment for the first clean option example flowsheet, which was used for the assessments described in the initial overview report (Volume 1, Straalsund et al. 1992). Volume 2 also repeats much of the background information given in Volume 1.

The flowsheet presented here is based on the concurrent processing of all portions of the tank wastes. Because of the currently higher degree of technical uncertainties in the sludge processing area, it could be beneficial to begin treating the supernate and salt cake portions of the waste while deferring sludge processing for several years to allow time for the uncertainties to be resolved. Such a "decoupled or "phased implementation" approach would require some flowsheet modifications.

Other flowsheet modifications could be required if the waste processing were to be done in a number of small, field-deployed units rather than in a large central facility. Process simplification, even if at the expense of process performance, could be very important to such modifications.

The details presented in this report are a first step in providing the information needed to define the processing operations in sufficient detail to allow a facility cost estimate to be made. This report presents the stage of development as of December 1992. Subsequent efforts have led to some flowsheet modifications (generally simplifications), but the basic features are the same. Discussion of those modifications will await completion of those efforts.

Finally, it should be reemphasized that the clean option is not a flowsheet, but rather is a set of goals. The flowsheet details presented in this report are for the first example flowsheet, based on the initial assumptions of the study. The use of other assumptions regarding the nature of the HLW and LLW disposal forms could give significant improvements in both flowsheet simplicity and in predicted long-term risk. Assumption of a third type of waste, a "decay storage" waste for Sr-90 and Cs-137 (and perhaps $\mathrm{Ni}-63$ ), would also allow significant flowsheet simplification. Incorporation of such potential improvements is left to await the outcome of additional study; in this report we continue to assume grout to be the LLW form and borosilicate glass of the composition currently planned for the Hanford Waste Vitrification Plant (HWVP) to be the HLW form. 


\subsection{Study Bases}

The primary goal of the effort discussed in this report was to develop a reasonable example flowsheet describing some process steps typical of those likely to be required to meet the objectives of the clean option. This flowsheet could then be used in preliminary evaluations of technical feasibility, impacts on waste volumes, and costs. This section describes the objectives and goals to be met and the wastes to be treated, and then describes the separations process requirements that are necessary to process the waste in accordance with these goals and objectives.

\subsection{Clean Option Objectives}

The Tank Waste Remediation System planned for Hanford encompasses several options, including the clean option. The broad objectives of the clean option compared with the other options being considered are listed below:

- minimize the residual radioactivity and chemical toxicity of the bulk of the waste, most often referred to as LLW, to further reduce the long-term environmental effects on the Pacific Northwest region

- decrease the volume of the HLW tó reduce long-term demands on the geologic repository space

- accomplish the first two goals without increasing the amount of waste requiring disposal.

The specific goals developed to achieve these objectives are given in the following section.

\subsubsection{Specific Goals for First Example Clean Option Flowsheet}

The following goals have been adopted as the basis for formulating an aggressive but feasible strategy for separating the components of the waste to meet the clean option objectives:

- The radioactivity in the waste will be removed from the bulk of the waste such that the radionuclides in the remaining LLW will not exceed NRC Class A maximum allowable concentrations for shallow land burial of radioactive materials.

- Even though not required in order to meet the Class A limits, the concentrations of technetium, iodine, and uranium are reduced on an as low as reasonably achievable (ALARA) basis.

- Additional radioactivity will be removed from the LLW where significant reductions can be achieved through minor modifications to the process scheme.

- The LLW will be disposed of in a manner that complies with U.S. Environmental Protection Agency (EPA) and state regulations for disposal of hazardous wastes. 
- The radionuclides that have been removed from the bulk of the waste will be disposed of within about 1000 canisters of a borosilicate glass that meets current HWVP glass specifications.

- Waste minimization principles will be used to minimize the volume of LLW.

\subsubsection{Assumptions and Rationale for Selection of Goals}

One of the principal objectives of the clean option is to reduce the radioactivity and toxicity in the bulk of the waste to a level that would be publicly acceptable and would reduce the long-term environmental effects on the Pacific Northwest region. Drinking water standards were initially considered as the limit for the concentration of radionuclides in the LLW stream; however, it was not feasible to achieve the separation factors required to meet these standards. Instead, the NRC Class A specifications were selected as the next most stringent standards that are legally established. In general, these standard represent a high level of risk reduction. However, for the Hanford tank wastes, several assessments (Droppo et al. 1991; Buck et al. 1991) have indicated that, if not retained within the disposal system, Tc-99, I-129, and U-238 are primary contributors to long-term radioactivity-related risk even at concentrations allowed by the Class $\mathrm{A}$ limit. Thus, the clean option goals include an additional reduction for these constituents.

Grout is an acceptable waste form for heavy metals and is assumed to be the waste form used for the LLW in the specific clean option example outlined later in the report. To reduce the chemical toxicity from other components, the clean option will include destruction of nitrates, nitrites, and organics prior to grouting. Actual limits on nitrates, nitrites, and organics in the grout are not defined.

Another main objective of the clean option is to reduce the volume of HLW that would require disposal in a geologic repository. The target volume for the HLW, 1000 canisters of glass, appears to be a reasonable one based on the following information:

- 1000 canisters is a quantity large enough to accommodate the heat generation from the radionuclides in the Hanford tank wastes.

- 1000 canisters would yield a significant reduction in demands on repository space.

Borosilicate glass is assumed to be the HLW form. Work has been under way for a number of years in the HWVP project to determine the concentrations of various constituents that can be accommodated by existing borosilicate vitrification technology. Hanford tank waste includes abundant nonradioactive species such as iron, zirconium, and aluminum that would substantially increase the volume of the glass beyond 1000 canisters if not diverted to the LLW stream. Also, less abundant nonradioactive species exist that are sufficiently insoluble in molten glass that their concentrations need to be limited in the feed to the HWVP.

The third principal objective of the clean option is to achieve the first two goals without substantially increasing the amount of waste for disposal. This objective appears achievable through the aggressive use of waste minimization and recovery and recycle of key chemicals used to process the waste, such as nitric acid and sodium hydroxide. 


\subsection{Wastes to be Treated}

Hanford tank wastes are generally grouped in two categories, single-shell tank (SST) wastes and double-shell tank (DST) wastes. In actual fact, each of these two groupings contains a variety of wastes that have significant compositional variations. In this study, a feed composition representing the average of all SST wastes was assumed for simplicity in flowsheet development. However, DST wastes were also included in estimating the quantities of waste and the radionuclide contents of the wastes that would result from implementation of the flowsheet.

The total quantities of bulk chemical constituents and important radionuclides present in the SST wastes, as assumed for this study, are given in Table 2.1. These values were developed in other studies at Hanford and are accepted in this study as a basis for flowsheet development and waste quantity comparisons, with the realization that results of future waste characterization work may give a somewhat different picture. The quantities of bulk components present in the DST wastes are generally smaller than those present in the SST wastes; exceptions are aluminum, fluoride, and zirconium, where comparable quantities are present in the two types of waste. Thus, the data of Table 2.1 provide a good approximation of the total quantities of bulk components present in Hanford tank waste.

The constituents of the Hanford tank wastes are divided among three categories: supernate, salt cake, and sludge. Supernates are liquid phases that generally contain high concentrations of soluble salts such as sodium nitrate, sodium hydroxide, etc. Salt cakes are solid phases that contain salts that crystallized out as a result of evaporative concentration of supernates; they can be dissolved in water. Sludges are solid phases containing primarily insoluble hydroxides that precipitated out when the (acidic) process waste solutions were made basic for storage in the carbon steel underground storage tanks.

The quantities of barium and of the lanthanide elements present in the wastes are of special significance to development of a flowsheet capable of meeting the clean option goals. This is because the chemical similarities between barium and strontium and between lanthanides and americium make their separations difficult and because such separations are required if strontium and americium are to be disposed within $\sim 1000$ canisters of HWVP-type glass. As noted in Table 2.1 , the estimated lanthanide value is the midpoint between two estimates that differ by a factor of $\sim 10$. The estimated barium content is even more uncertain; some estimates are lower than that given in Table 2.1 by a factor of several hundred. Recent evaluations by the author indicate that the current "best" estimate should be lower than that given here by a factor of $\sim 10$; however, the higher value is retained in this report to be in accord with that of Volume 1. 
Table 2.1. Bulk Constituents of Total SST Waste

\section{Component}

Al

Am

$\mathrm{Ba}$

$\mathrm{Bi}$

$\mathrm{Ca}$

$\mathrm{Cr}$

Cs

$\mathrm{Fe}$

$\mathrm{Hg}$

$\mathbf{K}$

Lanthanides

$\mathrm{Mn}$

$\mathrm{Na}$

$\mathrm{Ni}$

$\mathrm{Np}$

Pd

$\mathrm{Pu}$

$\mathrm{Si}$

$\mathrm{Sr}$

Tc

Th

U

$\mathrm{Zr}$

$\mathrm{Cl}$

$\mathrm{CO}_{3}$

$\mathrm{F}$

$\mathrm{Fe}(\mathrm{CN})_{6}$

$\mathrm{H}_{2} \mathrm{O}$

$\mathrm{NO}_{3}$

$\mathrm{NO}_{2}$

$\mathrm{OH}$

$\mathrm{PO}_{4}$

$\mathrm{SO}_{4}$

Amount Present ${ }^{(a)}$

\begin{tabular}{|c|c|}
\hline Mole & Gram \\
\hline $9.05 \times 10^{7}$ & $2.44 \times 10^{9}$ \\
\hline$\sim 4 \times 10^{1}$ & $-10^{4}$ \\
\hline $4 \times 10^{6(b)}$ & $5 \times 10^{8}$ \\
\hline $1.25 \times 10^{6}$ & $2.61 \times 10^{8}$ \\
\hline $3.25 \times 10^{6}$ & $1.30 \times 10^{8}$ \\
\hline $2.21 \times 10^{6}$ & $1.15 \times 10^{8}$ \\
\hline $4.2 \times 10^{3}$ & $5.6 \times 10^{5(b)}$ \\
\hline $1.12 \times 10^{7}$ & $6.27 \times 10^{8}$ \\
\hline $4.49 \times 10^{3}$ & $9.00 \times 10^{5}$ \\
\hline $9 \times 10^{6(b)}$ & $4 \times 10^{8}$ \\
\hline $6 \times 10^{5(b, c)}$ & $8 \times 10^{7}$ \\
\hline $2.18 \times 10^{6}$ & $1.20 \times 10^{8}$ \\
\hline $2.25 \times 10^{9}$ & $5.17 \times 10^{10}$ \\
\hline $3.04 \times 10^{6}$ & $1.78 \times 10^{8}$ \\
\hline $2.0 \times 10^{2}$ & $4.7 \times 10^{4(b)}$ \\
\hline$\sim 2 \times 10^{4}$ & $-2 \times 10^{6(b)}$ \\
\hline $2.4 \times 10^{3}$ & $5.8 \times 10^{5(b)}$ \\
\hline $7.93 \times 10^{6}$ & $2.22 \times 10^{8}$ \\
\hline $4.11 \times 10^{5}$ & $3.60 \times 10^{7(b)}$ \\
\hline$\sim 5 \times 10^{3}$ & $-5 \times 10^{5}$ \\
\hline $5.6 \times 10^{4}$ & $1.3 \times 10^{7(b)}$ \\
\hline $5.9 \times 10^{6}$ & $1.4 \times 10^{9(\mathrm{~b})}$ \\
\hline $2.70 \times 10^{6}$ & $2.46 \times 10^{8}$ \\
\hline $1.13 \times 10^{6}$ & $4.00 \times 10^{7}$ \\
\hline $2.68 \times 10^{7}$ & $1.61 \times 10^{9}$ \\
\hline $4.24 \times 10^{7}$ & $8.05 \times 10^{8}$ \\
\hline $1.52 \times 10^{6}$ & $3.22 \times 10^{8}$ \\
\hline $2.49 \times 10^{9}$ & $4.48 \times 10^{10}$ \\
\hline $4.3 \times 10^{3}$ & $5.6 \times 10^{5(b)}$ \\
\hline $1.56 \times 10^{9}$ & $9.67 \times 10^{10}$ \\
\hline $1.04 \times 10^{8}$ & $4.80 \times 10^{9}$ \\
\hline $5.38 \times 10^{8}$ & $9.15 \times 10^{9}$ \\
\hline $9.20 \times 10^{7}$ & $8.74 \times 10^{9}$ \\
\hline $1.72 \times 10^{7}$ & $1.65 \times 10^{9}$ \\
\hline
\end{tabular}

(a) From values in HDW-EIS (DOE 1987) unless indicated otherwise.

(b) Separate estimate.

(c) Midpoint between $1.7 \times 10^{6}$ in HDW-EIS and $2.0 \times 10^{5}$ in separate estimate. 


\subsection{Separations Required to Meet Objectives}

Stated in its simplest form, the initial objectives of the clean option would lead to disposal of all radionuclides in two fractions, a LLW fraction that contains very minimal radioactivity, to be disposed of onsite, and a HLW fraction to be disposed of in a geologic repository, with each fraction being environmentally acceptable and having the minimum possible volume. Not surprisingly, the tank contents require that trade-offs be made between radionuclide contents and volumes of the waste fractions. However, the contents do not preclude attainment of the initial goals of having a LLW fraction that meets NRC Class A criteria and a HLW fraction that occupies $~ 1000$ canisters of HWVP-type glass. This is discussed in more detail in the following sections.

\subsubsection{HLW-driven Separations Requirements}

The separations requirements that are driven by requirements on the HLW fraction are concerned primarily with the quantities of the bulk chemical constituents of the wastes that can be contained within -1000 canisters of HWVP-type waste. Estimation of the number of canisters that would result from separate vitrification of each of the waste constituents provides an indication of which constituents can be completely accommodated in -1000 canisters and, for those that exceed that amount, an indication of the extent of separation that is required from those waste constituents that are to be disposed of in glass.

Table 2.2 shows estimates of the mass percentage increases in the glass composition allowed by the addition of some individual waste constituents, based on current plans for the HWVP. Many of these estimates were derived from the current HWVP feed specifications, and assume a $25 \%$ waste oxide: $75 \%$ glass frit mixture in the vitrification process. Where values needed for this study were not available from the HWVP information, they were estimated separately as indicated in the table. The actual percentage of sodium in the glass is higher than is indicated here because of the sodium content of the glass frit. It should be possible to increase the sodium content of the waste feed by decreasing the sodium content of the frit, but that is not assumed here.

It should be emphasized that these HWVP-type glass "limits" have not been challenged or evaluated in this study. It is probable that some of them could be increased as a result of additional consideration. Mixed effects that might occur when more than one of these waste constituents is added to the glass at the same time are also not addressed here, except for the intuitive judgment that the total number of canisters required to contain all the waste constituents will be less than the number obtained by summing all the individual values.

Table 2.3 contains estimates of the number of HWVP-type glass canisters that would be required to dispose of the Hanford SST + DST waste constituents, based on $1650 \mathrm{~kg}$ of glass per canister, if none of the constituents were routed to LLW instead. Also listed in Table 2.3 are estimated percentages of the various waste constituents that could be accommodated in 1000 canisters of HWVP-type glass, again considering each constituent on an individual basis. These data indicate that appreciable separation from the radioactive constituents-TRUs, technetium, cesium, and strontium-will be 
Table 2.2. Allowable Additions to Glass in Waste Feed

\begin{tabular}{|c|c|c|}
\hline $\begin{array}{c}\text { Waste } \\
\text { Constituents }\end{array}$ & $\begin{array}{c}\text { Maximum Weight } \\
\text { Percent }^{(a)} \\
\end{array}$ & Basis \\
\hline $\mathrm{Al}$ & 3.4 & HWVP feed specification \\
\hline $\mathrm{Ba}$ & 4.5 & HWVP feed specification \\
\hline $\mathrm{Bi}$ & 12 & Estimate from glass formulation expert \\
\hline $\mathrm{Ca}$ & 3.6 & HWVP feed specification \\
\hline $\mathrm{Cr}$ & 0.34 & HWVP feed specification \\
\hline Cs & 23 & $\begin{array}{l}\text { Molar equivalent to } \mathrm{Na}, \mathrm{K} \text {; heat loading } \\
\text { more restrictive }\end{array}$ \\
\hline $\mathrm{Fe}$ & 12 & HWVP feed specification \\
\hline Lanthanides & 1.7 & HWVP feed specification \\
\hline $\mathrm{Mn}$ & 3.2 & HWVP feed specification \\
\hline $\mathrm{Na}$ & 3.8 & HWVP feed specification \\
\hline $\mathrm{Ni}$ & 1.6 & HWVP feed specification \\
\hline Pd & 0.22 & HWVP feed specification \\
\hline $\mathrm{Si}$ & 2.0 & HWVP feed specification \\
\hline $\mathrm{Sr}$ & 4.8 & Midpoint of molar equivalence to $\mathrm{Ba}$ and $\mathrm{Ca}$ \\
\hline Tc & 0.22 & Assume the allowed percentage for $\mathrm{Pd}$ \\
\hline Th & 7.0 & Assume to be analogous to $\mathrm{U}$ and $\mathrm{Zr}$ \\
\hline TRU & 1.0 & HWVP feed specification \\
\hline $\mathrm{U}$ & 6.8 & HWVP feed specification \\
\hline $\mathrm{Zr}$ & 7.4 & HWVP feed specification \\
\hline $\mathbf{F}$ & 1.7 & HWVP feed specification \\
\hline $\mathrm{PO}_{4}$ & 1.3 & HWVP feed specification \\
\hline $\mathrm{SO}_{4}$ & 0.7 & HWVP feed specification \\
\hline
\end{tabular}

(a) Gram of constituent per $100 \mathrm{~g}$ of glass. 
Table 2.3. Effect of Important Constituents on Canister Count

\begin{tabular}{|c|c|c|}
\hline Waste Constituents & Number of Canisters $^{(a)}$ & $\begin{array}{l}\text { Allowed Addition to } \\
\text { HLW } \% \text { (b) }\end{array}$ \\
\hline $\mathrm{Na}$ & $1 \times 10^{6}$ & 0.1 \\
\hline $\mathrm{PO}_{4}$ & $4 \times 10^{5}$ & 0.2 \\
\hline $\mathrm{SO}_{4}$ & $2 \times 10^{5}$ & 0.5 \\
\hline $\mathrm{Cr}$ & $8 \times 10^{4}$ & 1.2 \\
\hline F & $6 \times 10^{4}$ & 1.7 \\
\hline $\mathrm{Al}$ & $5 \times 10^{4}$ & 2.0 \\
\hline $\mathrm{U}$ & $1 \times 10^{4}$ & 10 \\
\hline $\mathrm{Ba}$ & $7 \times 10^{3}$ & 14 \\
\hline $\mathbf{N i}$ & $7 \times 10^{3}$ & 14 \\
\hline Si & $7 \times 10^{3}$ & 14 \\
\hline Lanthanides & $5 \times 10^{3}$ & 20 \\
\hline $\mathrm{Zr}$ & $5 \times 10^{3}$ & 20 \\
\hline $\mathrm{Fe}$ & $4 \times 10^{3}$ & 25 \\
\hline $\mathrm{Ca}$ & $2 \times 10^{3}$ & 50 \\
\hline $\mathrm{Mn}$ & $2 \times 10^{3}$ & 50 \\
\hline $\mathrm{Pd}$ & $1 \times 10^{3}$ & 100 \\
\hline $\mathrm{Bi}$ & $1 \times 10^{3}$ & 100 \\
\hline $\mathrm{Sr}$ & $5 \times 10^{2}$ & 100 \\
\hline $\mathrm{Tc}$ & $5 \times 10^{2}$ & 100 \\
\hline Th & $1 \times 10^{2}$ & 100 \\
\hline TRU & $5 \times 10^{1}$ & 100 \\
\hline $\mathrm{Cs}$ & $<1 \times 10^{1(\mathrm{c})}$ & 100 \\
\hline
\end{tabular}

(a) Includes both SST and DST wastes.

(b) To meet the goal of 1000 canisters.

(c) Heat loading considerations would require a higher number. 
required for all of the bulk chemical constituents, except perhaps bismuth, in order to meet the 1000-canister goal for disposal of the radioactive constituents. To be prudent, separations should be performed to give levels even lower than those indicated here; thus, separation of bismuth is also desired.

In addition to the chemical composition limits discussed above, radiolytic heat generation is also a factor in defining the number of canisters needed for disposal of the HLW fraction. Based on a tentative limit of 1500 watt/canister, it would require $\sim 400$ canisters to dispose of the Sr-90 and Cs-137 currently contained in the tank wastes. An additional $\sim 300$ canisters would be required to dispose of the Sr-90 and Cs- 137 that were removed from the waste and are currently stored in capsules. Thus, to obtain a HLW fraction much smaller than 1000 HWVP-type canisters, the Sr-90 and Cs-137 would have to be disposed of in some other fraction.

\subsubsection{LLW-driven Separations Requirements}

The concentrations of radionuclides allowed in the three classifications of LLW defined by the NRC are summarized in Table 2.4. As was discussed in Section 2.1.2, the Class A limits, which are markedly more restrictive than the Class B or Class C limits, were selected as the upper concentration level goals for the study, with some additional separations being done on an ALARA basis.

Table 2.4. NRC LLW Limits for Radionuclides Present in SST Waste

\begin{tabular}{|c|c|c|c|}
\hline & Class A & Class B & Class C \\
\hline Radionuclide & \multicolumn{3}{|c|}{ Allowed Concentration. $\mathrm{Ci} / \mathrm{m}^{3}$} \\
\hline $\mathrm{H}-3$ & 40 & -- & -- \\
\hline C-14 & 0.8 & 8 & 8 \\
\hline Co-60 & 700 & -- & -- \\
\hline $\mathrm{Ni}-63$ & 3.5 & 70 & 700 \\
\hline $\mathrm{Sr}-90$ & 0.04 & 150 & 7000 \\
\hline Tc-99 & 0.3 & 3 & 3 \\
\hline I. 129 & 0.008 & 0.08 & 0.08 \\
\hline Cs- 137 & 1 & 44 & 4600 \\
\hline \multirow[t]{2}{*}{ Other $^{(a)}$} & 700 & - & -- \\
\hline & \multicolumn{3}{|c|}{ Allowed Concentration, $\mathrm{nCi} / \mathrm{s}$} \\
\hline $\left.\begin{array}{c}\text { Np-237 } \\
\text { Pu-239,240 } \\
\text { Am-241 }\end{array}\right\}$ & 10 & 100 & 100 \\
\hline Pu-24l & 350 & 3500 & 3500 \\
\hline
\end{tabular}

(a) Total of all radionuclides with less than 5-year half-life. 
The minimum separation factors that must be achieved to meet the Class A portion of the initial clean option goals can be estimated by 1) estimating the eventual volume of the LLW fraction after the treatment and pretreatment steps, 2) dividing the radionuclide inventories by this volume to obtain the hypothetical concentrations that would result if no separations processing was performed, and 3) dividing these hypothetical concentrations by the Class A LLW limits. Results of such comparisons for the SST wastes and radionuclides having half-lives of $>13$ years are shown in Table 2.5.2 For these comparisons, the volume of the LLW grout was assumed to be governed by the sodium content at a concentration $5 \mathbf{M}$.

Table 2.5. Important Radionuclides in SST Waste

\begin{tabular}{|c|c|c|c|}
\hline Radionuclide & $\begin{array}{c}\text { Total } \\
\text { Quantity. } C^{(a)}\end{array}$ & $\begin{array}{c}\text { Concentration in } \\
\text { Average Waste } \\
\text { at } 5 \mathrm{M} \mathrm{Na} \text {, } \\
\mathrm{Ci} / \mathrm{m}^{3} \\
\end{array}$ & $\begin{array}{c}\text { Required } \\
\text { Decontamination } \\
\text { Factor (DF) } \\
\text { for Class } A^{(b)} \\
\end{array}$ \\
\hline \multicolumn{4}{|l|}{ Class A Listed } \\
\hline C- 14 & $1.4 \times 10^{2}$ & $3.1 \times 10^{-4}$ & $3.9 \times 10^{-4}$ \\
\hline $\mathrm{Ni}-63$ & $3 \times 10^{5}$ & $6.2 \times 10^{-1}$ & $1.8 \times 10^{-1}$ \\
\hline Sr-90 & $4.5 \times 10^{7}$ & $1.0 \times 10^{2}$ & $2.5 \times 10^{3}$ \\
\hline Tc-99 & $9 \times 10^{3}$ & $2.0 \times 10^{-2}$ & $6.7 \times 10^{-2}$ \\
\hline I-129 & $2.4 \times 10^{1}$ & $5.3 \times 10^{-5}$ & $6.6 \times 10^{-3}$ \\
\hline Cs- 137 & $9.5 \times 10^{6}$ & $2.1 \times 10^{1}$ & $2.1 \times 10^{1}$ \\
\hline Np-237 & $3.1 \times 10^{1}$ & $6.8 \times 10^{-5}$ & $4.0 \times 10^{-3(d)}$ \\
\hline Pu-239 & $2.7 \times 10^{4}$ & $6.0 \times 10^{-2}$ & $3.5 \times 10^{0(\mathrm{~d})}$ \\
\hline Am-241 & $3.6 \times 10^{4}$ & $8.0 \times 10^{-2}$ & $4.7 \times 10^{0(d)}$ \\
\hline \multicolumn{4}{|l|}{ Qther } \\
\hline$\overline{\mathrm{Se}-79}$ & $1 \times 10^{1(c)}$ & $3 \times 10^{-5}$ & \\
\hline $\mathrm{Zr}-93$ & $4 \times 10^{3(c)}$ & $9 \times 10^{-3}$ & \\
\hline Pd-107 & $3 \times 10^{1(\mathrm{c})}$ & $7 \times 10^{-5}$ & \\
\hline Sn-126 & $4 \times 10^{2(c)}$ & $1 \times 10^{-3}$ & \\
\hline Sm-151 & $4 \times 10^{5(c)}$ & $1 \times 10^{0}$ & \\
\hline Th-232 & $1^{(c)}$ & $3 \times 10^{-6}$ & \\
\hline \multirow[t]{2}{*}{ U-238 } & $4 \times 10^{2(c)}$ & $2 \times 10^{-4}$ & \\
\hline & & $1 . \overline{2 \times 10^{2}}$ & \\
\hline
\end{tabular}

(a) From values in HDW-EIS (DOE 1987) unless indicated otherwise. Daughter activities not included.

(b) Required DF = (concentration in waste at $5 \mathrm{M} \mathrm{Na}) \div$ (concentration allowed in Class A LLW); see Table 2.4 for Class A values. A value $<1$ indicates that no decontamination may be necessary to meet Class $A$ regulations.

(c) Separate estimate.

(d) For a waste form density of $1.7 \mathrm{~g} / \mathrm{mL}$. 
The $5 \mathrm{M} \mathrm{Na}$ limit for grout was thought to represent the upper limit of currently demonstrated grout formulations, based on information such as a feed sodium concentration of $122,000 \mathrm{ppm}$ and a volume of grout being 1.4-fold greater than the volume of the feed solution. However, it was subsequently learned that the "ppm" units given for the concentration of sodium in the grout feed were meant to indicate $\mathrm{mg} / \mathrm{L}$ rather than the generally accepted $\mathrm{mg} / \mathrm{kg}$. This means that the currently demonstrated maximum concentration of sodium in grout is really $-4 M$ rather than the $5 M$ value assumed here. However, we will continue to use the $5 \mathrm{M}$ assumption to be consistent with Volume 1.

It should be pointed out that the compositional envelopes of suitable grouts have not yet been defined; thus, estimates of the minimum grout volume resulting from processing of tank wastes are subject to large uncertainties. The currently demonstrated grout feed composition "limits" are really not limits at all; they merely reflect the compositions of grout feeds that result from the compositions of wastes studied to date and the grout limitation on radiolytic heat generation.

Also shown in Table 2.5 are the estimated quantities of some radionuclides that are present in the wastes, but are not governed by the NRC regulations. These are presented for comparison and because one of them, Sm-151, enters into a flowsheet decision. Again, only those radionuclides having half-lives $>13$ years are included here.

The decontamination factors (DFs) shown in Table 2.5 were calculated assuming concurrent processing of sludge and supernate, with the volume of LLW being defined by the total sodium content of the two fractions. Other processing approaches would lead to different decontamination requirements unless the determinations can be made on an overall average basis. For example, if sludge and supernate are processed separately and if the sludge contains $10 \%$ of the sodium, and if each increment of grout is required to meet the Class A limits, then tenfold higher DFs would be required while processing the sludge for those radionuclides (e.g., strontium, plutonium, americium) that are present in the sludge.

The data of Table 2.5 show that only Sr-90, Cs-137, Pu-239, and Am-24I need to be removed from the SST waste (considering an average of all tanks) for the LLW to meet Class A limits. However, removal of other components might be required because of variabilities in compositions among the tanks (e.g., $\mathrm{Ni}-63$ ). Removal of $\mathrm{Ni}-63$ was not included in the example flowsheet; it will need to be added to ensure that the LLW form does not exceed the Class $A$ limit during processing of some of the SST waste unless the waste feeds can be blended appropriately or unless the radionuclide content of the grout can be considered on an overall average basis instead of on an individual increment basis.

If it is necessary to implement a nickel removal process, then disposition of the nickel becomes a problem because it cannot be accommodated by HWVP-type glass without exceeding the $-10(0)$ canister goal (Table 2.3). Decay storage in a surface facility or repository disposal in an alternative waste form are possibilities for handling this special problem.

The process steps used to separate the indicated radionuclides from the waste must be capable of providing higher DF values than those given in Table 2.5 in light of the sum-of-fractions-rule portion 
of the Class A regulations and feed variability possibilities, especially in the SSTs. Target DFs tenfold greater than those listed in Table 2.5 may be required to ensure that clean option goals are met.

Because DFs in excess of $-10^{4}$ may be difficult to achieve in practice in one cycle, sequential cycles may be needed in some cases to achieve adequate removals of strontium and cesium. Such needs could be obviated by appropriate blending of feeds or by overall averaging of the contents of the LLW grout, is was discussed earlier for Ni-63. The current flowsheet, based on the overall average feed composition, implicitly assumes that such blending does occur.

\subsubsection{ALARA-driven Separations Requirements}

As was discussed earlier, Tc-99, I-129, and U-238 can be prime contributors to long-term radioactivity-related risk even at concentrations that are allowed by the Class A LLW limit. Thus, the example clean option flowsheet includes steps to reduce the concentrations of these radionuclides in the LLW fraction, which will be disposed of under much less stringent conditions than will the HLW fraction.

The separated Tc-99 can be accommodated within 1000 HLW canisters, but not the separated U-238 (Table 2.3). Thus, it is assumed that the separated uranium will undergo additional purification steps so that it can be added to the existing stockpile of such material. The separated iodine is assumed to be disposed of in a special form, as it could not be easily incorporated in HLW glass.

Other ALARA-driven separations incorporated in the example flowsheet are those to send Th-232 and Sm-151 to the HLW fraction. Thorium separation is included simply because it will likely occur along with the separation of plutonium. Samarium separation is included because $\mathrm{Sm}-151$ is one of the major radionuclides present in the waste (Table 2.5), and this fission product lanthanide can be separa ed along with americium from the bulk chemical lanthanides (primarily lanthanum and cesium) hat are present in the wastes because of their use in processing steps.

\subsubsection{Disposition of Tank Waste Constituents}

Table 2.6 presents a summary of the disposition of $t \mathrm{l} .:$ tank waste constituents. As discussed in the previous subsections, most of the bulk chemical constituents of the wastes must go the LLW grout in order to dispose of most of the radioactivity within $\sim 1000$ canisters of HLW glass. Grout is considered to be the best demonstrated available technology for toxic metals in non-nuclear industries, and should be applicable to these mixed wastes as well. However, the toxicity of the grout waste form can be reduced by destroying materials such as nitrate, nitrite, and organics. These destructions are assumed in this example flowsheet to be accomplished by calcination; this has the added benefit of allowing the recovery of sodium hydroxide for flowsheet use without affecting the volume of the LLW fraction. 
Table 2.6. Disposition of Tank Waste Constituents

\begin{tabular}{|c|c|c|c|c|}
\hline LLW & HLW & Destroy & Special Disposal & Stockpile \\
\hline Hydroxide & Cs & Nitrate & 1 & $\mathrm{U}$ \\
\hline Carbonate & $\mathrm{Sr}$ & Nitrite & $\mathrm{Ni}^{(\mathrm{a})}$ & \\
\hline Phosphate & $\mathrm{Tc}$ & Organics & & \\
\hline Sulfate & Th & & & \\
\hline Fluoride & $N p$ & & & \\
\hline Chloride & $\mathrm{Pu}$ & & & \\
\hline Ferrocyanide & Am & & & \\
\hline Al & $H L n^{(b)}$ & & & \\
\hline $\mathrm{Ba}$ & & & & \\
\hline $\mathrm{Bi}$ & & & & \\
\hline $\mathrm{Ca}$ & & & & \\
\hline $\mathrm{Cr}$ & & & & \\
\hline $\mathrm{Fe}$ & & & & \\
\hline $\mathrm{Hg}_{\mathrm{g}}$ & & & & \\
\hline $\mathbf{K}$ & & & & \\
\hline $\operatorname{LLn}^{(c)}$ & & & & \\
\hline Mn & & & & \\
\hline $\mathrm{Na}$ & & & & \\
\hline $\mathrm{Ni}^{(\mathrm{a})}$ & & & & \\
\hline Pd & & & & \\
\hline $\mathrm{Si}$ & & & & \\
\hline $\mathrm{Zr}$ & & & & \\
\hline
\end{tabular}

(a) Nickel is currently planned for LLW disposal, but combinations of processing sequence and regulatory interpretation could necessitate a special disposal form in some cases.

(b) $\mathrm{HLn}=$ lanthanides heavier than promethium.

(c) $L L n=$ lanthanides lighter than promethium. 


\subsection{Example Flowsheet Description}

For purposes of this study, an example flowsheet was constructed to provide the separations needed to achieve the clean option objectives, starting with a feed made up of the total SST contenis. It is known that processing the waste on a tank-by-tank basis would give a wide range of feed compositions, thus perhaps a wide range of required decontamination needs. In some cases additional cycles may be needed for radionuclides requiring high decontamination factors $(e .8 . .5 r-90)$ and in other cases it may be possible to eliminate some process steps (e.8. Cs-137 removal from dissolved sludge). However, this flowsheet is thought to provide a reusonable example of the process complex. ity, and low waste generation capability, of a flowsheet needed to achieve the objectives of the clean option.

The flowsheet includes processes to remove several radionuclides (e.8, Sr-90, Tc-99, Cs-137. and perhaps $\mathrm{Pu}-239$ ) from both acidic and basic solutions, even though these materials will likely be predominantly in only one type of solution. This was done because of the likelthood that, with some wastes at least, the quantity, though small, of some of these radionuclides present in the "other" solution will still mean that the required overall DF cannot be achieved without treating the "other" solution.

The example clean option flowsheet developed for the preliminary evaluations of technical feasibility and of impact on waste volumes is outlined in Figure 3.1. This flowsheet was developed with SST wastes specifically in mind, but it should be amenable to DST wastes as well.

A number of potential processes are avallable for each of the radionuclide removal and separa. tion steps needed to meet the clean option objectives. Similarly, the individual process steps can be used in a number of different sequences. The processes and the process sequence identified in Figure 3.1 were selected after consideration of the suitability of options with regard to 1) suitability for the specific problem (Hanford tank wastes), 2) level of development, and 3) ease of developing meaningful estimates of shemical additions to the wastes from published information.

This flowsheet was developed primarily with only "technical feasibility" in mind. The impon. ance of process complexity and costs is well recognized and will be addressed in future efforts Future cost/benefit evaluations could well conclude that the cost of a certain operation is too yreut for the resultant benefit; this could lead either to a search for a less costly operation lo achieve the same result or to a decision that the result is not of practical value. Such "practical feasibility" questions are not addressed in this study.

As the first step of the flowsheet, the retrieved waste slurry containing the sludge (primarily insoluble hydroxides, phosphates, etc.) and the solution (primarily sodium nitrate/nitrite, hydroxide. and aluminate from waste supernates and dissolved waste salt cakes) may be treated to destroy organic complexants that could have deleterious effects on the subsequent process chemistry. Complexani destruction will certainly be required for this flowsheet to work properly on the DST waste called complexant concentrate $(\mathrm{CC})$, and may well be beneficial on wastes from many other tanks 


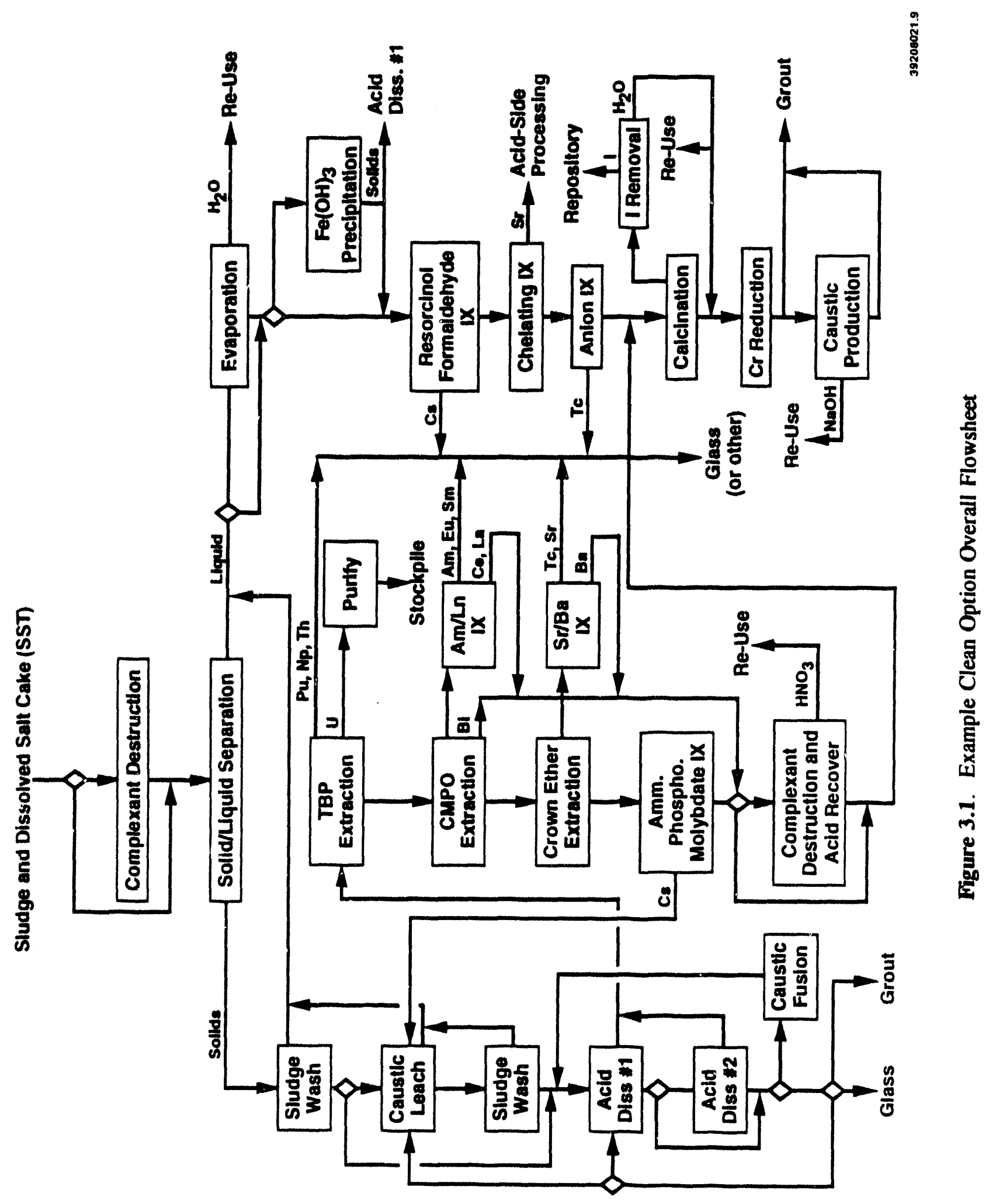


Following complexant destruction (if applied), the waste slurry is divided into its solid (sludge) and liquid components. An efficient solid/liquid separation (SLS) process will be required here (or later in the process) to prevent radionuclide-containing solids from entering the $L L W$ form in quantities that prevent it from meeting Class A LLW criteria. Similarly, highly efficient solid/liquid separation processes will be required at many other locations in the flowsheet. This point should be kept in mind even though these locations are not shown on the presented flowsheets (in an effort to keep them simple).

Sludge washing and dissolution steps are outlined in the left portion of Figure 3.1. These steps are crucial to the success of the clean option. The 1000-canisters of HLW glass objective of this option can be met only if the sludges can be dissolved nearly quantitatively, unless the undissolved residues have been leached free enough of radionuclides to meet Class A LLW criteria. Dissolution data for Hanford tank wastes are very incomplete, but it is known that different tank wastes exhibit markedly different dissolution behaviors. Thus, multiple sequential leach/dissolution steps are shown and the possibilities of additional treatment of the residues by fusion and/or multiple cycling are included. It is currently felt that a fusion step will not be necessary to meet the clean option goals.

Radionuclide removal steps are outlined in the center and in the right-hand side of Figure 3.1, with steps for removal from acidic, dissolved sludge solutions being presented in the center and those for removal from basic solutions being on the right. Removal processes are included here for the fission products Sr-90, Tc-99, I-129, Cs-137, and for the actinides thorium, uranium, neptunium, plutonium, and americium (the traces of curium that are present will behave the same as americium). As was discussed in Section 2.0, the activation product $\mathrm{Ni}-63$ may need to be removed from the wastes in some tanks in order for the Class A LLW limits to be achieved in all processing increments.

In order to meet the clean option objective of incorporating the HLW within $\sim 1000$ glass canisters, separations steps beyond the removal of radionuclides from the waste streams will also have to be performed. Two such steps are included in Figure 3.1: 1) the separation of americium from lanthanide elements that were added as process chemicals, and 2) the separation of strontium from barium.

A major feature of this flowsheet is the recycle of process chemicals (especially sodium hydroxide) in order to minimize the "growth" of waste during processing. Calcination is included in Figure 3.1 primarily as a means of removing nitrate, nitrite, and organic complexants so that the LLW waste form will be less toxic and will have greater stability. Recovery of sodium hydroxide from the calcined waste oxides should be relatively straightforward.

\subsection{Sludge Washing and Dissolution}

Essentially complete sludge dissolution or, alternatively, extensive leaching of radionuclides from undissolved sludge components, is necessary for success of the clean option. Experimental results have been obtained with several different types of sludges (Lumetta and Swanson 1993; Lumetta et al. 1993); in nearly all cases the clean option objectives were met quite simply. However, studies with a much greater range of tank sludge compositions will be required before a sludge 
dissolution flowsheet can be defined. The flowsheet given in Figures 3.2 and 3.3 provides a good indication of what might be finally determined to be appropriate.

With some wastes, as was mentioned earlier, the first step in the pretreatment series may be a complexant destruction treatment. This is because some wastes are known to contain high enough concentrations of organic complexants that they interfere significantly with the effectiveness of radionuclide removal processes (Schulz 1980). Ozone has long been considered for use in such an application (Schulz 1980), largely because its reduction product does not add any nonvolatile material to the waste. Avoiding the addition of nonvolatile (and insoluble) materials was an important consideration in the earlier approaches to tank waste pretreatment, where sludge vitrification was assumed, but it is of much less importance in the clean option, where sludges will be dissolved and their bulk components will go to LLW grout. Thus, (as suggested by D. O. Campbell, consultant) oxidants such as potassium permanganate might find application here, especially in tanks where the organic complexant concentrations are not high.

One possible side effect of oxidative destruction of organic complexants is that the concentration of plutonium in the liquid phase might be increased by oxidation of $\mathrm{Pu}(\mathrm{IV})$ to $\mathrm{Pu}(\mathrm{VI})$, which is sorbed less efficiently by the sludge components. If such an effect is too large, the Pu(VI) can be reduced back to $\mathrm{Pu}(\mathrm{IV})$ before the liquid is separated from the sludge.

The current volume of SST has been estimated to be $1.4 \times 10^{5} \mathrm{~m}^{3}\left(1.4 \times 10^{8} \mathrm{~L}\right)$. It is assumed here that retrieval and/or salt cake dissolution operations will increase this volume fourfold, ending up with a liquid supernate phase having a sodium concentration of $4 \underline{M}$ and a solid (sludge) phase containing the insoluble metal hydroxides, phosphates, etc.

In the flowsheet portion shown in Figure 3.2, it is assumed that the SLS step is filtration or centrifugation with the collected solids being washed with sufficient water to increase the liquid volume by $5 \%$. This should give efficient removal of the interstitial liquid components from the solids.

The first dissolution step of the example flowsheet is a caustic $(\mathrm{NaOH})$ leach step aimed at dissolving selected solids (e.g., aluminum hydroxide, silica, silicates) and converting some insoluble phosphates to hydroxides. This step is envisaged as involving digestion at the boiling temperature for several hours in several-molar sodium hydroxide; conditions that have been found to dissolve incinerator ash (Thompson et al. 1979) and fiberglass (Jantzen 1990), materials similar in composition to some of those that may be present in the waste tanks. An initial $\mathrm{NaOH}$ concentration of $4 \mathrm{M}$ is shown for this step; the indicated volume should be sufficient to prevent the solubility of sodium aluminate from being exceeded. Data of Delegard (1985) indicate that the room-temperature solubility of Pu(IV)-hydroxide in the resultant leach solution would be $<10 \mathrm{nCi} / \mathrm{mL}$; if necessary, this could be decreased by addition of a reducing agent such as hydroxylamine, as is shown in Figure 3.2.

It is important to note that the $\mathrm{NaOH}$ used in this leach step is recovered from a calcine of the decontaminated waste solution (Section 3.4.3), and thus does not add more material to the waste. This is also true of the $\mathrm{NaOH}$ used in many other flowsheet steps. 


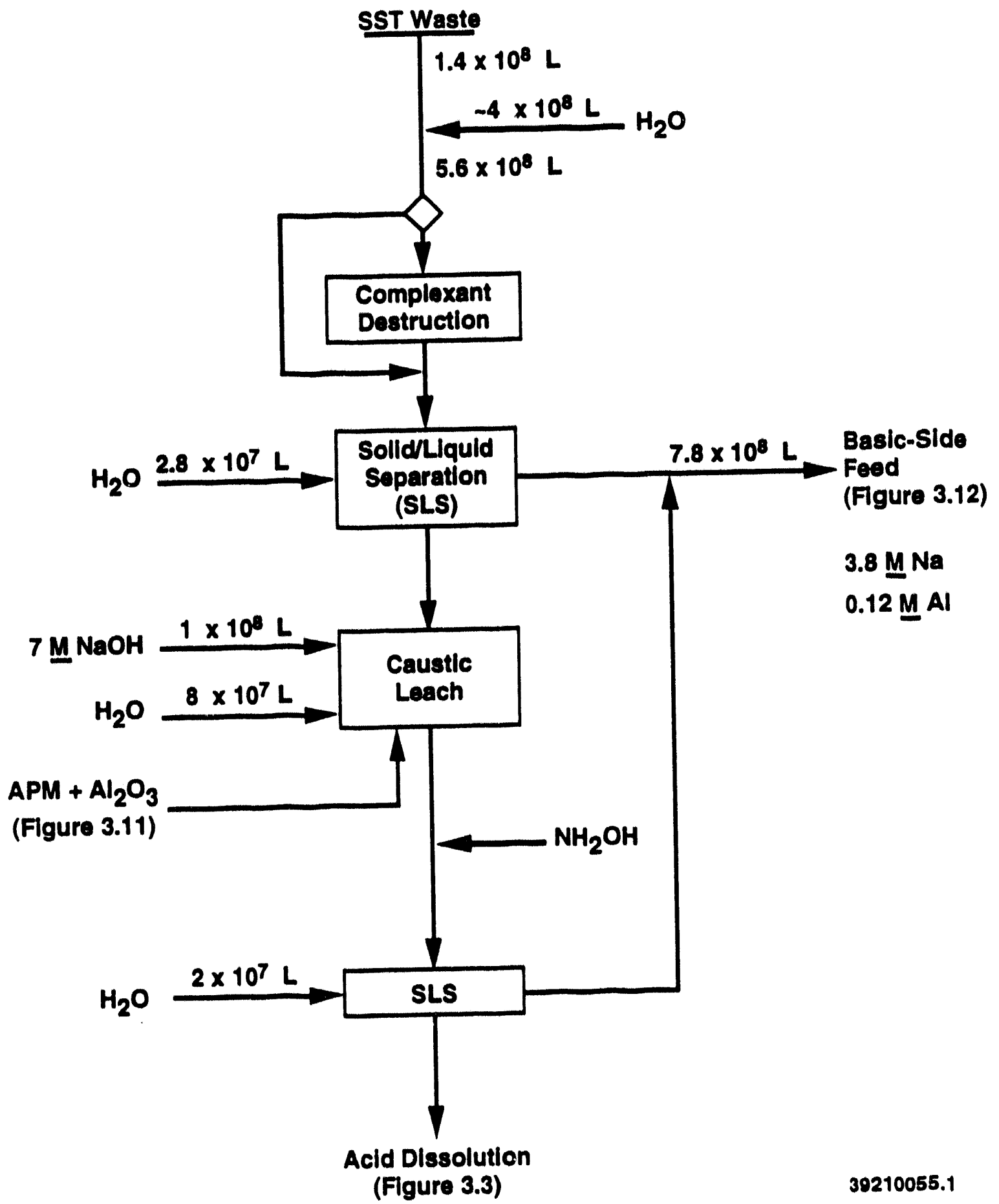

Figure 3.2. Sludge Washing and Caustic Leaching Portion of Flowsheet 
In addition to the waste sludges, the caustic leach step will also treat the ammonium phosphomolybdate used to remove cesium from acidic solution (Section 3.2.4). Residues from the oxidation of spent ion exchange resins used in many separations steps will a' o be treated here.

The solids remaining after the caustic leach step are again collected by filtration or centrifugation, and are washed to remove the interstitial solution. The leach and wash solutions are combined with the liquid from the first SLS step to provide the feed to the basic-side separations process steps. These steps are discussed in Section 3.3.

The washed, leached sludge is then dissolved in nitric acid (Figure 3.3); it is very likely that complexants will need to be added to the nitric acid to achieve efficient dissolution (or leaching of radionuclides) of many of the sludges. It is also very likely that, with some wastes at least, more than one dissolution step will be required to achieve complete dissolution (or leaching). Thus, the flowsheet shows two acid dissolution steps, one employing mixed nitric-oxalic acids and one employing mixed nitric-hydrofluoric acids. With many waste sludges, these steps will probably involve periods of several hours and temperatures at or near the boiling point. Solution volumes are chosen to give $\sim 0.1 \mathrm{M}$ iron in the dissolved sludge solution, and complexant amounts are chosen to give a slight excess over the quantity required to form 1:1 complexes with the metal ions. The complexant amounts given in Figure 3.3 assume that $10 \%$ of the aluminum is in the acid-side feed solution.

Also added to the acid dissolution step is the strontium removed in the basic-side removal step (Section 3.3.2). Thus, the dissolved sludge solution contains all of the strontium that is present in the waste.

The use of fluoride in the dissolution step will require that some equipment be constructed of special alloys in order to minimize corrosion. Several promising alloys for such service have been identified in ongoing work at PNL (Smith et al. 1992).

Residual solids (if any) from these dissolution steps could be treated in a variety of ways, depending on their quantity and their radionuclide content. They could be treated by caustic fusion; they could be recycled to one of the aqueous dissolution/leach steps discussed above; or they could be disposed of in either the HLW glass or the LLW grout. Disposal in grout would require that the solids have a low radionuclide content, and disposal in glass would require that the solids contain only a small fraction of the bulk components of the waste, as was discussed in Section 2.3.

The acid dissolution solutions give a combined dissolved sludge solution to be fed to the acidside separations process steps that are described in Section 3.2. However, other steps may be required before the separations steps can be operated properly. One such step is solution clarification. which is very important to the success of highly efficient separations processes. Solids removed during clarification would be combined with the other residual solids for recycle to the dissolution process or for disposal.

Another step that might be required prior to the acid-side separations processing comes from the use of complexants in the sludge dissolution step. If the amounts of complexants are too much in excess of the complex-forming bulk metal ions present, they may complex significant portions of the actinides and thus decrease their efficiency of removal. 


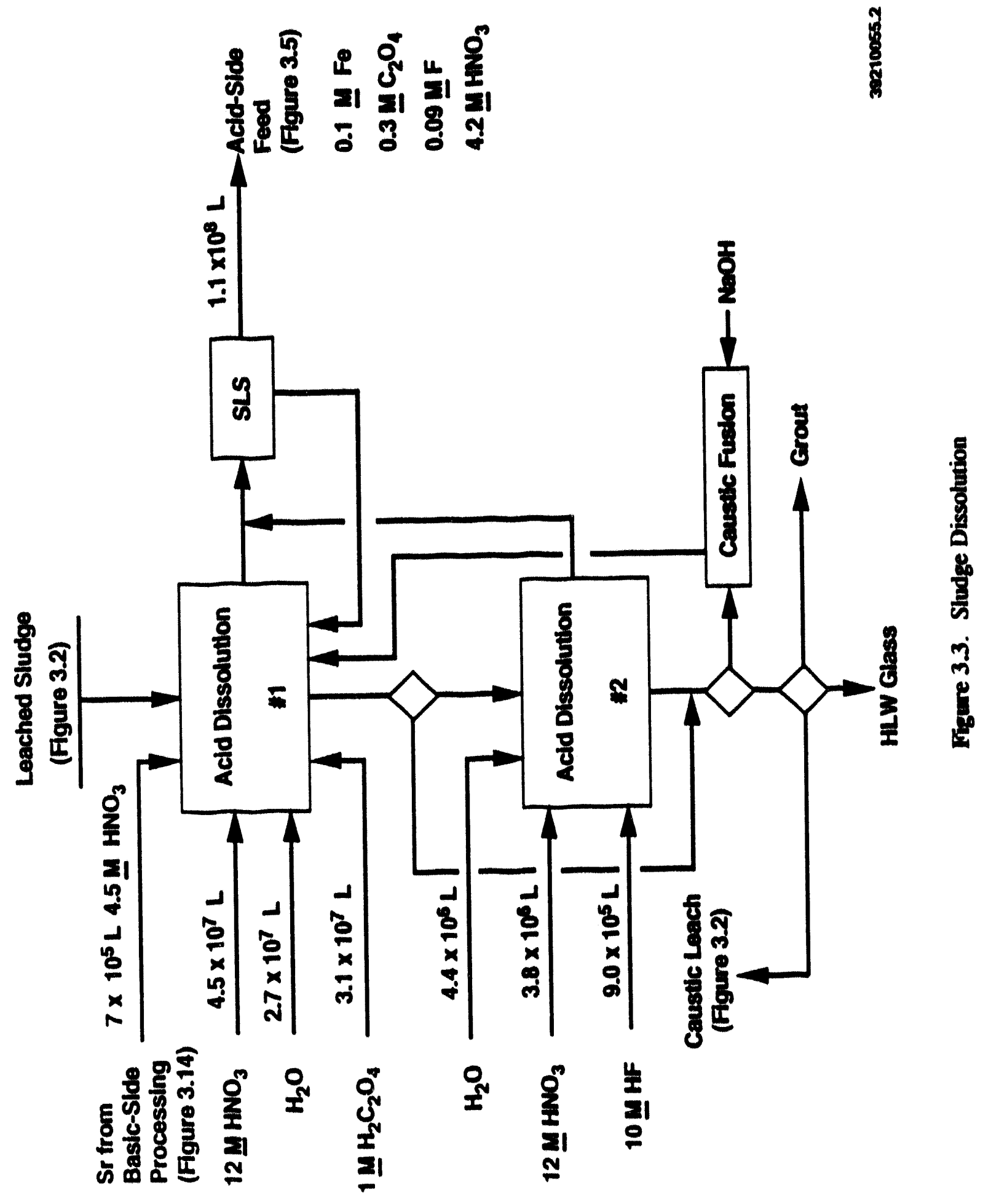


If necessary, oxalate can be destroyed by digestion of the dissolved sludge solution, especially in the presence of manganese ion (Bibler et al. 1981). Manganese is present in SST sludge (Table 2.1), and more could be added to give a more rapid reaction without increasing the waste volume because manganese will be only a minor component of the LLW grout. In fact, the use of permanganate to rapidly destroy the oxalate could be appropriate (but is not included in the current flowsheet).

A class of substituted diphosphonic acids that are stronger complexants than oxalate but are more easily destroyed by reaction with nitric acid have been termed TUCS (for thermally unstable complexants) compounds by workers at Argonne National Laboratory (Horwitz et al. 1990). These compounds have some advantages over oxalate, but they suffer from the potential disadvantage that phosphoric acid is a product of their destruction. Phosphoric acid should not present any problem in LLW disposal, but there is concern that insoluble phosphates might form and cause problems in some steps of the flowsheet. The effects of these compounds should be considered in more depth before their use is adopted.

Fluoride cannot be destroyed like organic complexants, but its complexing of actinide ions can be minimized by providing additional amounts of complex-forming metal lons (e.8.. $\mathrm{Al}^{3+}, \mathrm{Zr}^{4+}$ ) to tie up most of the fluoride. With the added fluoride concentration and the overall average SST zirconium concentration shown in Figure 3.3, most of the fluoride would be tled up even if no additional metal were added. However, fluoride might be used in the dissolution of some sludges that do not contain either aluminum or zirconium; in those uses, addition of some complex-forming metal ion would be necessary for efficient actinide extraction. If aluminum is used for this purpose, as it was for years when fluoride-containing feeds were processed in the Hanford PUREX plant, the quantity of aluminum needed (for the amount of fluoride given in Figure 3.3) would amount to only $-10 \%$ of that already present in the waste. Thus, such a use should have no effect on the quantity of grout required for the LLW fraction of the waste.

\subsection{Acid-side Separations}

The (acidic) dissolved sludge solution is expected to contain nearly all of the actinides and the strontium, as well as nickel and other transition metals (e.g., iron, chromium) that are present in the wastes. It may also contain small, but significant, fractions of the cesium, technetium, and alumi. num. An acidity of $\sim 4 M$ is assumed for the feed to the acid-side separations processes, primarily because of the feeling that attainment of "complete" sludge dissolution will be easier at that high an acidity, and of the desire to avoid dilution of dissolved sludge solutions.

Radionuclides that need to be removed from the dissolved SST sludge solution in order to meet Class A LLW criteria are Sr-90, Cs-137, Pu-239, and Am-241; Ni-63 removal may also be required when processing some SSTs, as was discussed in Section 2.3. Other radioactive isotopes whose removal would be potentially beneficial from the standpoint of long-ierm risk are Tc-99, 1-129. Np-237, and U-238 (Droppo et al. 1991; Buck et al. 1991). Demonstrated or highly promising processes exist for removing all of these radionuclides (with the possible exception of Ni-63 and 1-129) from dissolved sludge solution. Process selection and process sequencing require consideration of many factors; some of those considerations will be discussed next. It should be emphasized that 
most of these factors were considered in only a qualitative fashion, and many decisions were based on then current knowledge and the availability of data required to describe an example flowsheet.

The processing sequence selected here is to first remove the actinide elements from the dissolved sludge solution and then remove the fission products. This sequence was chosen to ensure that the transuranic actinides would be removed before they could contaminate the solvent and/or sorbent material used in fission product removal processes, and perhaps thus present processing complications.

Figure 3.4 presents distribution coefficient (D) values for several important actinide (and other) constituents of Hanford SST wastes between nitric acid solutions and a) $1.1 \mathrm{M}(30 \%)$ TBP.NPH, the solvent used for years in the PUREX process, and b) $0.2 \mathrm{M}$ CMPO - $1.4 \mathrm{M} \mathrm{TBP}$-NPH, a typical solvent composition proposed for the TRUEX process. (D is defined as the concentration of a material in the organic phase divided by its concentration in the aqueous phase.) The bismuth data shown here were obtained from Lumetta et al. (1993); the other data were obtained from Bond (1990) and from Horwitz et al. (1985). These data are shown to compare the relative strengths of the two extractants, and to provide some background for the following discussion. They were obtained under nonprocess-type conditions (e.8., absence of macro amounts of uranium, which tends to load the solvent and thus decrease the $D$ values, and absence of complexants, which also decrease the $D$ values), and should not be used in a quantitative way.

Earlier studies of the removal of actinide elements from dissolved Hanford sludge solutions have centered on the use of the TRUEX solvent extraction process to simultaneously remove all of these elements (and sometimes technetium). The actinides (and coextracted lanthanides) would be disposed of in the HLW glass, and the bulk sludge components, which do not extract, would be disposed of (after a strontium removal process) in the LLW grout. In a more recent approach, the strontium and actinide removal processes would be combined in one step (Horwitz 1991). The degree to which the earlier studies considered the behavior of bismuth is uncertain.

Bismuth is present in SST sludges in signiflcant quantities (Table 2.1 ) because of the use of a bismuth phosphate carrier precipitation process in the firat plutonium recovery plants. This quantity may be 100 large to be accommodated in 1000 canisters of HLW glass (Tables 2.2 and 2.3 ), so separation of bismuth from the TRU elements is planned. However, bismuth exhibits an acid dependency in its extraction by TRUEX solvent (Figure 3.4b) that muy complicate its separation from the TRU clements.

Several options have been explored in the earlier studies for stripping extracted actinides from the TRUEX solvent. Trivalent actinides can be stripped into dilute acid, but the high distribution coefficients of the tetravalent and hexavalent lons make it necessary to use complexants io strip them. Two principal stripping approaches have been proposed: 1) simultaneous stripping of all actinides using complexing agents, and 2) selective stripping of a) trivalent actinides (e.8., americium) into dilute acid; b) tetravalent actinides $(0.8$. plutonium) into dilute acid containing fluoride as a complexing agent; and c) stripping hexavalent actinides $(0.8$. uranlum) into carbonate solution. In these approaches, extracted rechnetium is stripped only by carbonate solution. 


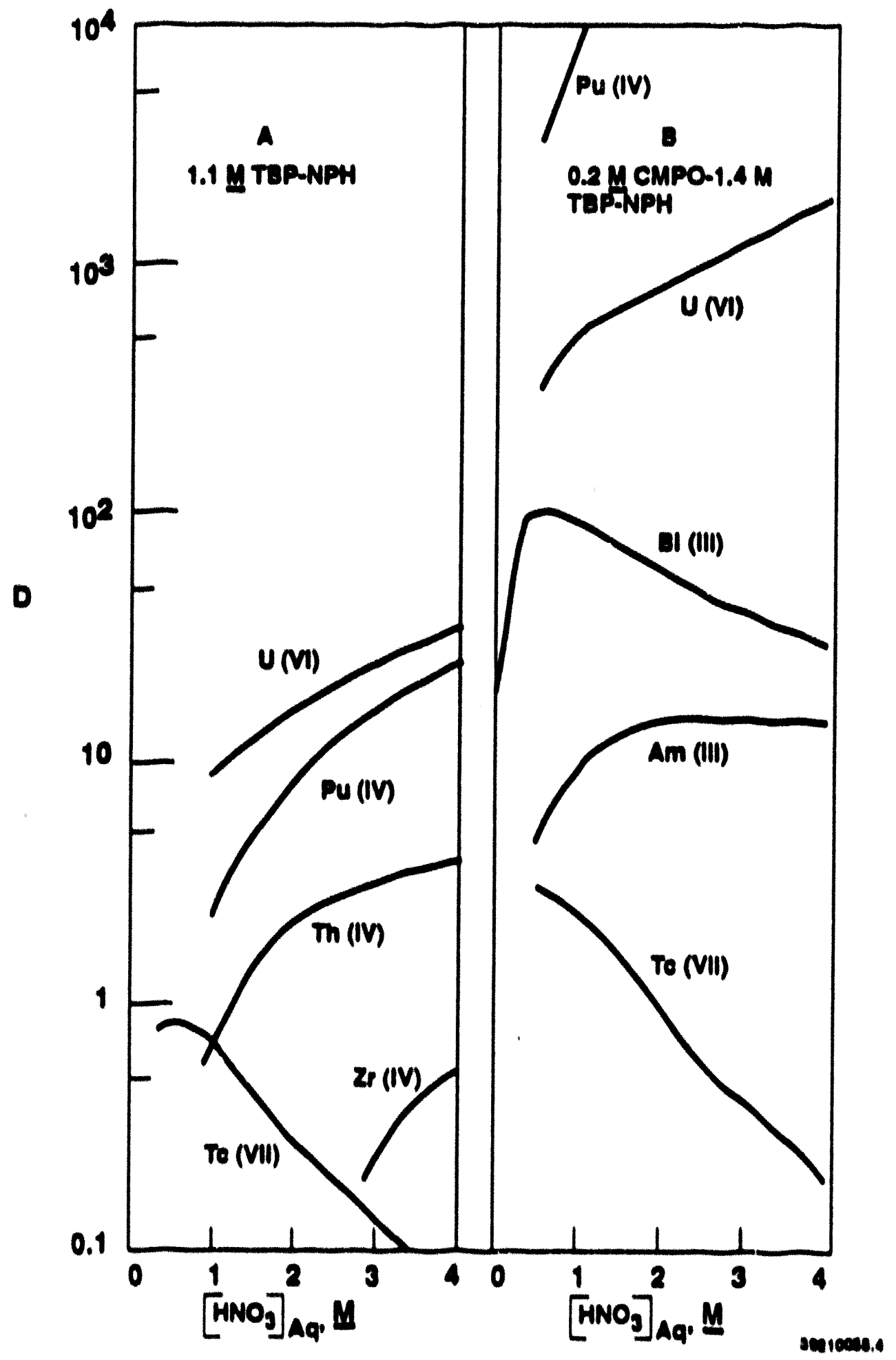

Manno 3.4. Typleal Distribution Coofincionts for TBP and CMPO Extractions 
If Approach 1 were used for the clean option with SST waste, additional processing of the stripped mixture would be required to separate uranium (and possibly bismuth) from the transuranic elements (if such processing were not done, the amount of glass required to contain the TRU. contaminated fraction would exceed 1000 canisters). Additional processing inight also be required to separate the TRUs from the complexing agents; this would be the case if the complexing agents (or their decomposition products) interfere in the vitrification process. Approach 2 would require additional processing to recover uranium (and perhaps technetium) from the carbonate solvent wash solution, and the uncertain behavior of bismuth could be a complicating factor.

Considerations such as these led to the decision that, while the above approaches are certainly feasible, it would be simpler to prepare a defensible example flowsheet employing first a TBP solvent extraction cycle to handle the recovery and needed purifications of the tetravalent and hexavalent actinides and then CMPO extraction cycle to handle the recovery of the trivalent actinides and their separation from bismuth. This approach also eliminates the use of complexants in stripping actinides. Such a flowsheet may also be simpler to operate, but that will not be known until much more detailed study has been completed. In addition, high acid TBP and CMPO cycles were selected for the example flowsheet to minimize technetium extraction and ensure that the carbonate wash solutions used for solvent purification would not contain Tc-99 in amounts that exceed the Class A limit.

Extractants other than CMPO may also be suitable for use in extracting the trivalent actinides. CMP (also know as DHDECMP) was considered for use in this example flowsheet; one reason for not selecting it was the absence of bismuth extraction data lother than the "partial retention" noted by Marah and Yarbro (1988) in an extraction chromatographic study) on which to base an example flowsheet. The pros and cons of these two extractants should be evaluated in more depth before any choice for final implementation is made, but the ultimate choice should have little, if any, effect on conclusions based on the example flowsheet using CMPO.

Thus, the processing sequence chosen here for the acidic, dissolved sludge solution is: 1) a TBP solvent extraction step to remove tetravalent and hexavalent actinides (pentavalent neptunium is converted to the hexavalent state for removal here also), 2) a CMPO solvent extraction process for removal of trivalent actinides (trivalent lanthanides are also removed), 3) a crown ether solvent extraction process for removal of strontium and technetium, and 4) an ammonium phosphomolybdate (APM) ion exchange process for removing ceslum. These steps are discussed further in the following sections.

\subsubsection{TBP Solvent Extraction for Removal of Uranium, Plutonlum, Neptunium, and Thorlum}

The TBP solvent extraction process for removal of uranium, plutonium, neptunium. and thorium is shown in Figure 3.5. For a perapective regarding plant size. it will be mentioned that the feed now rate for processing the dissolved SST sludges in 20 years of operation would be approximatcly the sume as the feed now rate in a spent hel reprocesaing plant that processes 800 ) MTU/year (which is the capacity of the planta recently completed in France and planned for construction in Japan).

The feed to this cycle contains not only the dissolved sludge solution (Figure 3.3), but also a stream to provide chemicals to adjust (if necessary) the degree of complexation of the contained ions. 


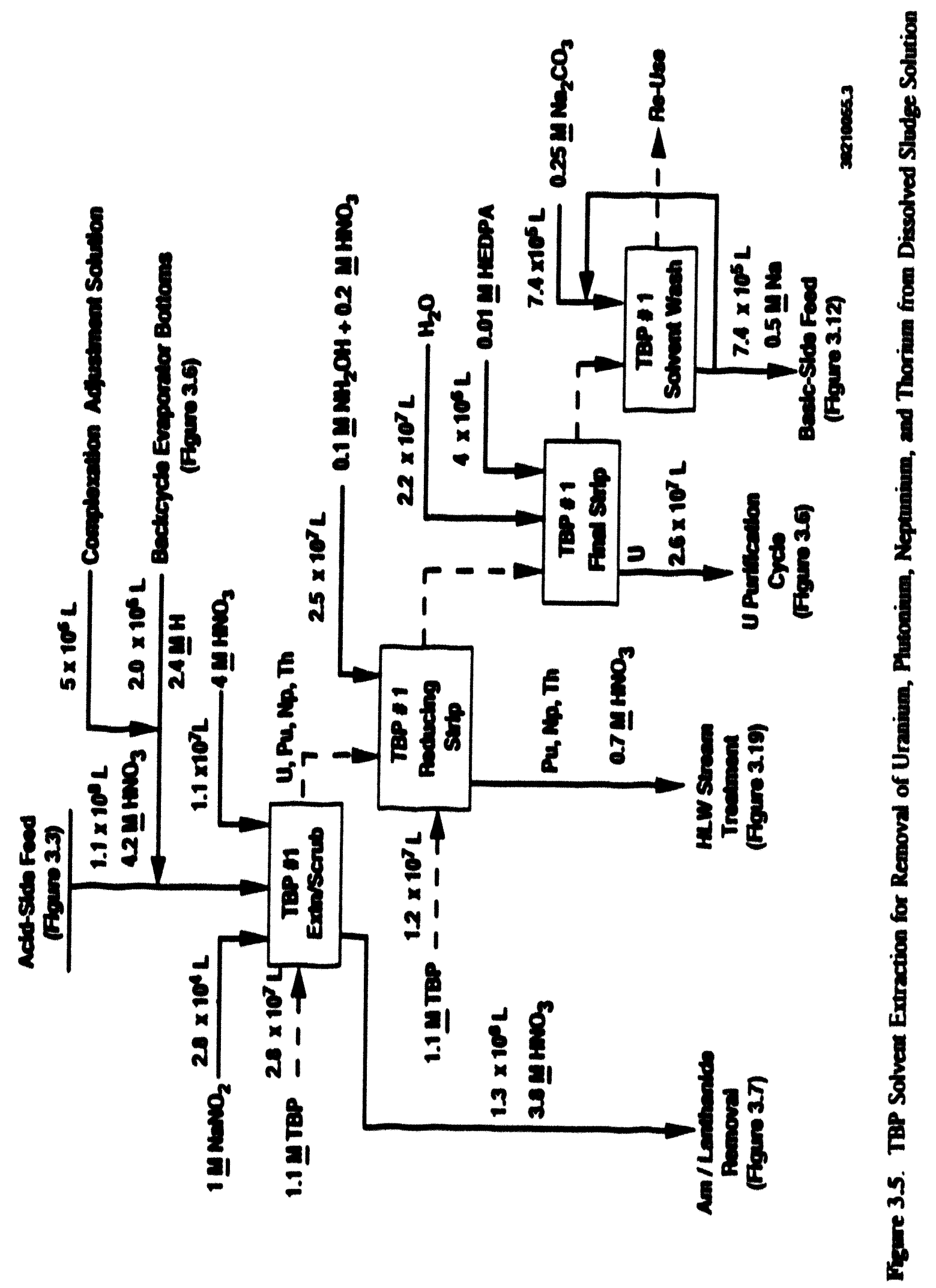

3.12 
and a stream containing the bottoms solution from the backcycle evaporator used to concentrate the waste solution from the subsequent uranium purification cycle. The latter two streams are discussed later in this section; for now, the proper degree of complexation is assumed to be achieved in the sludge dissolution step so that no chemicals (other than water) are used in the complexation adjustment solution.

In the first extraction contactor of this TBP cycle, uranium, plutonium, neptunium, and thorium are extracted into the TBP organic phase, which is then scrubbed with nitric acid to increase the separation from the bulk metal lons, some of which have a slight extractability. The raffinate from this contactor contains the remaining components of the dissolved sludge solution, and is routed to the next step of the treatment process (Section 3.2.2). The extracted plutonium, neptunium, and thorium are selectively stripped back into an aqueous phase in the second contactor (to be routed to HLW glass for disposal); and the uranium is stripped in the third contactor. The uranium is purified further in another TBP cycle so that it can be added to the existing uranium stockpile.

The solvent composition chosen here is the same, 30\% $(\sim 1.1 \mathrm{M})$ TBP in hydrocarbon diluent, as is usually used in the well-known PUREX process. At the $-4 \mathrm{M} \mathrm{HNO}_{3}$ concentration of the feed and scrub streams, efficient removal of uranium, plutonium, and thorium can be achieved. Both the high acidity and the relatively low saturation of the TBP $(0.2 \mathrm{M}$ uranium) assist in efficient recovery of neprunium by the nitrite-catalyzed oxidation of inextractable $N p(V)$ to extractable $N p(V I)$, as was done for years in the Hanford PUREX plant. The dissolved sludge stream is assumed to be decontaminated from uranium and plutonium by factors of $10^{4}$ and from thorium and neptunium by factors of $10^{2}$. The lower factor is assumed for neptunium and thorium because neptunium removal is controlled by kinetic factors and because thorium is less extractable than uranium or plutonium. Cesium, strontium, americium, and trivalent lanthanides are virtually inextractable by TBP, and technetium extracts very little at the high acidity used here (Figure 3.4). Thus, these elements will remain in the dissolved sludge stream in this step, along with the nonradloactive elements present in the stream.

Neptunium removal is not needed in order for the LLW to meet Class $A$ limits (Table 2.5), but is included in the flowsheet for ALARA reasons (and because neptunium tends to be the most environmentally mobile TRU element). Neptunium recovery may be beneficial for other reasons (e.8. Pu-238 heat source production), but that is not the reason for removing it from the waste stream in this flowsheet.

The extracted plutonium, neptunium, and thorium are stripped from the TBP phase into an aqueous phase under conditions ( $-0.7 \mathrm{M} \mathrm{HNO}_{3}$ containing reductant) that leave the uranium with the TBP. A reductant is added to reduce Pu(IV) to Pu(III) and $N p(V I)$ to $N p(V)$ to allow these elements to be efficiently stripped. Hydroxylamine $\left(\mathrm{NH}_{2} \mathrm{OH}\right)$ should be suitable for this purpose; and because it can be decomposed to gaseous products, its use will add nothing to the final waste form. In the "bottom" part of the strip contactor, the aqueous stream is scrubbed with a fresh TBP stream to improve the separation of uranium from the stripped plutonium, neptunium, and thorium. In this example application, the stripped actinide stream will be routed to the HLW for disposal. Should further separation of these actinides be desired (e.g., further minimization of the number of HLW glass canisters by sending plutonium and/or thorium to existing stockpiles or to use Np-237 to make Pu-238), well-known process steps could be added to give such separations. 
The uranium is then stripped into a separate aqueous phase using dilute acid. In the "top" portion of this strip contactor, the TBP phase is contacted with a strong complexing agent (HEDPA in this example) to ensure complete removal of TRU elements from the TBP, so that they will not end up in the subsequent solvent wash solution. The stripped uranium is then purified further so that it can be added to the existing depleted uranium stockpile.

The solvent is then washed with sodium carbonate solution to prepare it for reuse. This wash solution will remove not only the TBP hydrolysis products (and traces of radionuclides), but also any elemental lodine $\left(I_{2}\right)$ that had been extracted from the dissolved sludge solution. Other extractable iodine species (e.8., organic lodides), if present, may also be removed in solvent washing. In order to minimize the $\mathrm{I}-129$ content of the LLW, this solvent wash stream is not sent directly to LLW; instead, it is sent through the basic-side processing steps described in Section 3.3 and ultimately to calcination, where the iodine may be volatilized and removed from the offgas stream.

Final uranium purification is accomplished in a second TBP cycle (Figure 3.6) that is based on the 2D Cycle of the Hanford PUREX plant. In this cycle, the uranium stream is first concentrated by evaporation and is then sent to a TBP extraction contactor; this contactor is run at low acidity and at a high degree of saturation of the TBP by uranium, and with hydroxylamine reductant in the scrub stream, to enhance removal of fission product and TRU elements. These conditions lead to a significant uranium "loss" from the contactor, but the "loss" is recovered by backcycling this stream (after evaporation) to the start of the first TBP cycle. Finally, the purified uranium is again stripped into dilute acid; this stream is concentrated by evaporation and then calcined to convert the uranium to $\mathrm{UO}_{3}$ for transfer to the stockpile.

The solvent from the second TBP cycle is also washed with carbonate to prepare it for reuse. This wash solution should not contain any $1-129$, so it is combined with other LLW streams for final treatment (Section 3.4.2).

The backcycle evaporator shown in Figure 3.6 to treat the raffinate from the uranium purification cycle can also have other important uses. It can concentrate off-standard streams so that their contained radionuclides will be recycled to the removal cycles, instead of being sent to waste. It could also provide a place to dissolve for re-work any radionuclide-contaminated solids that are removed from process streams (e.g., in feed clarification steps preceding the various separations processes).

For successful operation of the primary TBP extraction step, where most actinides (but nothing else) are removed from the dissolved sludge solution, it is assumed to be necessary to have complexants present in the feed and/or scrub solutions. One reason is that because of the (relatively) high concentration of zirconium in dissolved SST sludge solutions, highly extractable, mixed $\mathrm{Tc}-\mathrm{Zr}$ species could form unless the zirconium is "tied up" in a complex.

This effect of zirconium on technetium extraction was investigated by Vialard and Germain (1986), who found $D_{T c}$ to increase very rapidly as the organic-phase zirconium concentration increases. The $D_{\mathrm{Tc}}$ was found to be -1 from $4 \mathrm{M} \mathrm{HNO}$ when the organic-phase zirconium concentration was $0.005 \mathrm{M}$ (Figure 3.4a indicates a value $<0.1$ in the absence of zirconium). However, by adding oxalate to complex zirconium and thus suppress its extraction, these authors were able to decrease the $\mathrm{D}_{\mathrm{Tc}}$ greater than tenfold withnut decreasing the extraction of $\mathrm{Pu}(\mathrm{IV})$. 


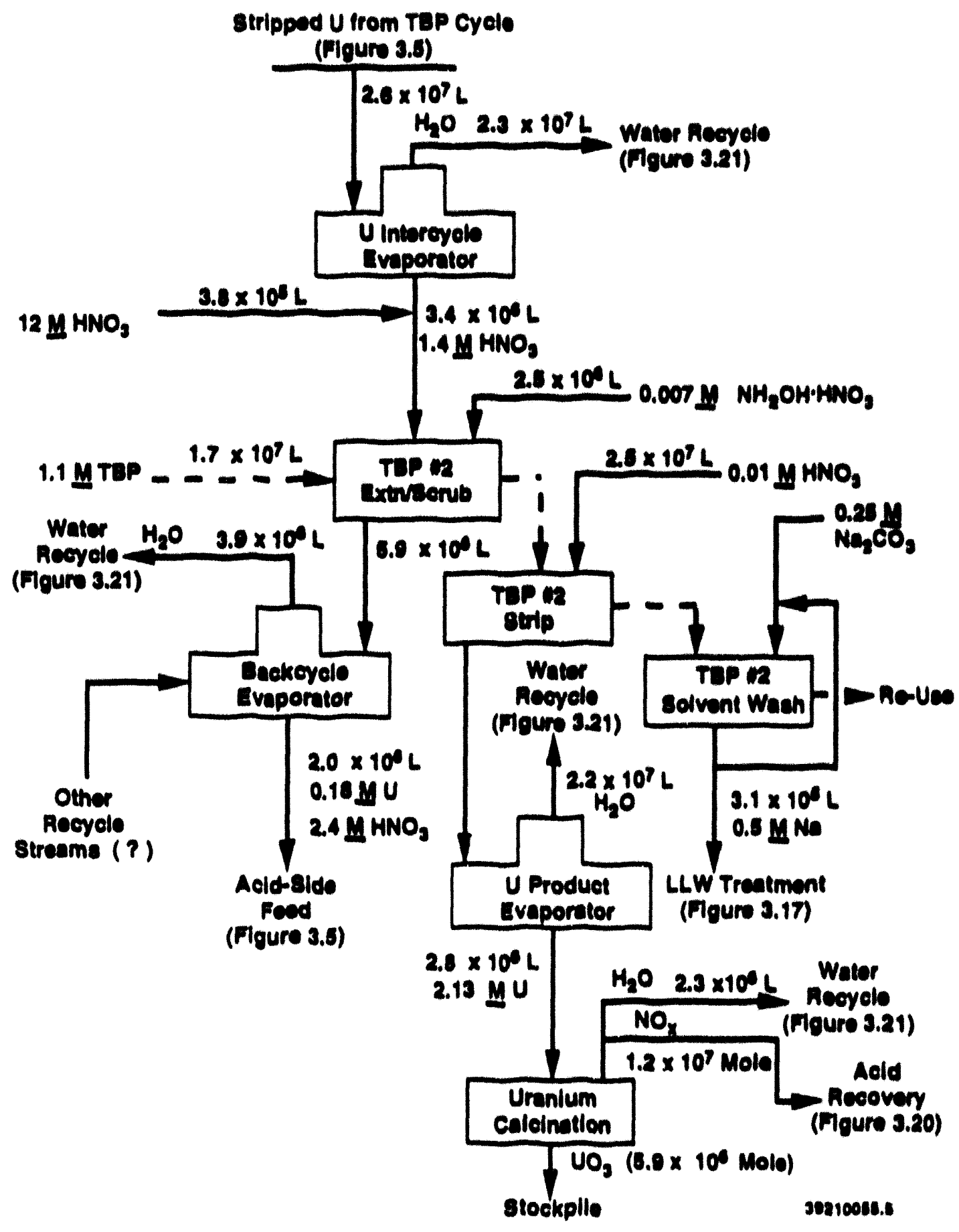

Figure 3.6. Second TBP Extraction Cycle for Purification of Uranium 
Because complexing of hexavalent actinides is less pronounced than complexing of tetravalent actinides, it appears to be safe to assume that a TBP extraction cycle employing aqueous-phase complexants can be used to extract the hexavalent and tetravalent actinides away from the technetium and zirconium (as well as from the trivalent actinides and lanthanides and other components of the dissolved sludge solution). Aqueous-phase complexants would likely be present in the feed to this cycle anyway, because of their use in the sludge dissolution process (Figure 3.3).

If the TBP cycle feed contains too much free complexant, the degree of removal of tetravalent actinides from the dissolved sludge solution will be lowered. Based on the distribution coefficient values given in Figure 3.4a, a tenfold lowering of the distribution coefficients would still allow $\mathrm{Pu}$ (IV) to be removed efficiently, but Th(IV) would not be removed (because its distribution coefficient would be $<1$ ). This would not be of great concern because thorium removal was included on the basis of its expected behavior in a system design that was based on removal of other elements. Thorium removal is not required by either Class A LLW criteria (Table 2.4) or by a desire to decrease the total radionuclide content of the LLW grout (Table 2.5).

The potential effect of excess complexant on neptunium removal is of greater concern because of the environmental mobility of that element. If excess complexant stabilizes $\mathrm{Np}$ (IV) instead of the mixture of $N p(V)$ and $N p(V I)$ that is usually present in nitric acid solutions, neptunium removal could be decreased because of the slow kinetics of oxidation of $N p(I V)$ by the nitrate/ nitrite solution mixture used in the TBP cycle extraction contactor. This difficulty could be overcome by the use of a more rapid oxidizing agent, perhaps $\mathrm{V}(\mathrm{V})$ or $\mathrm{Cr}(\mathrm{VI})$ as used by Koch (1969), but avoidance of excess complexant would appear to be the desired approach.

The use of complexants to obtain the desired split of radionuclides in the TBP extraction cycle will require careful process control. The relative quantities of complexants and of complex-forming metal ions (e.g., iron, aluminum, zirconium) must be properly adjusted, and the extraction conditions to be used must be selected carefully.

Residual tetravalent and hexavalent actinides that were not removed from the dissolved sludge solution in the TBP cycle will be removed in the subsequent CMPO cycle described in the following section because CMPO is a much more powerful extractant than TBP (Figure 3.4). However, removal of these species in the CMPO cycle will not benefit the overall process decontamination factor unless steps are added to that cycle to treat additional streams before they are routed to LLW. Because such treatment steps are not included in the example flowsheet developed here, efficient overall removal of tetravalent and hexavalent actinides in this flowsheet depends on their removal in the TBP extraction cycle.

\subsubsection{CMPO Solvent Extraction and Americium/Lanthanide Ion Exchange}

The raffinate from the first TBP cycle provides the feed to the CMPO extraction contactor (Figure 3.7). The solvent composition assumed for this step is $0.2 \underline{\mathrm{M}} \mathrm{CMPO}+1.4 \underline{\mathrm{M}}$ TBP in hydrocarbon diluent, which has been studied extensively by many workers (e.g., Horwitz et al. 1985). This CMPO step is used to remove trivalent actinides (e.g., americium and curium) from the dissolved sludge solution. Trivalent lanthanides are also highly extracted and must be separated in 


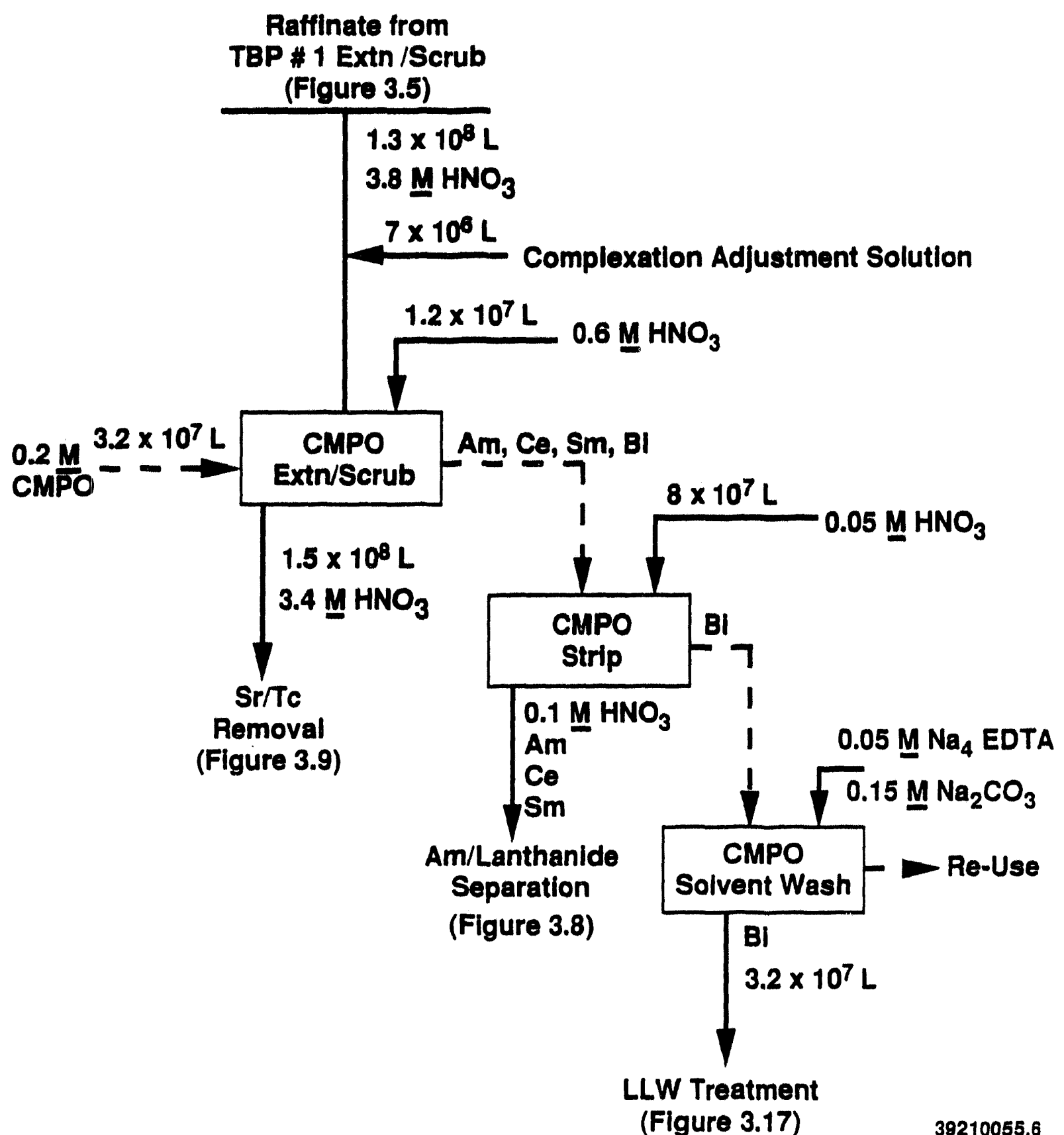

Figure 3.7. CMPO Solvent Extraction Cycle for Removal of Americium (and Lanthanides) from First TBP Cycle Raffinate 
subsequent operations to allow americium to be disposed of in the HLW glass without exceeding the 1000-canister objective of the clean option (Table 2.3). Depending on the degree of complexation of the feed, an excessive amount of bismuth may also be extracted; thus, the conditions of the strip steps were chosen to give separation of bismuth from the americiur: and the lanthanides.

As in the TBP cycle, technetium extraction is minimal at the relatively high feed acidity used here, and strontium and cesium, and the nonradioactive elements in the sludge, are inextractable. The dissolved sludge stream is assumed to be decontaminated from trivalent actinides and lanthanides by factors of $10^{4}$ in this step; however, the lighter lanthanides are subsequently added back to the nonradioactive components (after they have been separated from americium and the heavier lanthanides).

The trivalent americium and lanthanides are stripped from the CMPO extract into dilute nitric acid in the second contactor. This stripping must be at least $99.99 \%$ complete in order to maintain an overall americium decontamination factor of $10^{4}$; many strip stages may be needed. The portion of the bismuth that extracted is not well stripped under the indicated conditions, and thus passes to the solvent wash step where it is removed by a sodium carbonate solution containing an organic complexant (EDTA in this example) to prevent bismuth from precipitating in the basic solution. The bismuthcontaining wash solution is combined with other LLW streams for final treatment (Section 3.4.2).

As indicated above, the CMPO extraction process used to remove americium from the waste stream removes lanthanides as well because of their similar chemical properties. Because of the quantity of lanthanides present in the waste, additional separation of americium from at least the bulk of the lanthanides must be made if the americium is to be incorporated in 1000 glass canisters (Table 2.3). The separated lanthanides could all be disposed of in grout without exceeding the Class A LLW limit; however, the lanthanide radionuclide $\mathrm{Sm}-151$ is the third most abundant radionuclide (of those having half-lives $>20$ years) in the waste (Table 2.5 ), and its presence in the grout would be undesirable. Fortuitously, one of the leading candidate processes for separating americium from all lanthanides (band displacement cation exchange) can just as easily be used for separating americium plus heavier lanthanides (such as samarium) from lighter lanthanides. Because the bulk of the lanthanides in the wastes are lighter ones (e.8., lanthanum and cerium) that were added as process chemicals, this separations process allows the americium/lanthanide split to be made in a way that allows the americium and heavier lanthanides to be vitrified without exceeding 1000 canisters and also allows the lighter lanthanides to be grouted without contributing to the radionuclide content. The flowsheet for this separations process is shown in Figure 3.8; it is based primarily on that given by Wheelwright et al. (1974), with the quantities being adjusted in proportion to the relative trivalent ion contents of the waste studied by Wheelwright et al. and of the Hanford SST waste.

In the first step of this separation process, the trivalent actinides and the lanthanides are removed from the strip solution of the first CMPO cycle (Figure 3.7) by sorption onto a cation exchange resin. The effluent from the sorption step can be routed to a backcycle evaporator (possibly the one shown in Figure 3.6) if needed to ensure the maintenance of high decontamination factors to the LLW form. but this is currently assumed to not be necessary. Following a water wash of the resin, the trivalent ions are eluted with a pH-adjusted $0.05 \mathrm{M}$ DTPA solution onto a zinc (or other barrier ion)-loaded cation exchange resin column. Continued elution through a series of columns results in the establishment of discrete bands of metal ions in a sequence that depends on the magnitudes of the constants governing the formation of the metal ion-DTPA complexes. This order is zinc: curium. americium. 


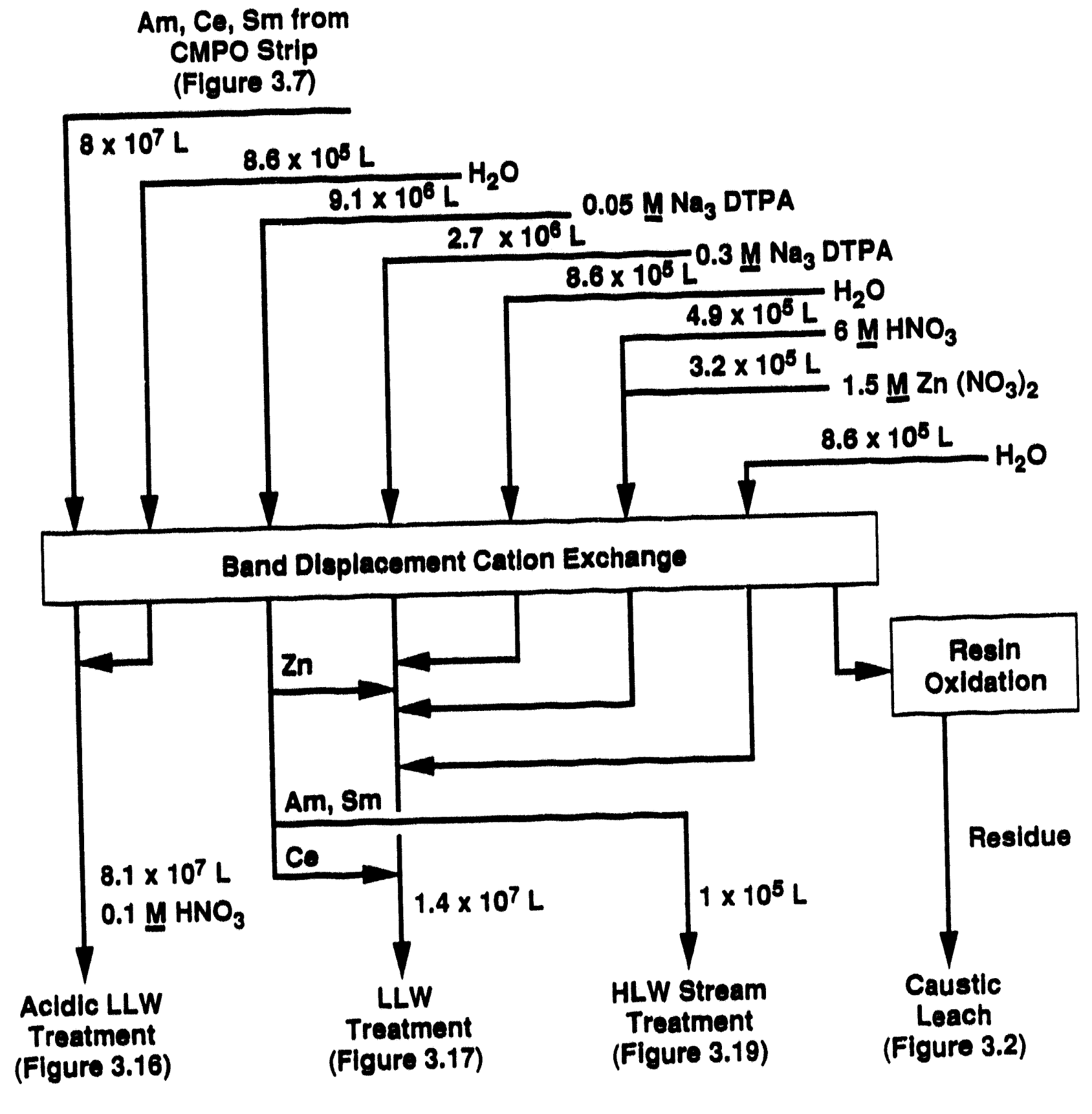

Figure 3.8. Band Displacement Cation Exchange for Separation of Americium and Heavy Lanthanides from Light Lanthanides 
terbium, and dysprosium (together); gadolinium; europium; samarium; yttrium; and then the light lanthanides. For the application in this flowsheet the first effluent cut would contain most of the zinc; the second cut would contain the remainder of the zinc and at least some of the yttrium along with all of the americium, curium, and lanthanides heavier than promethium; and the third cut would contain the remainder of the yttrium plus the lanthanides lighter than samarium.

Final removal of light lanthanides from the resin is accelerated by using a more highly concentrated DTPA solution to strip them. The resin beds are then regenerated, following a water wash, to prepare them for the next cycle. The first (sorption) bed is regenerated with $\mathrm{HNO}_{3}$ and the subsequent (band displacement) beds are regenerated with $\mathrm{Zn}\left(\mathrm{NO}_{3}\right)_{2}$. After another water wash, the resin beds are ready for the next cycle of operation.

For this example, pH adjustment of the DTPA solution is assumed to occur by addition of $\mathrm{NaOH}$, and $3 \mathrm{NaOH}$ per DTPA are assumed required. Sodium hydroxide was chosen for use here instead of the ammonium hydroxide proposed by Wheelwright et al. (1974) in order to minimize the potential for release of ammonia gas, which is an environmental concern.

The first and third effluent cuts and the resin stripping and regeneration cuts will be sufficiently free of radionuclides that they can be combined with other LLW effluents, as discussed in Section 3.4. The second cut could be processed further to separate the americium and heavy lanthanides from the added chemicals (zinc, sodium, and DTPA). However, preliminary analysis indicates that the added chemicals will be present in quantities small enough that they can be accommodated within $\sim 1000$ canisters of HLW glass; thus, such additional processing is not included in the flowsheet. If subsequent analysis indicates that additional processing is needed, it could be accomplished, after adding nitric acid, by a second CMPO extraction and strip cycle.

The ion exchange resin will have to be replaced periodically. It is assumed that the spent resin will be destroyed by oxidation, and that a sulfate-containing residue will result. This residue is routed to the caustic leach step (Figure 3.2), so that its contained radionuclides (if any) will not end up in the LLW.

\subsubsection{Crown Ether Solvent Extraction for Strontium and Technetium Removal and Strontium/Barium Ion Exchange}

The raffinate from the first CMPO cycle, which contains all of the components of the dissolved sludge solution except the actinides, the lanthanides, and possibly the bismuth, is then fed to a crown ether (CE) solvent extraction step in which strontium and technetium are removed. The flowsheet for this step (Figure 3.9) is based on the use of a solvent composition of $0.2 \underline{\mathrm{M}}$ di-t-butylcyclohexano-18crown-6 in 1-octanol, as used by Horwitz, Dietz, and Fisher (1991) in their SREX process study.

In this CE extraction cycle, the strontium and technetium are extracted from the dissolved sludge solution aqueous phase into the $C E$ organic phase; the organic phase is then scrubbed with $\sim 1 \underline{M}$ $\mathrm{HNO}_{3}$ to remove less strongly extracted materials; and the strontium and technetium are then stripped from the organic phase into a dilute acid aqueous phase. Also stripped are barium, which behaves very similarly to strontium in this system, and nitric acid. 


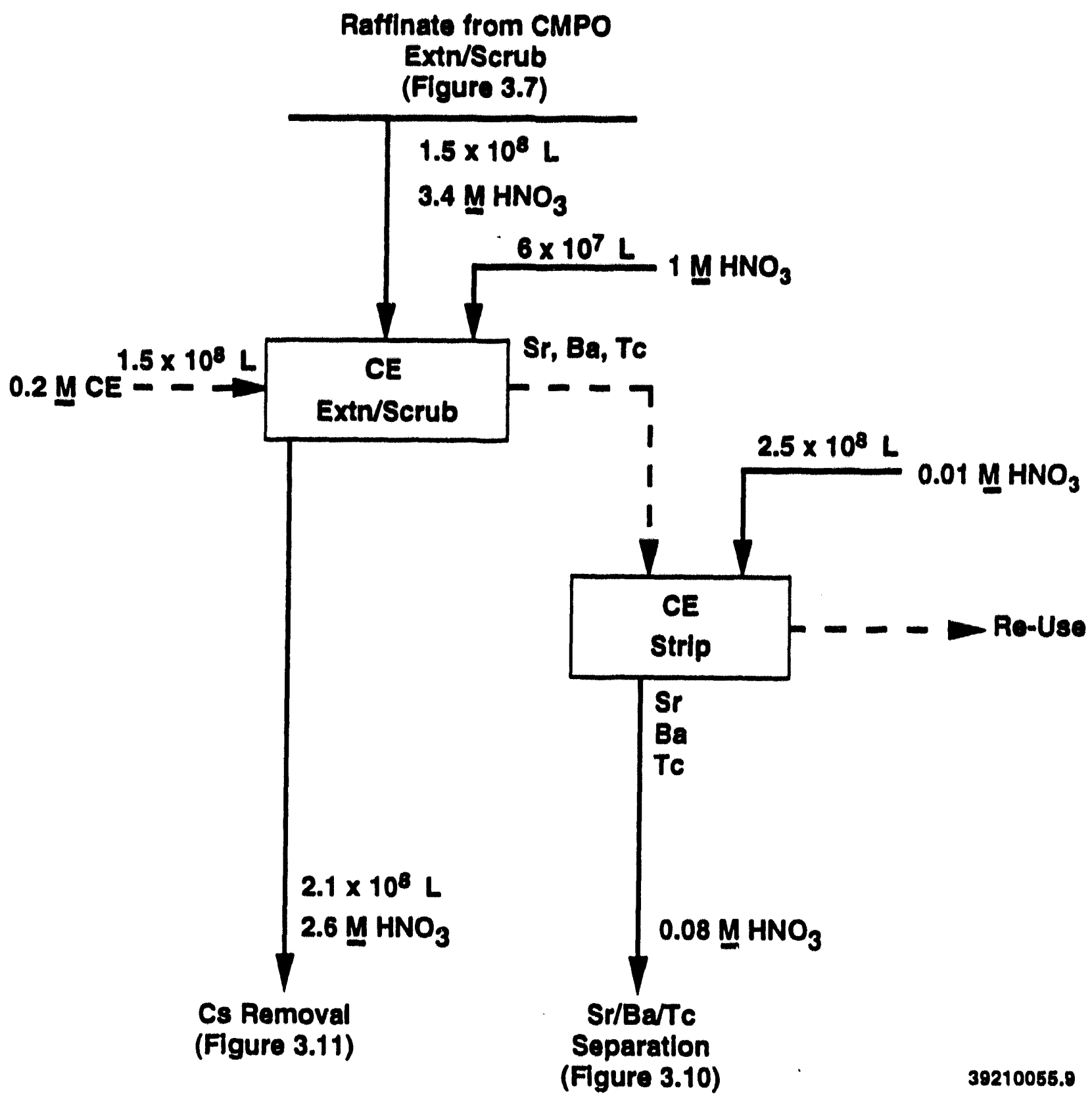

Figure 3.9. Crown Ether Solvent Extraction Cycle for Removal of Technetium and Strontium (and Barium) from CMPO Cycle Raffinate 
The data of Horwitz, Dietz, and Fisher (1991) indicate that only strontium, barium, and technetium have $\mathrm{D}>\mathrm{I}$ between I to $3 \mathrm{M} \mathrm{HNO}_{3}$ in this solvent. The dissolved sludge stream is assumed to be decontaminated from technetium by a factor of $10^{2}$ and from strontium and harium by a factor of $10^{4}$; however, the barium is subsequently separated and added back to the other nonradioactive components. Other likely components of the dissolved sludge solution that are slightly extractable (D -0.1$)$ are sodium, calcium, molybdenum, ruthenium, and palladium; the portions of these metals that do extract should be easily removed in the scrub section of the contactor. Iron and aluminum are essentially inextractable $\left(D<10^{-3}\right)$ in this system.

The data of Table 2.3 indicate that barium must be separated from strontium, if strontium disposal within 1000 canisters of HLW glass is to be achieved. As was discussed in Section 2.2.1. the barium content of SST waste given in Table 2.1 may be too high by a factor of -10 . If this factor were much higher, no strontium/barium separation step would be required. However, such a step is included here (Figure 3.10) for conservatism.

The method chosen to illustrate the strontium/barium separation is a band displacement cation exchange process that is very similar to that described in the preceding section for separation of the americium and heavy lanthanides from the light lanthanides. In this application, the strontium and barium are removed from the strip solution of the CE cycle by sorption onto a cation exchange resin. The effluent from this sorption step will contain the technetium (which is present in an anionic form); this stream is concentrated and the technetium is routed to HLW. The strontium and barium are then eluted by a complexant solution onto a barrier ion-loaded cation exchange resin column; Bray et al. (1964) reported results with the complexants EDTA and HEDTA and with several different barrier ions. The materials used in this example (Figure 3.10) are EDTA complexant and zinc barrier fon. The EDTA is actually partially neutralized to give the required $\mathrm{pH}_{\text {; }}$ it is assumed here that this neutralization is done with sodium hydroxide and that $3 \mathrm{NaOH}$ per EDTA are required. Sodium hydroxide was chosen for use here instead of the ammonium hydroxide used ty Bray et al. $(1964)$ in order to minimize the potential for release of ammonia gas, which is an environmental concern

Continued elution of the strontium and barium through a series of columns results in segregution into discrete bands. For the application in this flowsheet, the first effluent cut would contain most of the zinc: the second cut would contain the remainder of the zinc plus all of the strontium plus some of the barium; and the tinal cut would contain the remainder of the barium.

The first (barrier ion-containing) and the last (barium-containing) cuts from the band displacement cation exchange step will be sufficiently free of radionuclides that they can be combined with other LLW streams for final treatment (Section 3.4). The second cut, which contains portions of the zinc barrier ion and of the $\mathrm{Na}_{3}$ EDTA solution used in developing the bands, in addition (o) the strontium (and a portion of the barium), could be processed further to remove the zinc and the $\mathrm{Na}_{3}$ EDTA. However, preliminary analysis indicates such processing would not be needed to achieve the 1000-canister objective. If it is needed, it could be accomplished, after addition of nitric acid, in a second $\mathrm{CE}$ extraction plus stripping cycle. 


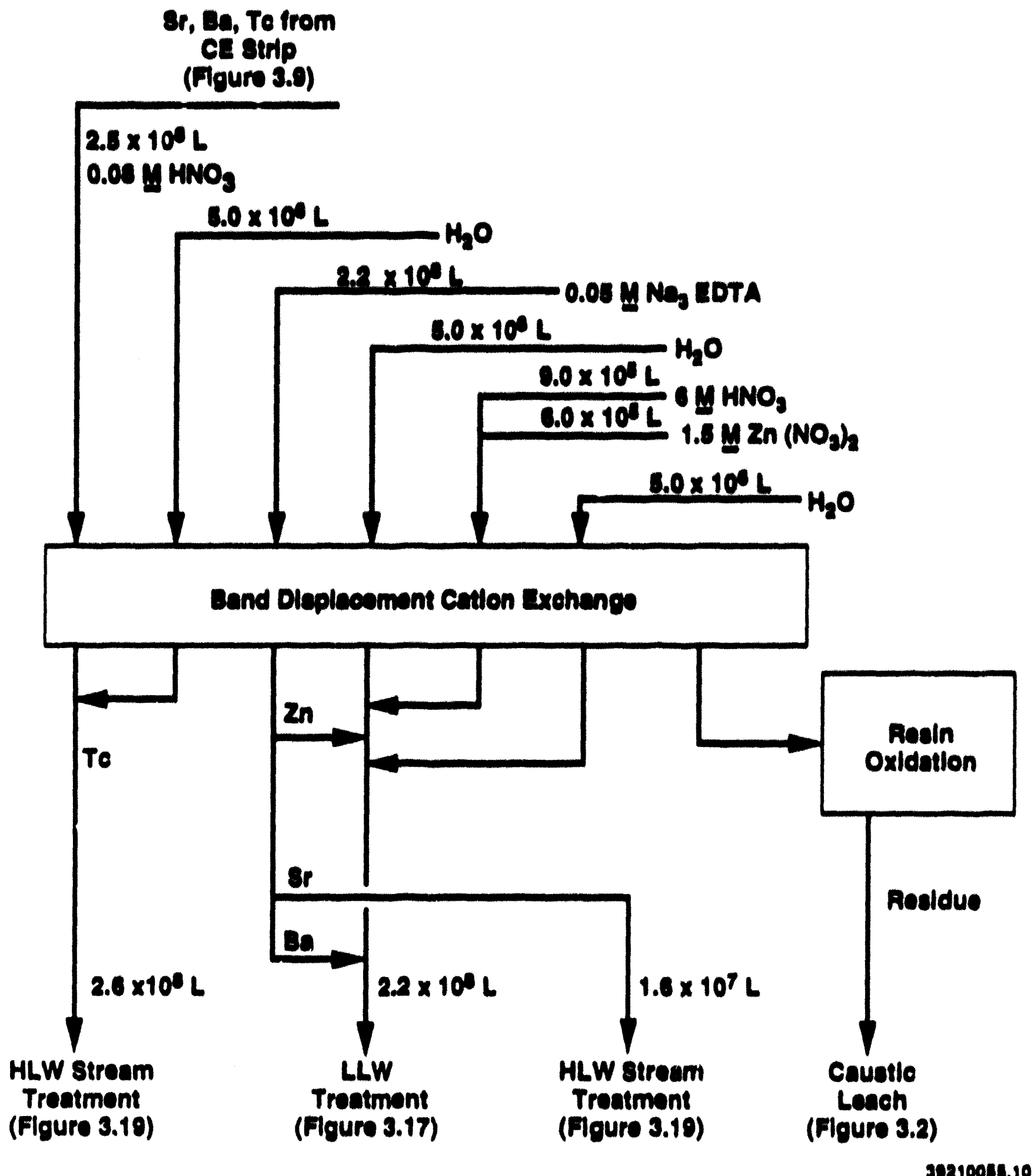

Digure 3.10. Separation of Technetum, Stronelum, and Barium by Cation Exchange 


\subsubsection{Ammonlum Phosphomolybdate (APM) Ion Rxchange for Ceslum Removal}

The find redionuclide removal step currenty included for ireatment of the dissolved sludge solution is for removal of $\mathrm{C}-137$ (removal of $\mathrm{NI}-63$ may be included in the hiture, as was diacussed earlier). No completely satiafactory solven extraction process has yet been developed for cestum removal from strone acid solution, but several potential lon exchange/sorption proceases have been studied with promising results.

The cholce of sorption by APM for the removal of cealum frotin disuolved aludge solution was based primarily on the work of Paubel and All (I9as). These workers inveatigated removal of cesium from acidic solution (som of which contained $7 \times 10^{3} \mathrm{M}$ Fe and $9 \times 10^{4} \mathrm{M} \mathrm{Zn}$ ) by several inoreanic lon exchengers. Anmonium phosphomolybdate, $\left.\left(\mathrm{NH}_{4}\right)_{3} \mathrm{PMO}_{3} \mathrm{O}_{10}\right)_{4}$, gave the beat loading a nitric acid concentration of several molar (as in the case in the CE cycle rafnnate), and was chomen for use here. Faubel and All mesuured 100 s remion of cealum up to a cealum loading of $30 \mathrm{~g} / \mathrm{kg}$ APM in batch experimont:

In his recen review, Kolarik $(1991)$ discuaces the difineulty in eluting cealum from APM, but comments that the sorber an be deatroyed by NaOH. Thus. the example nowhere asumes that the loaded sorben will be imtroduced to the cevalic leach wep of the slude dissolution process (Section 3.1), where if will be disuolved and the componoms will flow to baslesside Ireatment proceasing for removel of the contained calum slone with that presen in the waler soluble portion of the rank contents.

As poined oul by Paubal and All (1986). the use of undiluted APM in a column mode is diffleult because of the microcryitulline structure of the material and because of the porential nead is provide a cooling syatem to proven heatsposs from the rediolytic heal generation. Thus, it is assumed tha the APM will be prepared or mixed with a suilable suburate tha given the required how properites and reduces the averace hou load on the column. For purpowen of this exumple, a cenfold dilution of APM with dumin is asumed

A depiction of this process is thown in Figure 3.11 . A cosium DF of $10^{3}$ in this procesn is asumed here: with 105 of the total cealum in this stream, an overall DF of I0t can sill be main.

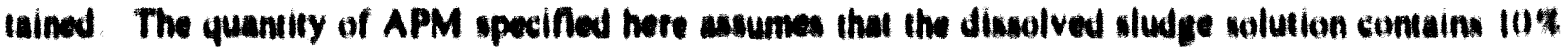
of the lotal cestum prosent in the waste, and thas ine APM is loaded 1050 Cv/kg APM. This weighe of APM equates to -600 mole, so the oullined process will rewull in the codilion of - 60 mole phosphoris and $\mathbf{- 7 2 0 0}$ mole molybdenum to the waile: these quanilies are very small relative to the other components of the waste, and should have no offoct on waste volumes The - 1800 mole of ammonis tha will be released during discoluition of APM in the hes caustic culution may have to be scrubbed from the offeas uroam in ordar to moet ammonia release limits. The resulting scrub solution could be combined with other basic alde wase solution for dispowali those solution probably already contain conalderable anounis of anmonis because mout of the $-11^{7}$ mule of nuoride in the wase (Table 2 .1) was added to the process as ammonium nuoride wolution 


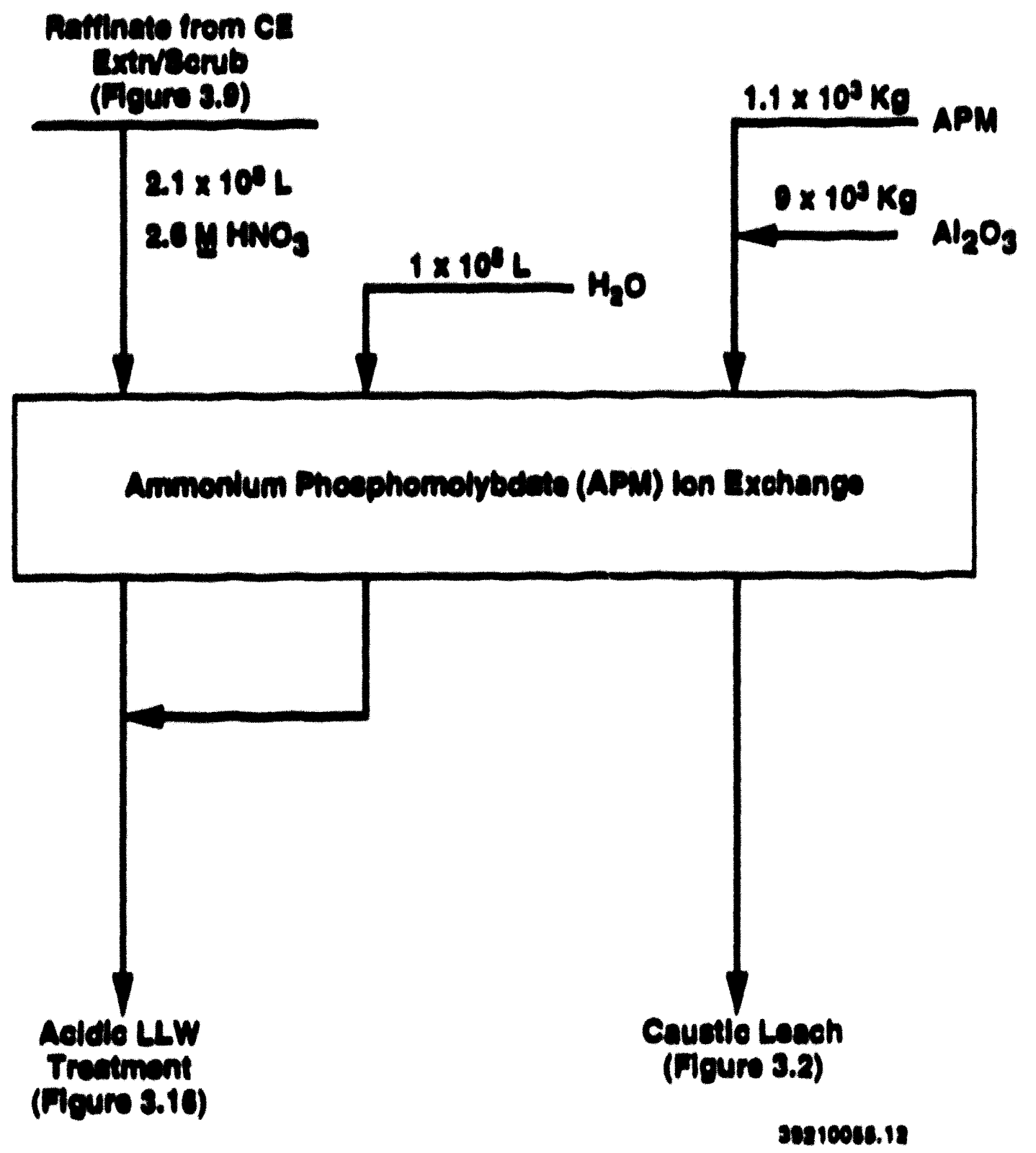

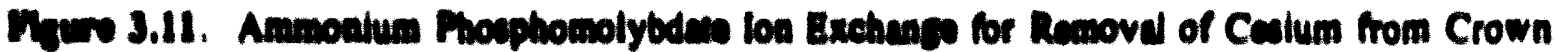
Benor Cyclo Remacto 


\subsection{Basic-side Separations}

As indicated in Figure 3.2, the feed to the basic-side separations processes is composed of solution from the disalved salt cake, from the caustic leach step, and from sludge washing opera. tion. If will contain the bulk of the sodium, aluminum, and silicon present in the waste as well as easentially all of the waste anions. If is expected to contain most of the Cs-137 and Tc-99 present in the waste, plus a significant fraction of the $\mathbf{S r}-90$ and posalbly traces of transuranic elements (eapecially if organic complexants are present in sufficient concentration). This stream is also expected to contain most of the 1.129 present in the wate, especially after addition of the TBP NI solven wah solution (Section 3.2.1), which will contain extractable lodine from the dissolved sludge solution.

The initial processing steps selected for the stream in this example flowaheet are outlined in Figure 3.12. Following addition of a solvent wash solution and an offges scrub solution, an evaporative concentration step is performed to decrease the volume of solution to be processed: evaporation to sodium concentration of $S M$ is susumed.

An optional forric hydroxide scavenging precipitation step is also shown as a posulble initial basic-alde procesaing utep. This is not thought to be necessary (eapecially in light of the relatively low required plutonium DF shown in Table 2.5) unleas the caustc lench utep solubilizes too much plutonium from the sludge, as discused in Section 3.1. If this step is necessary, It might require that - reductant aleo be added to reduce Pu(V), which is the soluble species and not well scavenged by ferric hydroxide, to Pu(IV). The Iron addition could come elther from an added proceas chemical or by recycling a portion of the concentrated LLW stream from acid-side procesaing.

The radionuclide removal steps included in the example flowheet for the basic-side solutions are: 1) ceslum removal uaing a resorcinol-formaldehyde cation exchange reain, 2) strontium removal using chelating cution exchange reain, and 3) technetium removal using an anion exchange resin. These steps are discussed further in the following sections.

\subsubsection{Recoreinol-Formaldahyde Ion Exchange for Cealum Removal}

Removal of cestum from basic-side feed solutions has been performed on a plant scale both at Hanford, uaing a phenolle lon exchange reain. and at the Weat Valloy Demonatration Project, using a zeolite sorbent. In recent years, workers at the Savannah River Site (Bibler and Wallace 1987) and at Pacifle Northweat Laboratory (Bray, Blovich, and Carson 1990) have conducted studies of a resorcl. nol-formuldehyde reain. with oxtremely promising reaults. This reain was chosen for use in the example nowheet developed in this study. Use of zeolite sorbent was not considered to be a strong contender for this applicaiton because of difnculties in elution and reuse, and because the cesium. loaded sorbent could not be vitrified (a is planned at Weat Valley) without greally exceeding the 1000 -caniater objective of the clean option. 


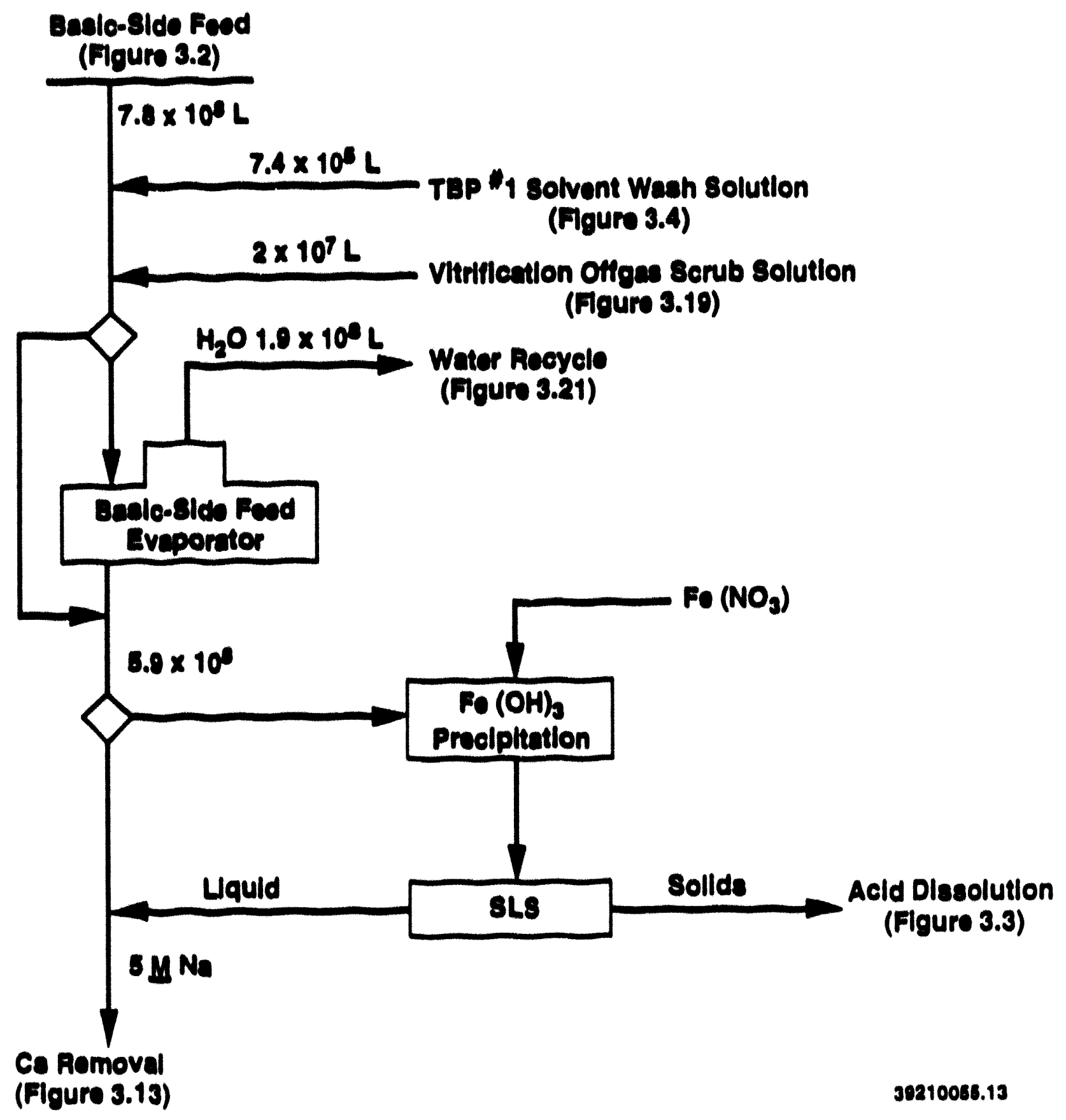

Mrum 3.12. Preparation of Feed for Builc-side Procesaing of Supernate, Dissolved Salt Cake, and Caustic Laech Solutions 
A flowsheet for cesium removal based on the results of Bray, Elovich, and Carson (1990) is shown in Figure 3.13. By running columns in series, these workers achieved DFs $>10^{4}$ with cesium loadings on the resin of up to 0.05 mole $\mathrm{Cs} / \mathrm{L}$. Based on the concentration of cesium expected in the SST waste solution, the flowsheet shown here would give a cesium loading approximately one-third as high. A DF of $10^{4}$ is assumed for this example.

After loading the cesium from -2000 column volumes (CV) of the feed solution, the resin is washed with $2 \mathrm{M} \mathrm{NaOH}(3 \mathrm{CV})$ and water $(6 \mathrm{CV})$ before it is eluted with $20 \mathrm{CV}$ of $1 \mathrm{M} \mathrm{HCOOH}$ (formic acid). The resin is then rinsed with water $(3 \mathrm{CV})$ and washed with $2 \mathrm{M} \mathrm{NaOH}(3 \mathrm{CV})$ to prevent the next batch of feed from contacting water (which might lead to localized precipitation of aluminum hydroxide at the lower $\mathrm{NaOH}$ concentration).

The formic acid solution that contains the eluted cesium is routed to HLW. The contained formic acid is used to denitrate part of the other HLW waste streams, as discussed in Section 3.5.

The Na-10-Cs ratio in the eluted product was found by Bray, Elovich, and Carson (1990) to be $-7 \times 10^{-4}$ as large as that ratio in the feed, with the cesium "product" having a Na-to-Cs mole ratio of -10 . This ratio could be reduced greatly in a second cycle, if desired, but this is not thought to be necessary for the example flowsheet.

An alternative processing approach with this resin is to simply feed the cesium-loaded resin into the vitrification system. Such an approach would markedly increase resin consumption and would also become less feasible as the quantity of glass becomes smaller, because of the amount of carbon added per unit of glass.

\subsubsection{Chelating Ion Exchange for Strontium Removal}

In a recent study of the removal of strontium from basic-side wastes similar to that being considered here. Campbell and Lee (1991) chose sodium titanate as the most promising for these applications, with organic chelating resins chosen as the backup. However, the chelating resin approach was selected for this clean option example flowsheet because of the concern that direct vitrification of strontium-loaded sodium titanate along with the other radionuclide fractions might lead to an excessive number of HLW glass canisters.

In their study of chelating resins, Campbell and Lee (1991) found several to be quite effective in removing strontium from their basic-side feed solution, and to show potential column capacities in the vicinity of 2000 to 3000 bed volumes. Presumably, such capacities can also be achieved with basicside feed solutions from the Hanford SST (and other) wastes; the achievable capacity might depend on the concentrations of calcium and barium, as well as that of strontium, because, as pointed out by Campbell and Lee (1991), removal of strontium might also require removal of these elements.

The flowsheet assumed for this strontium removal process, shown in Figure 3.14, is very similar to that used for cesium removal (Figure 3.13). After loading the strontium from $\sim 2000 \mathrm{CV}$ of the feed solution, the resin is washed with $-2 \mathrm{M} \mathrm{NaOH}$ and water and is then eluted with $-1 \mathrm{M} \mathrm{HNO}_{3}$. The resin is then washed with water and $\sim 2 \mathrm{M} \mathrm{NaOH}$ to prepare it for the next loading cycle. As in 


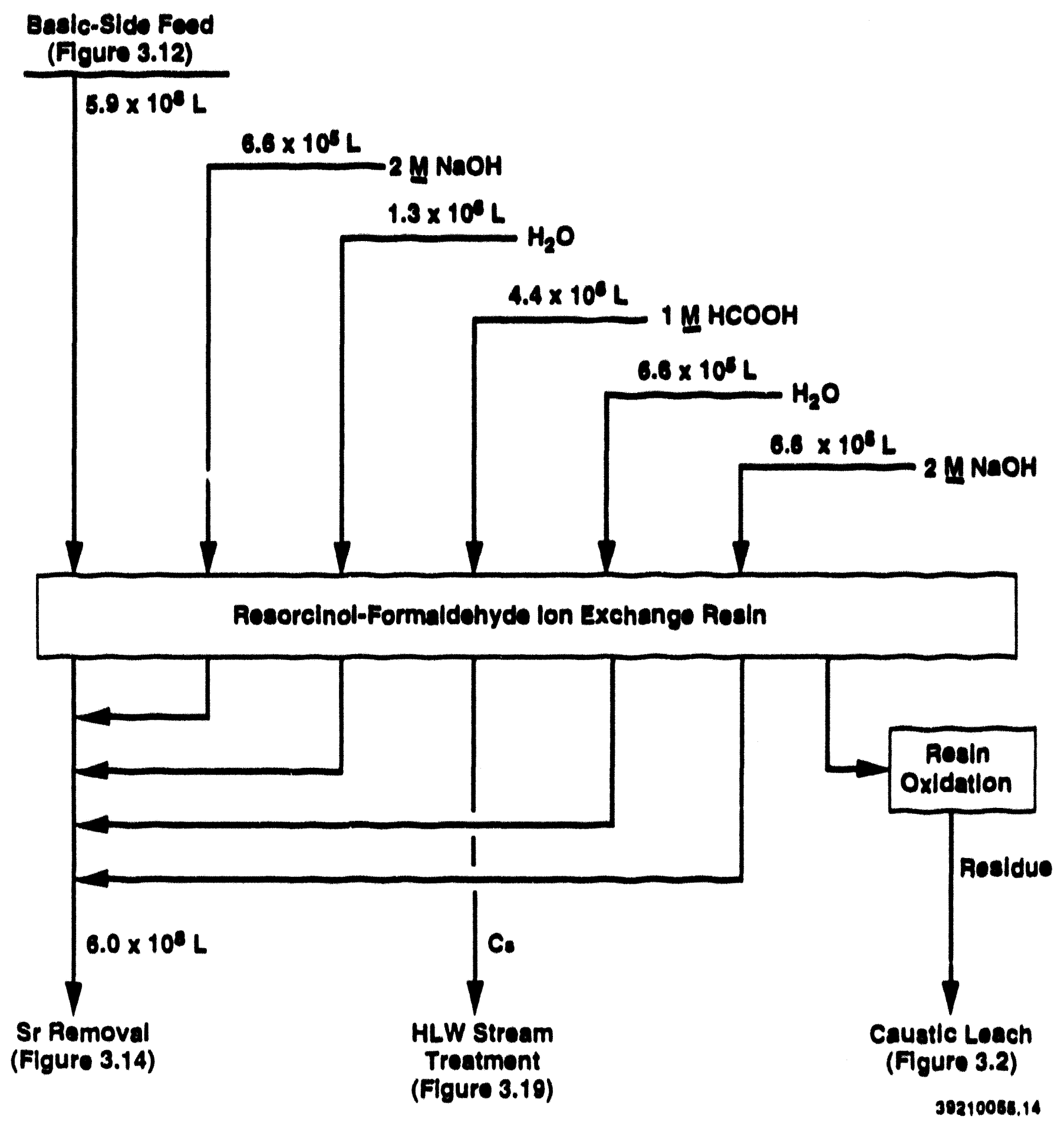

Figure 3.13. Resorcinol-Formaldehyde lon Exchange for Removal of Cesium from Basic-side Feed 
the cesium removal case, the resin wash solutions are combined with the effluent from the loading cycle as feed to the next process step. A strontium DF of $10^{4}$ is assumed in this step.

Because of the contamination of the strontium in this eluted material by calcium and barium, the acidic elution solution is routed (after evaporative concentration) to the acid-side processing sequence wher: separation from these contaminants is achieved. The eluted strontium solution is assumed to be rol:ced to the acid dissolution step (Figure 3.3), where its contained nitric acid can be put to good use in dissolving the sludge.

The choice of the chelating resin approach over the sodium titanate sorption approach for removing strontium from the basic-side feed in this example flowsheet should perhaps be reexamined in future studies. The total amount of titanate required to be added to achieve the required DF will not be known until the fraction of the strontium that is present in this solution has been determined. It may also be possible to avoid vitrification of the added titanium by dissolving the strontium-loaded titanate in acid and separating the strontium from the titanium in the acid-side CE cycle (Section 3.2.3). Also, the concern over the impact on vitrified HLW quantity would disappear if some other disposition of separated strontium (e.g., special storage) were selected.

\subsubsection{Anion Exchange Removal of Technetium}

Anion exchange processes have been used to recover technetium from basic-side Hanford tank wastes both on a laboratory scale (Buckingham et al. 1967; Roberts, Smith, and Wheelwright 1963; Schulz 1980) and on a plant scale (Beard and Caudill 1964; General Electric 1964). Because of this experience, such a process was included in the flowsheet of this study.

In this process, the pertechnetate ion is removed from the basic-side solution by sorption on a strong-base anion exchange resin. After the resin bed is loaded, it is washed first with dilute sodium/ hydroxide to remove residual feed solution and then with dilute nitric acid to ensure conversion of the resin to the nitrate form before the elution step is done. The technetium is eluted with $6 \underline{\mathrm{M}} \mathrm{HNO}_{3}$, and the bed is prepared for the next loading cycle by displacing the acid first with water and then with dilute $\mathrm{NaOH}$.

The technetium product stream is concentrated, and the distilled nitric acid is condensed and reused in the next elution cycle. A small amount of technetium may be volatilized during concentration, but it accompanies the acid to the next elution cycle and thus is not lost from the system.

A flowsheet for this technetium removal step is shown in Figure 3.15. It is based on an early flowsheet (Beard and Caudill 1964) used to recover technetium from Hanford tank wastes, but has been modified here to include a higher elution volume in order to ensure higher removal of technetium from the waste (the early work was aimed at recovering most of the technetium for 


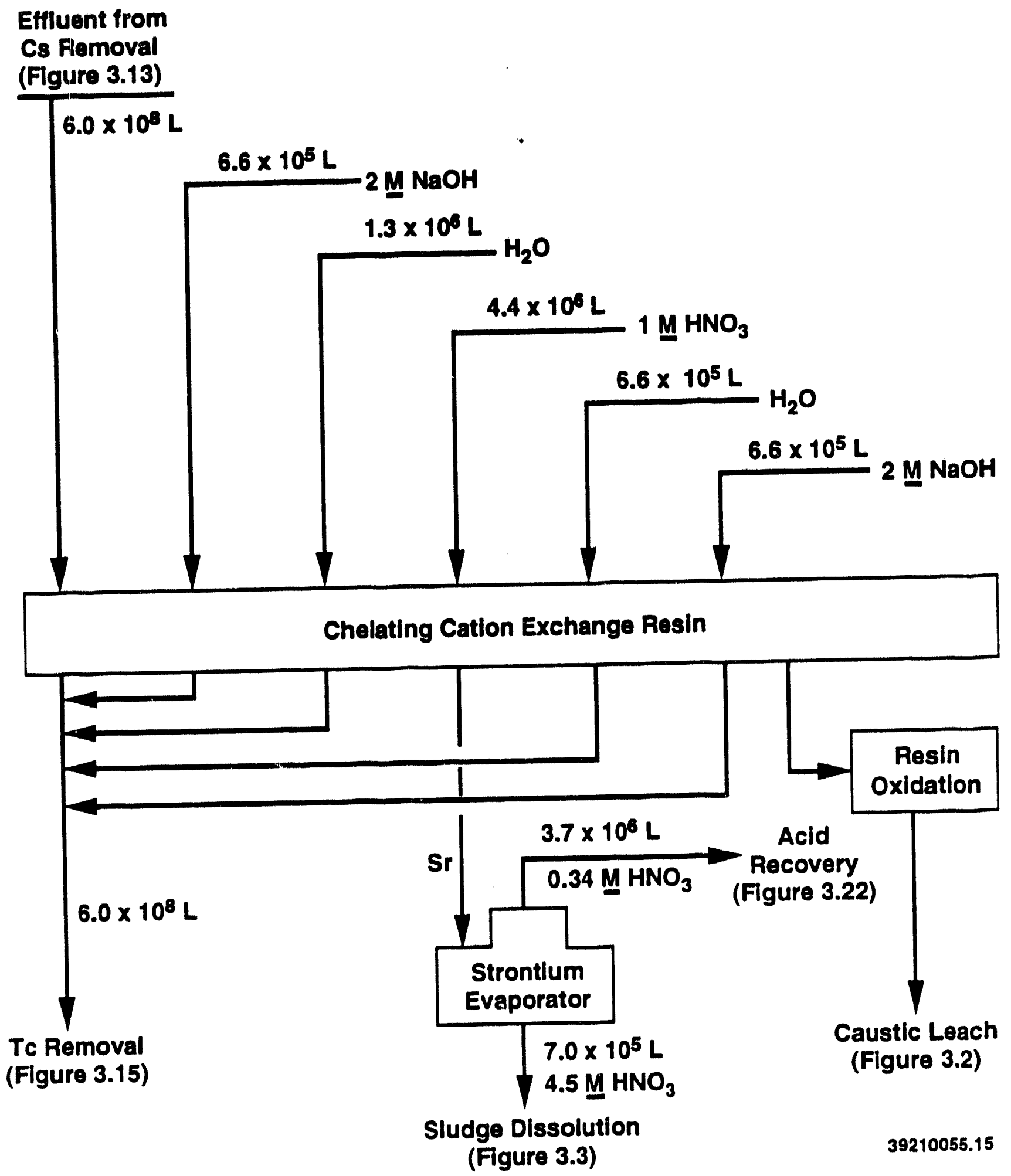

Figure 3.14. Chelating Cation Exchange for Removal of Strontium from Resorcinol-Formaldehyde Process Effluent 


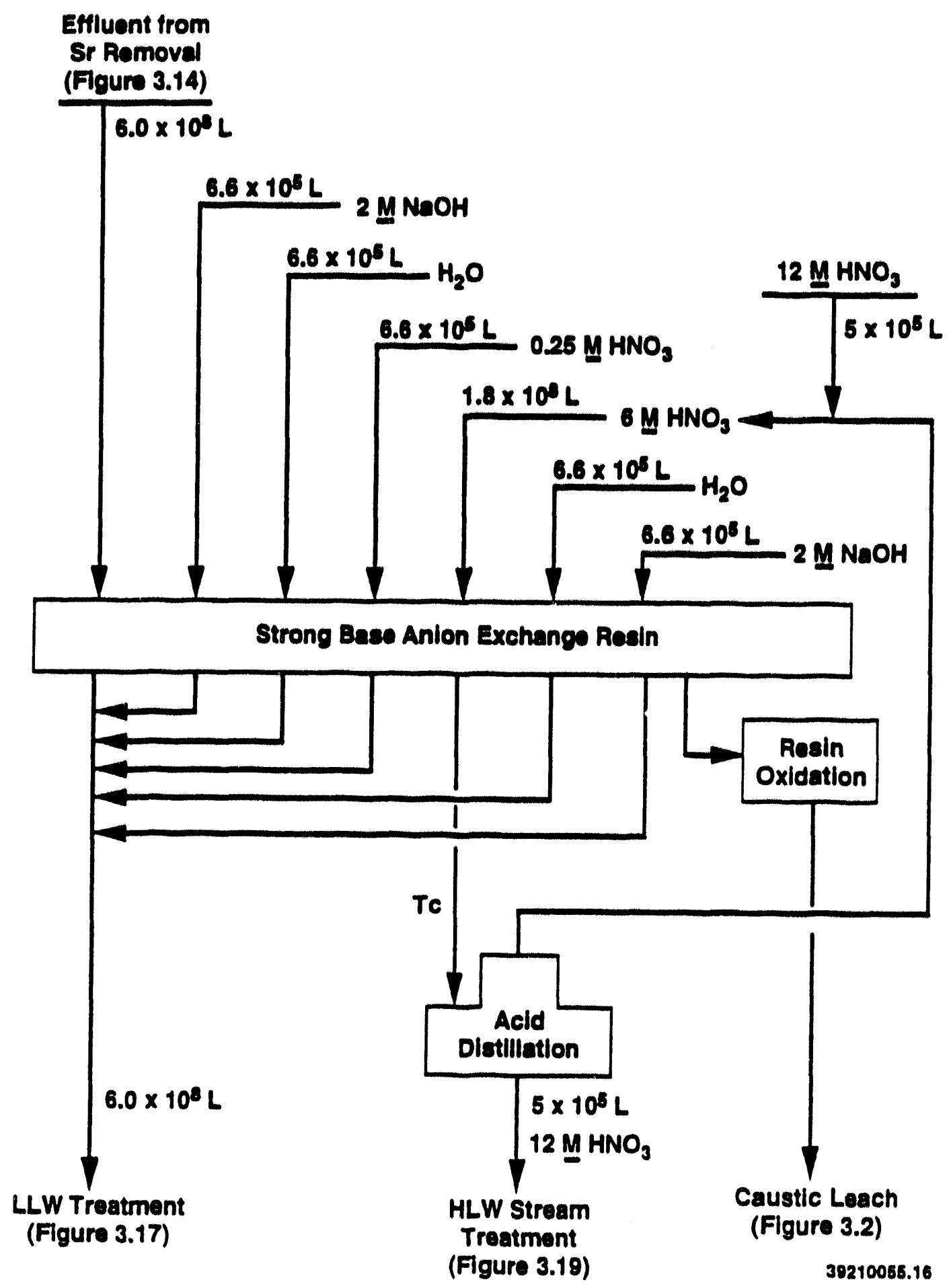

Figure 3.15. Strong-base Anion Exchange for Removal of Technetium from Chelating Cation Exchange Process Effluent 
beneficial use, rather than at attaining high removal from the waste). Based on the results of Schulz (1980), loading and elution volumes of $-50 \mathrm{CV}$ of feed and $\sim 20 \mathrm{CV}$ of $6 \mathrm{M} \mathrm{HNO} \mathrm{HN}_{3}$ eluant are used in this flowsheet, and a technetium DF of $10^{2}$ is assumed in this step.

Because technetium is sorbed more strongly from hydroxide solutions than from alkaline nitrate solutions, a more efficient technetium removal process could result if it were done after, instead of before, the nitrate destruction step, as in the current flowsheet (Figure 3.1). Volatilization of technetium during calcination, the currently indicated nitrate destruction step, could pose a problem to be addressed in that case, however.

\subsection{Treatment of LLW Streams Resulting from Separations}

The LLW streams resulting from the separations steps described in Sections 3.2 and 3.3 are treated further before they are finally disposed of. These treatments are discussed in this section, first for the LLW streams from the acid-side processing steps and then for the basic-side processing LLW stream. The recovery for recycle of $\mathrm{NaOH}$ from the treated LLW will also be described.

\subsubsection{LLW Streams from Acid-side Separations}

A variety of LLW streams occur from the acid-side separations processes described in Section 3.2. The primary stream is the highly acidic, decontaminated, dissolved sludge solution. The ion exchange process to separate americium from the bulk of the lanthanides gives both an acidcontaining waste solution and a near-neutral waste solution. A near-neutral waste solution also results from the ion exchange process used to separate strontium from barium. Basic LLW solutions are also present as a result of the solvent washing operations in the TBP and CMPO solvent extraction processes.

A common feature of several of these LLW streams is that they contain organic complexants (e.g., oxalate, DTPA, EDTA) that were added in the dissolution and the separations steps. Destruction of these complexants could be performed at this point of the process (e.g., by reaction with the nitric acid and/or with added hydrogen peroxide) or, alternatively, the destruction could be performed after these acid-side processing LLW streams are combined with the basic-side processing LLW streams. The latter approach to ultimate destruction of organic complexants was chosen for this example flowsheet, with some preliminary destruction likely occurring during acid recovery.

There are also choices regarding the approach to be followed for disposition of the $\mathrm{HNO}_{3}$ contained in these LLW streams. The $\mathrm{HNO}_{3}$ could be converted to $\mathrm{NaNO}_{3}$ with $\mathrm{NaOH}$, or (most of) it could be recovered for reuse. If it were converted to $\mathrm{NaNO}_{3}$ with new $\mathrm{NaOH}$, an increase in the final volume of treated LLW would result; however, such an increase would not result if recycled $\mathrm{NaOH}$ were used. If most of the $\mathrm{HNO}_{3}$ is recovered for reuse, the quantity of $\mathrm{NaOH}$ required for conversion to $\mathrm{NaNO}_{3}$ is minimized. The approach selected for the example flowsheet includes $\mathrm{HNO}_{3}$ recovery (from selected streams); this approach is shown in Figure 3.16. 


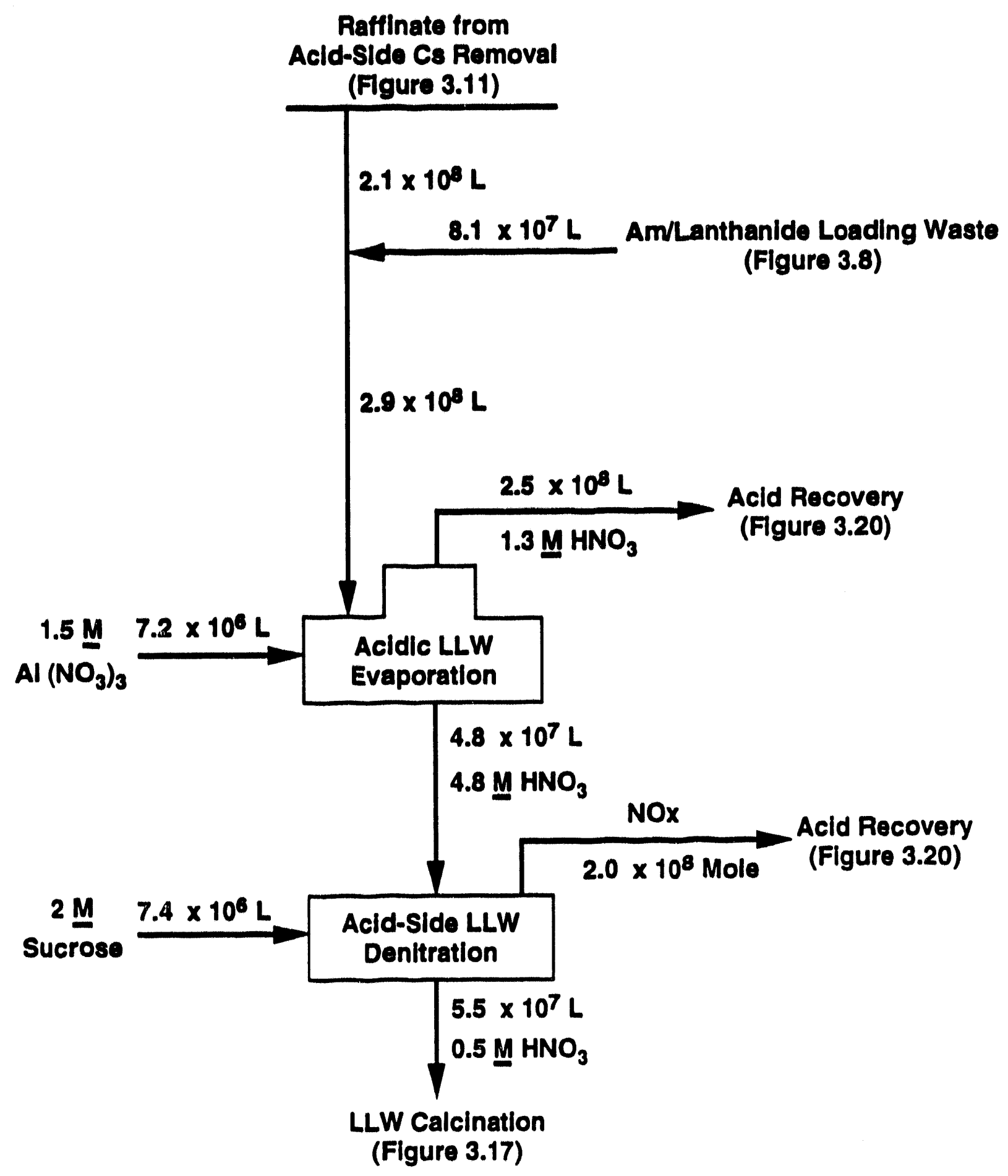

Figure 3.16. Initial Treatment of Acidic Low-Level Waste Streams 
Figure 3.16 identifies the two acid-side separations $\mathrm{LLW}$ streams from which $\mathrm{HNO}_{3}$ is to be recovered. The first step in the recovery process is an evaporative step to reduce the volume of solution to be treated; some of the $\mathrm{HNO}_{3}$ is recovered by distillation in this process. Aluminum nitrate is assumed to be added to the evaporator in order to minimize corrosion from the fluoride complexant that was used in sludge dissolution (Figure 3.3). The organic complexants that are present are expected to be partially destroyed during this evaporation step.

The bulk of the $\mathrm{HNO}_{3}$ recovery occurs from recovery of the $\mathrm{NO}$ and $\mathrm{NO}_{2}\left(\mathrm{NO}_{\mathrm{x}}\right)$ that are evolved when the concentrated waste solution is denitrated by reaction with sucrose. The $\mathrm{NO}_{\mathrm{x}}$ streams from this denitration operation will be combined with others, and treated to convert $\mathrm{NO}_{\mathrm{x}}$ back to $\mathrm{HNO}_{3}$ (Section 3.6).

\subsubsection{LLW Stream from Basic-side Separations}

The only LLW stream resulting from the basic-side separations processes described in Section 3.3 is the raffinate from the strong-base anion exchange process used for technetium removal (Figure 3.15). This is the case because the solutions used to wash and regenerate the ion exchange resins are of such small volume that they could be added to the mainline dissolved salt cake solution without markedly increasing its volume.

This LLW stream contains large quantities of nitrate and nitrite, and perhaps some organic complexants, from the SST inventory. In the example flowsheet, it is planned that the waste be calcined to destroy these constituents before the LLW is finally disposed of; this is done in order to increase the acceptability of the LLW. The LLW streams from the acid-side separations steps should also be calcined; it appears to be reasonable to calcine all the LLW streams in one combined operation.

Figure 3.17 depicts this approach. Four basic or near-neutral LLW solutions from the acid-side processing operations are added to the basic-side processing LLW stream and are assumed to be concentrated by evaporation (to decrease the quantity of water to be fed to the calciner); the evaporated water is condensed for reuse, as is discussed in Section 3.6. The denitrated, acid-side LLW solution is added to the evaporator bottoms solution, and the resulting (basic) mixture is calcined.

Figure 3.17 shows removal of iodine from the calciner offgas stream. This is based on the assumption that the iodine species fed to the calciner will volatilize, most likely as $\mathrm{I}_{2}$ or as organic iodides. Removal of such volatile species by sorption on silver-impregnated sorbents has been studied extensively, and is assumed for this example flowsheet. However, great uncertainty exists regarding this iodine removal operation. Little is known regarding such important factors as 1) the quantity of iodine that is actually present, 2) the nature of the iodine species present, and 3) the degrees of volatilization of these species during calcination. Because of these uncertainties, a low iodine DF of 10 was assumed for this example. 


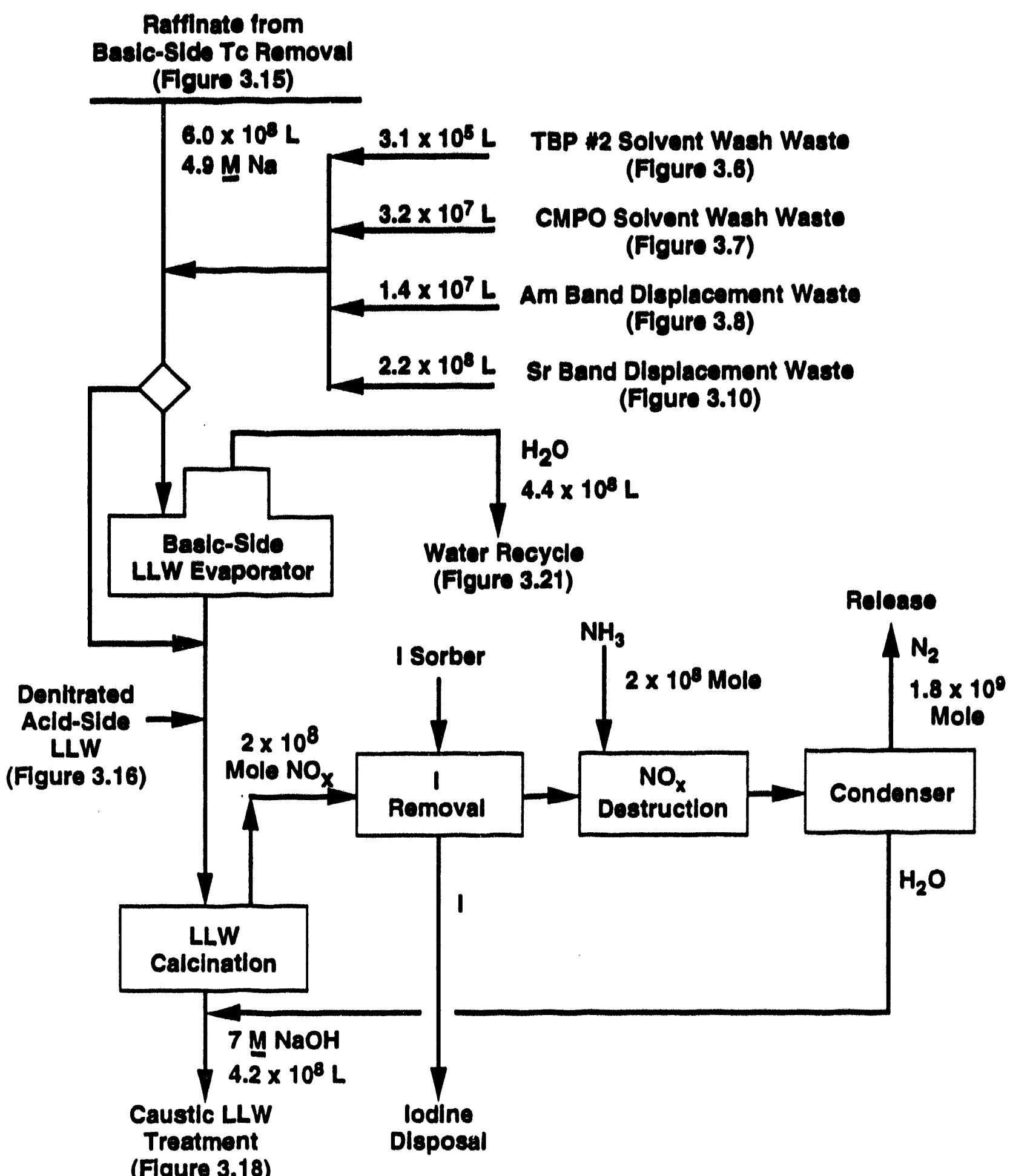

(Figure 3.18)

Figure 3.17. Treatment of Low-Level Waste Streams 
All of the $\mathrm{NO}_{x}$ produced in the calcination process is assumed in this example to be destroyed (converted to $\mathrm{N}_{2}$ and $\mathrm{H}_{2} \mathrm{O}$ ) by a catalyzed reaction with $\mathrm{NH}_{3}$. Alternatively, nitric acid could be recovered from the $\mathrm{NO}_{x}$ stream to decrease the amount of $\mathrm{NO}_{x}$ to be deatroyed. The quantity of $\mathrm{NO}_{1}$ shown in Figure 3.17 is based on the assumption that $10 \%$ of the nitrogen in $\mathrm{NaNO}_{3}$ and $\mathrm{NaNO}_{2}$ is evolved as $\mathrm{NO}_{x}$ (with the remainder being evolved as $\mathrm{N}_{2}$ ).

Finally, water is condensed from the calcination offges. This water is mixed back with the calcined material to give a slurry of insoluble metal hydroxides in a $\mathrm{NaOH}$ solution.

\subsubsection{Sodlum Hydroxide Reuse and Disposal}

The caustic slurry produced in the calcination operation is a source of sodium hydroxide that can be recovered for process uses, thus minimizing the increase in LLW disposal volume that resulis from the separations processing described in the preceding sections. All of the $\mathrm{NaOH}$ will ultimately be disposed of in the (grout) LLW form but, during processing operations, a portion of the NaOH solution can be reused.

Figure 3.18 outlines the steps anticipated for these reuse and disposal operations. The first step involves reduction of soluble $\mathrm{Cr}$ (VI) to insoluble $\mathrm{Cr}$ (III); hydroxylamine is used as the reducing agent in this example. This reduction is done to decrease the leachability and mobility of chromium from the grout, and to avoid recycle of chromium with the recycled $\mathrm{NaOH}$.

Following the reduction step, a portion of the slurry is clarified to produce the $\mathrm{NaOH}$ stream to be recycled. The removed solids are combined with the remainder of the slurry, and cement and fly ash are added to form the grout LLW form (that contains S $M$ Na). The grout technology development effort has not yet examined these particular conditions, but satisfactory grouts containing $5 \mathrm{M} \mathrm{Na}$ and several-molar hydroxide have been prepared. If necessary for preparation of a sultable waste form, a portion of the $\mathrm{NaOH}$ could presumably be converted to $\mathrm{N}_{2} \mathrm{SO}_{4}$ (or other salt) before grouting without affecting the $5 \mathrm{M} \mathrm{Na}$ in grout assumption of this flowsheet.

The recycled $\mathrm{NaOH}$ stream is expected to contain other soluble salts. This should not present significant problems because - 5 times as much $\mathrm{NaOH}$ goes to grout as is recycled, which should prevent appreciable build-up of any contaminant in the recycled $\mathrm{NaOH}$.

\subsection{Treatment of HLW Streams}

The process steps discussed in Sections 3.2 and 3.3 result in the generation of six acidic streams containing (partially) separated radionuclides that are to be disposed of in HLW glass. One of these streams is a formic acid stream containing the cesium. The other five contain nitric acid; these are 1) the plutonium, neptunium, and thorium stream from the TBP cycle; 2) the americium and heavy lanthanide stream from the CMPO cycle plus americium/lanthanide ion exchange; 3 ) the technetium stream from the CE cycle plus strontium/barium ion exchange; 4) the strontium stream from the $C E$ cycle plus strontium/barium ion exchange; and 5 ) the technetium stream from the anion exchange cycle. 


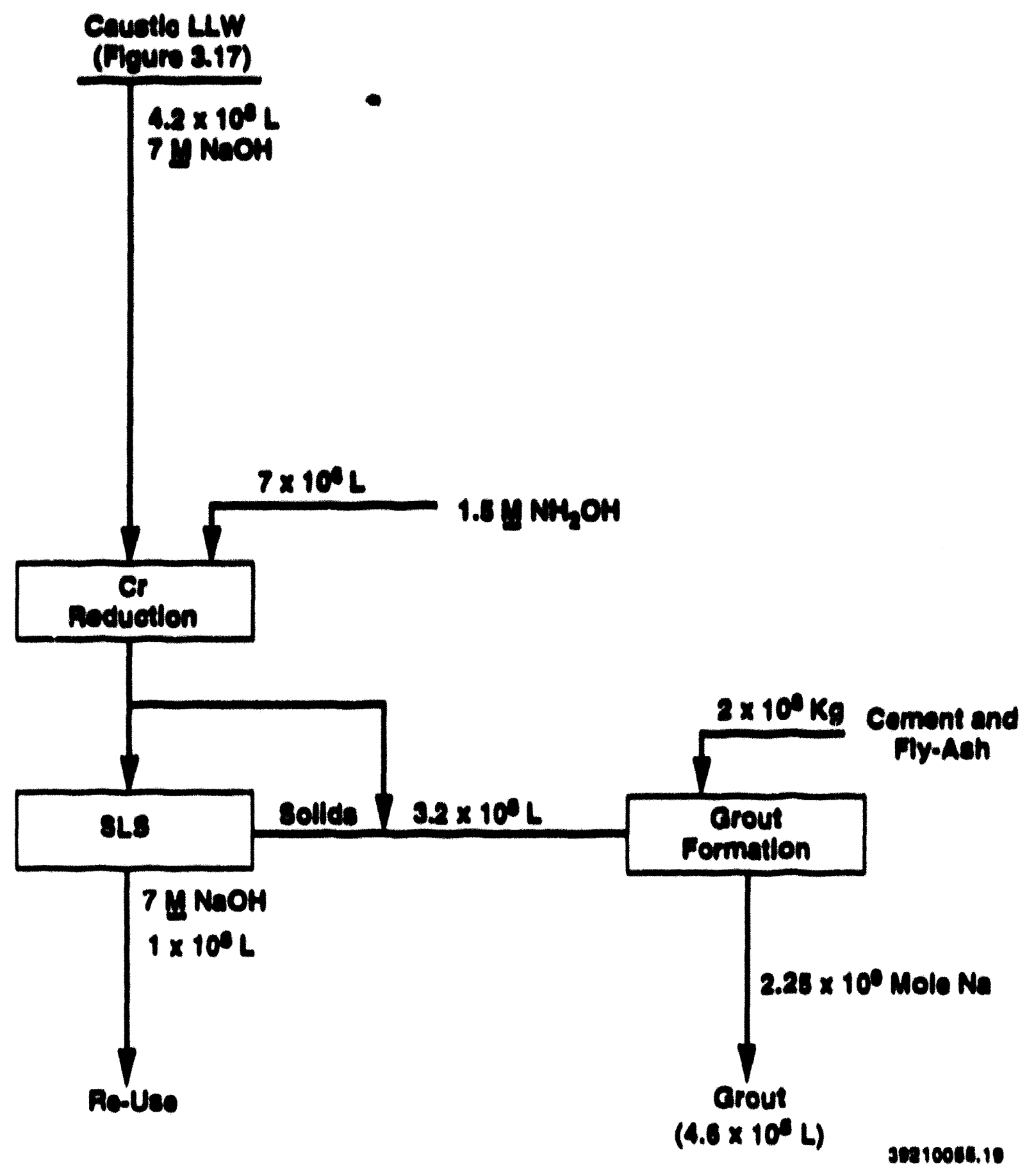

Dasure 3.18. Causele Treament and Orout Formation 
Theas streams could preaumably be sent to the HL.W glas melief without further treatment, hut that is not likely to be deairable because of theif diluteness. Thus, the example flowsheet includes provisions to concentrate and panially denitrate these streams and to recover the $\mathrm{HNO}_{3}$ and $\mathrm{NO}_{\text {, }}$ resulting from these operailon. The flowshea shown in Figure 3.19 cutlines these sleps, and also includes for completeneas the muterials given off durine operation of the melter liself

The $\mathrm{HNO}_{3}$-contuining uream are fint concentrated by eveporation; this concentration step is not carried to i very amall volume in ordar to avold the posability of prectpltation of strontium nitrate in the eveporator. The quanily of organic complexing agents (DTPA and BDTA) present in the americium. umartum. and strontium product solution might need to be reduced to meat the 1000-caniater objective. If wufinciom complexum deatniction doea not occur in the simple condilion outlined in Figure 3.19, then hydrogen peroxide (plus catalyat) could be added to the evaporator to increase the exient of deatruction. The evaporator bottom are then denitrated by reaction with sugar. a well as with the formie acid in the ceslum solution.

The concentrated and deniliraced solution, which coniain only -35 of the $\mathrm{H}_{2} \mathrm{O}$ and -10 of of the $\mathrm{HNO}_{3}$ thet was presen in the food stream, then enters the oluse molier. The scidle melter offens is scrubbed with $\mathrm{NaOH}$ solution to remove the containd $\mathrm{H}_{2} \mathrm{O}$ and $\mathrm{HNO}_{3}$ (and a portion of the $\mathrm{NO}_{\text {, }}$ ovolved from the meral nitrates); the serubber will also remove the portions of the cestum and iechnetium the volatilize from the moliet. This serubber solution is indicated to be routed to the bule-side proceasing foed (Figure 3, 12) to proven lows of the cesium and lechnetium, although it could perthep be handied otherwise in the vitrincation fecllity ituelf.

\subsection{Recycling of Nitric Acld and Water}

In this exemple nowahes, where the wates contain large quantities of sodium and where recycled NoOH is used to meutralize excess acids, recycling of $\mathrm{HNO}_{3}$ is not needed in order to minimize the increase in LLW disposal volume resuliting from procesaing the waste. However. recyeling of HNO, is included in the nowsheat 10 minimize the release of nitrate destruction products to the atmosphere, to decrease the load on the calcination and $\mathrm{NO}_{1}$ destruction operations, and to incresse the validity of this howaheet for wastes having lower ratios of sodium salis to insoluble hydroxide sludges. Similarly, recycling of $\mathrm{H}_{2} \mathrm{O}$ is included 10 minimize the quantity of th that must be disposed of in LLW, of dischared to the amouphere.

Higure 3.20 shows a now diagram for the recovery of $\mathrm{HNO}$ from the overheads streamu of acidic evaporators and from the guseous NO, ureams reauling fron denitration of Iwo liquid streams and from calcination of the purined uranium product. These stream are contacted in a witable absorber to convern the $\mathrm{NO}_{1}$ to $\mathrm{HNO}_{3}$; oxygen $\left(\mathrm{O}_{2}\right)$ and hydrogen peroxide $\left(\mathrm{H}_{2} \mathrm{O}_{2}\right)$ are added 10 aid in this conversion. The guseous efnuent from inis absorber is discharged to the aimosphere: presumably the abuorber effleiency will be high enough that the emuent will meet NO, discharge limits, otherwise a residual $\mathrm{NO}_{1}$ deatruction step would be required. The liquid $\mathrm{HNO}_{3}$ stream from the $\mathrm{NO}_{1}$ absentber feads a fractional diatillation column where the $\mathrm{HNO}_{3}$ is fractionated into a concentrated $(12 \mathrm{M})$ bottoms solutions and allute $(-0.005 \mathrm{M})$ overheads stream, both of which are recycled in the process. 


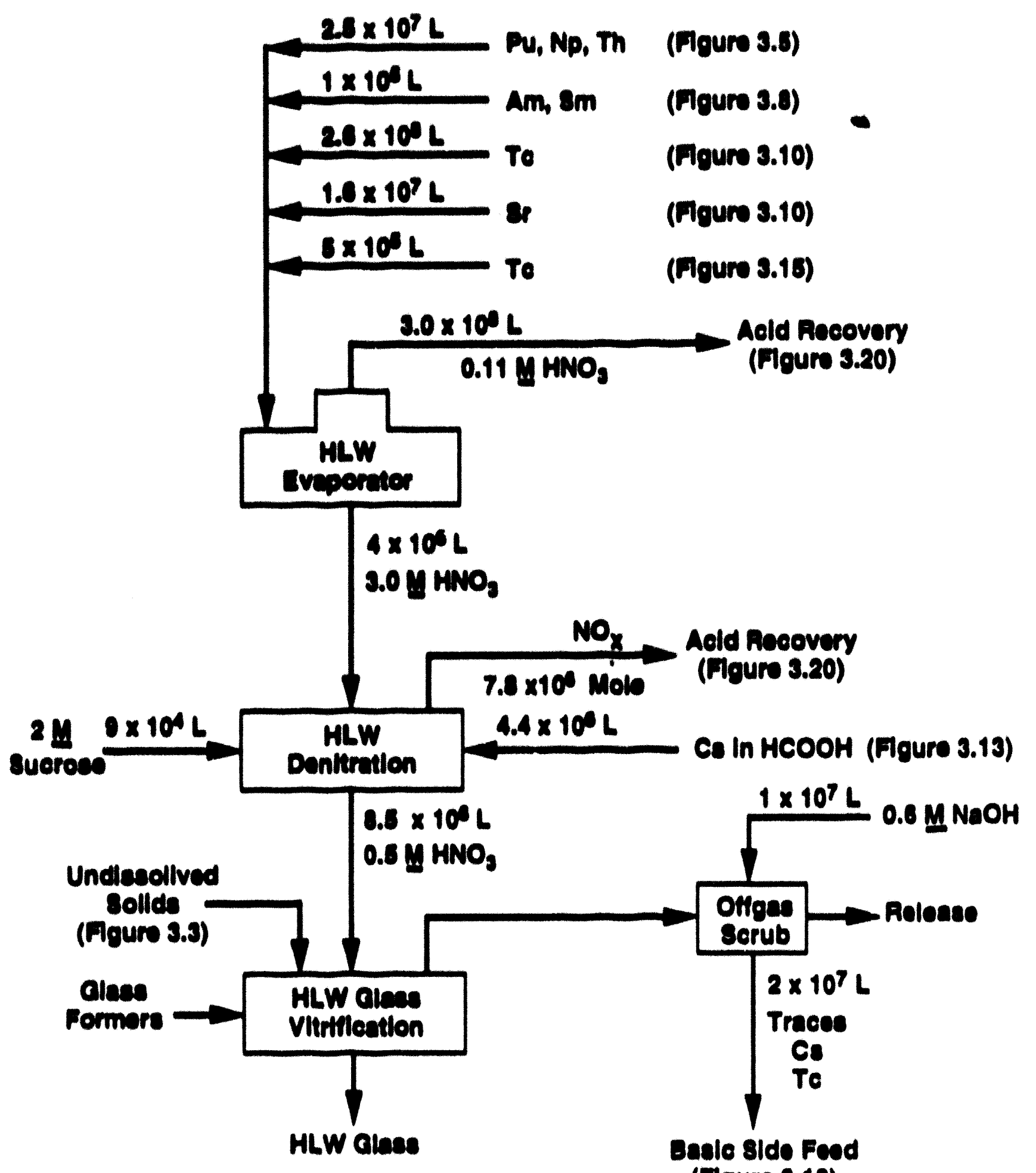

(Floure 3.12) 30210085.20

Mgure 3.19. Treatment of High-Lovel Wate Streams 


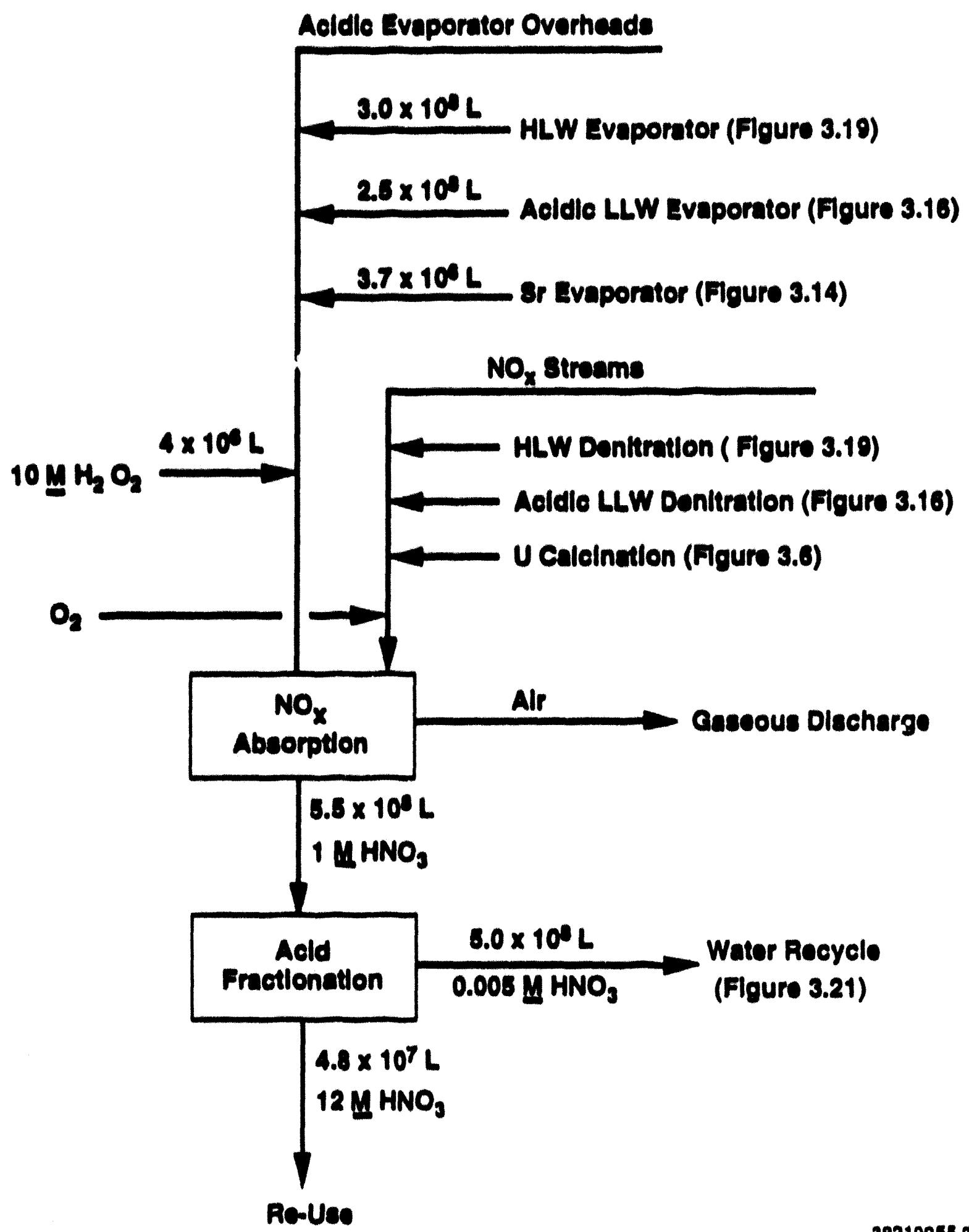

Figure 3.20. Nitric Acld Recovery 
The quantity of $\mathrm{HNO}_{3}$ recovered from the acid fractionator as $12 \mathrm{MHNO}\left(5.8 \times 10^{4}\right.$ mole $)$ is only $-80 \%$ of the $\mathrm{HNO}_{3}$ inputs to the steps discussed in Sections 3.1 through 3.3. Thus, a net system addition of $-1.5 \times 10^{8}$ mole $\mathrm{HNO}_{3}$ will be required to process the SST waste according to the example flowsheet presented here. This added $\mathrm{HNO}_{3}$ is effectively converted to $\mathrm{NaNO}_{3}$ by part of the $\mathrm{NaOH}$ present in the SST waste, giving a small increase in the total nitrate content of the waste to be calcined.

A detailed water balance has not been performed for the example flowsheet. However, because the SST wastes currently contain $-4 \times 10^{7} \mathrm{~L} \mathrm{H}_{2} \mathrm{O}$, and the grout LLW form resulting from processing these wastes by the example flowsheet contains $3.1 \times 10^{8} \mathrm{~L} \mathrm{H}_{2} \mathrm{O}$, an overall net input of $-2.7 \times 10^{8} \mathrm{~L}_{2} \mathrm{H}_{2} \mathrm{O}$ is required to process the SST wastes. Water recycle can be employed to mini. mize water additions in excess of the required amount. In this regard, the volume of water used in the steps outlined in Figure 32 (waste retrieval and dissolution, caustic leach, and solids washing) is noted to be the same as the volume of water present in basic evaporator overheads (Figures 3.12 and 3.17). It is also noted that the total volume of water required in the dissolution (Figure 3.3) and strontium stripping (Figure 3.9) operations is the same as the total volume present in the slightly acidic evaporator and fractionator overheads (Figures 3.6 and 3.20). Thus, reasonable recycling routes do exist for the recovered condensates.

It is possible that some excess water will require disposal during processing, because of variabilities in water inputs and disposal over time. It is assumed for this example that any excess water will be disposed of by evaporation to the atmosphere rather than by incorporation in grout. 


\subsection{Results of Flowsheet Implementation}

Results of implementing the example flowsheet can now be estimated in three important areas: 1) the quantity of HLW, 2) the quantity of LLW, and 3) the radionuclide content of the LLW. These estimates are discussed here.

\subsection{Quantity of HLW Glass}

The minimum quantity of glass required to contain each radionuclide separated from the SST waste can be calculated from the data presented in Section 2.3.1: results of such calculations are summarized in Table 4.1 (along with those for the DST plus SST wastes). The cotal of these separate considerations for both wastes is -1100 canisters; it is highly likely that fewer canisters will suffice because of component compatibilities. For example, strontium and technetium would not behave similarly in glass, so their individual quantity requirements should not be additive. Thus, it is highly likely that the total number of HLW glass canisters required for the separated radionuclides will be below the 1000-canister goal of the clean option, which is a 12-fold reduction in the number indicated in the current reference case.

However, as has been discussed in earlier sections, the number of HLW glass canisters resulting from implementation of the clean option could well be defined by the completeness of dissolution of the sludge components rather than by the number of canisters required to accommodate the radionuclides. Unless the undissolved material (or a blend of the undissolved material with other process waste streams) meets Class A LLW criteria, it must be disposed of in the HLW. In order to achieve the 1000-canister objective, the undissolved material must contain $<\sim 2 \%$ of the aluminum. $<-1 \%$ of the chromium, and $<-0.1 \%$ of the sodium present in SST wastes (Table 2.3). Much experimental testing must be done with various Hanford waste sludges before the probability of achieving the 1000-canister objective can be assessed. Resulti of the preliminary resting conducted 10 date are quite encouraging, as was discussed in Section 3.1.

While the hases of this study include the current HWVP bases for feed and glass composition, it should be pointed out that decreased HLW glass volumes could result from changes in the liquid-fed ceramic melter design (as well as from the changes in process chemistry that are the thrust of this report). A melter designed to operate at a higher temperature could produce glass with a higher waste loading, and incorporation of a bottom drain for discharge of accumulated insolubles from the melter could lead to marked reductions in the canister requirement.

\subsection{LLW Grout Quantity Considerations}

This section first presents estimates of the volume of LLW grout produced by processing with the example flowsheet both a) SST wastes alone and b) combined DST and SST wastes, and compares the volume for the combined waste case with that of a recent reference case estimate. The effect (actually, the lack of an effect) of process chemical additions on the LLW volume is then discussed. 
Table 4.1. Number of HLW Canisters Required for Radionuclides Separated from Wastes

\begin{tabular}{ccc} 
Waste Component & \multicolumn{2}{c}{ Number of HLW Glass Canisters Required } \\
SST Wastes Only & DST + SST Wastes \\
Cesium & $<1 \times 10^{1(\mathrm{~b})}$ & $<1 \times 10^{1(\mathrm{~b})}$ \\
Heavy Lanthanides & $<5 \times 10^{1}$ & $<5 \times 10^{1}$ \\
Strontium & $5 \times 10^{2}$ & $5 \times 10^{2}$ \\
Technetium & $1 \times 10^{2}$ & $5 \times 10^{2}$ \\
Thorium & $1 \times 10^{2}$ & $1 \times 10^{2}$ \\
Transuranics & $<5 \times 10^{1}$ & $<5 \times 10^{1}$
\end{tabular}

(a) Considering each component separately; based on $1650 \mathrm{~kg}$ glass/ anister, the quantities present in the wastes, and the allowed concentrations in glass (Table 2.5).

(b) Heat loading considerations would require a higher number of canisters.

\subsubsection{LLW Volume Comparison}

The volume of LLW grout resulting from processing the SST wastes is $4.6 \times 10^{8} \mathrm{~L}(4.6 \mathrm{x}$ $10^{5} \mathrm{~m}^{3}$ ), as shown in Figure 3.18. This volume is defined almost exclusively by the chemicals that are present in the existing waste rather than by the chemicals used in processing the wastes, as will be discussed in Section 4.2.2. This volume is based on a sodium concentration in the grout of $5 \mathrm{M}$, as was discussed in Section 2.3.2. It should also be mentioned again here that compositional envelopes of suitable grouts have not yet been defined, as was discussed in Section 2.3.2.

The quantity of sodium in the DST wastes is $-36 \%$ of that in the SST wastes. Thus, the volume of grout resulting from processing both DST and SST wastes should be $-36 \%$ higher than the volume resulting from processing only SST wastes, or $-6.3 \times 10^{5} \mathrm{~m}^{3}$. This volume is less than half of that indicated in the cited reference case; it would require 121 grout vaults of the size currently envisioned (each holding $5200 \mathrm{~m}^{3}$ of grout).

This lower LLW volume that results from use of the example clean option flowsheet is not unique to that flowsheet. It can be achieved by any flowsheet that uses the philosophy of recovering and recycling water and key chemicals (especially $\mathrm{NaOH}$ ) added during processing of the waste. 


\subsubsection{Effect of Process Chemical Additions on LLW Volume}

The processes described in Section 3.0 involve the use of many process chemicals (in addition to nitric acid and water) to accomplish the desired results. However, only a portion of the components of those chemicals will end up in the final LLW waste form, because of conversion to volatile compounds (water and gases) before the waste is finally disposed of. Furthermore, the only nonvolatile components whose additions are likely to have any impact at all on the final LLW grout volume are those that increase the quantity of a grout volume-controlling component, which appears to be sodium in mixtures such as the components of Hanford tank wastes.

Numerous process chemicals used in the; example flowsheet will be converted to volatile compounds, and thus will not be present in the LLW. Organic chemicals that fall into this category are organic complexing agents (e.g., oxalate, DTPA, and EDTA) used to achieve sludge dissolution, to prevent extraction of unwanted components, and to facilitate some special separations, and sugar and formic acid used in denitration reactions. Inorganic chemicals that behave in this manner are hydroxylamine $\left(\mathrm{NH}_{2} \mathrm{OH}\right)$ and hydrogen peroxide $\left(\mathrm{H}_{2} \mathrm{O}_{2}\right)$.

Numerous other process chemicals will be converted to materials that will be included in the final LLW waste form. Table 4.2 lists these components, compares the added quantities with those that are already present in the SST wastes (Table 2.1), and compares the mole ratios (relative to the initial sodium content) of the initial SST waste and the LLW after processing. With sodium being the grout volume-controlling component of these wastes, these data indicate that the LLW grout resulting from the processing steps of the example flowsheet would have a volume only $0.4 \%$ greater than if the tank wastes had been grouted without treatment.

Table 4.2. Additions to LLW Caused by Processing SST Wastes

\begin{tabular}{|c|c|c|c|c|c|}
\hline \multirow[b]{2}{*}{ Component } & \multirow{2}{*}{\multicolumn{2}{|c|}{$\begin{array}{l}\text { Added to LLW } \\
\text { During } \\
\text { Processing, } \\
\text { Mole } \\
\end{array}$}} & \multirow[b]{2}{*}{$\begin{array}{l}\text { Added, \% } \\
\text { of Initial }\end{array}$} & \multicolumn{2}{|c|}{ Mole per Mole $\mathrm{Na}$ in SST } \\
\hline & & & & In SST & $\begin{array}{l}\text { In LLW After } \\
\text { Processing }\end{array}$ \\
\hline $\mathrm{Na}$ & $2.25 \times 10^{9}$ & $1.0 \times 10^{7(\mathrm{a})}$ & 0.4 & 1.000 & 1.004 \\
\hline $\mathrm{PO}_{4}$ & $9.20 \times 10^{7}$ & $8 \times 10^{7}$ & $\sim 90$ & 0.041 & 0.076 \\
\hline $\mathrm{Al}$ & $9.05 \times 10^{7}$ & $1.1 \times 10^{7}$ & 12 & 0.040 & 0.045 \\
\hline$F$ & $4.24 \times 10^{7}$ & $4.5 \times 10^{6}$ & 11 & 0.019 & 0.021 \\
\hline $\mathrm{SO}_{4}$ & $1.72 \times 10^{7}$ & $1.4 \times 10^{6}$ & 8 & 0.0076 & 0.0083 \\
\hline $\mathrm{Zn}$ & -- & $1.4 \times 10^{6}$ & - & - & 0.0006 \\
\hline
\end{tabular}

(a) An additional $7.5 \times 10^{8}$ mole $\mathrm{Na}$ is used in processing, but does not add to the LLW because recycle $\mathrm{NaOH}$ is used. 
The only large addition to the LLW, relative to the amount initially present in the SST waste, is phosphate. Phosphorus is added to the waste intentionally (e.g., HEDPA and APM) and as a result of both dissolution and entrainment of phosphorus-containing extractants (e.g., TBP and CMPO) in the aqueous phases leaving the solvent extraction contactors. The dissolution and entrainment addi.tions are much larger than the intentional additions; assuming TBP and CMPO solubilities of $0.1 \mathrm{~g} / \mathrm{L}$ and entrainment amounting to $10^{-3} \mathrm{~L}$ of solvent per liter of aqueous solution, the example flowsheet would result in the addition of $\sim 8 \times 10^{7}$ mole phosphorus to the waste. Assuming that all of this phosphorus is converted to phosphate in waste evaporation and/or calcination steps, the amount added to the waste by the indicated processing would be $\sim 90 \%$ of that already present in the waste (Table 4.2). This is not surprising since most of the waste resulted from processes employing phosphorus-containing extractants. However, even this large increase in the phosphate content of the waste should have no effect on the volume of LLW grout resulting from SST waste processing, because the amount of phosphate will still be small relative to sodium ( 0.076 mole per mole).

The major use of nonvolatile materials for the flowsheet operations is in compounds of sodium (e.g., $\mathrm{NaOH}, \mathrm{Na}_{2} \mathrm{CO}_{3}, \mathrm{NaNO}_{2}, \mathrm{Na}_{3} \mathrm{DTPA}, \mathrm{Na}_{3} \mathrm{EDTA}$ ). Most of this usage involves $\mathrm{NaOH}$ in the caustic leach step, in partial neutralization and adjustment of DTPA and EDTA solutions to the pH values needed for proper separations, and in ion exchange column washes. Because recycle $\mathrm{NaOH}$ is used for these operations, no sodium addition to the waste will result. Sodium used in the $\mathrm{Na}_{2} \mathrm{CO}_{3}$ solutions used for solvent washing and in the $\mathrm{NaNO}_{2}$ solution used for neptunium oxidation will be added to the waste; this quantity is listed in Table 4.2 .

Sulfate is added to the LLW as a residue from the oxidation of some of the spent ion exchange resins used in the processing. The resins commonly used for the band displacement cation exchange separations of americium and of strontium are sulfonated polystyrenes, which will yield sulfate when oxidized. This is not the case with the resins used for the basic-side removals of cesium, barium, and technetium. The added sulfate value listed in Table 4.? assumes that the contribution from the resin used for strontium separation is the same as the contribution from the resin used for americium separation, which was estimated from the resin usage estimate given by Wheelwright et al. (1974) for a process involving recovery of curium from power reactor fuel wastes. Thus, the sulfate value listed here is likely a conservative (high) one.

Fluoride is used in the example flowsheet to assist in sludge dissolution, and aluminum is added later to minimize fluoride-enhanced corrosion during acidic waste evaporation and denitration. Neither addition is large relative to the initial SST contents, and the total quantities are small relative to sodium. Zinc and molybdenum are not listed as constituents of the SST waste, so the percentage increases by use of the flowsheet cannot be given. However, the added zinc and molybdenum are small fractions of other components.

\subsection{Radionuclide Content of LLW Grout}

Table 4.3 summarizes the DFs assumed to result from the separations steps described in Section 3.0, lists the quantities and concentrations of radionuclides present in the LLW, and compares 
Table 4.3. Radionuclides in Clean Option LLW from SST Wastes

\begin{tabular}{|c|c|c|c|c|}
\hline Radionuclide & $\begin{array}{c}\text { Assumed } \\
\text { Treatment DF }\end{array}$ & $\begin{array}{l}\text { Quantity in } \\
\text { LLW, Ci }\end{array}$ & $\begin{array}{l}\text { Concentration in } \\
\text { Average SST } \\
\text { LLW. Ci } / \mathrm{m}^{3} \\
\end{array}$ & $\begin{array}{c}\text { Fraction of } \\
\text { Class A } \\
\text { Limit } \\
\end{array}$ \\
\hline \multicolumn{5}{|l|}{ Class A Listed } \\
\hline$C-14$ & 1 & $1.4 \times 10^{2}$ & $3 \times 10^{-4}$ & $4 \times 10^{-4}$ \\
\hline $\mathrm{Ni}-63$ & 1 & $3 \times 10^{5}$ & $6 \times 10^{-1}$ & $2 \times 10^{-1}$ \\
\hline Sr-90 & $10^{4}$ & $4.5 \times 10^{3}$ & $1 \times 10^{-2}$ & $2 \times 10^{-1}$ \\
\hline Tc-99 & $10^{2}$ & $9 \times 10^{1}$ & $2 \times 10^{-4}$ & $7 \times 10^{-4}$ \\
\hline I-129 & $10^{1}$ & 2.4 & $5 \times 10^{-6}$ & $6 \times 10^{-4}$ \\
\hline Cs- 137 & $10^{4}$ & $9.5 \times 10^{2}$ & $2 \times 10^{-3}$ & $2 \times 10^{-3}$ \\
\hline Np-237 & $10^{2}$ & $3.1 \times 10^{-1}$ & $7 \times 10^{-7}$ & $4 \times 10^{-5}$ \\
\hline Pu-239 & $10^{4}$ & 2.7 & $6 \times 10^{-6}$ & $4 \times 10^{-4}$ \\
\hline Am-241 & $10^{4}$ & 3.6 & $8 \times 10^{-6}$ & $5 \times 10^{-4}$ \\
\hline
\end{tabular}

Qther

Se-79

$1 \times 10^{1}$

$3 \times 10^{-5}$

Zr-93

$4 \times 10^{3}$

$9 \times 10^{-3}$

Pd-107

$3 \times 10^{1}$

$7 \times 10^{-5}$

Sn-126

$4 \times 10^{2}$

$1 \times 10^{-3}$

Sm-151

$4 \times 10^{1}$

$1 \times 10^{-4}$

Th-232

$10^{4}$

$1 \times 10^{-2}$

$3 \times 10^{-8}$

U-238

$10^{2}$
$10^{4}$

$\underline{4 \times 10^{-2}}$

$9 \times 10^{-8}$

$3.1 \times 10^{5}$

$6.2 \times 10^{-1}$

$4 \times 10^{-1}$

the radionuclide concentrations in the average SST LLW with the Class A limits. The radionuclides whose concentrations are closest to the Class $\mathrm{A}$ limits are $\mathrm{Ni}-63$ and $\mathrm{Sr}-90$, each of which is present at $-20 \%$ of the limit, on an overall average basis. As has been discussed earlier, if it is required that each increment of the LLW grout meets the Class A standards, then higher DFs than those indicated for Ni-63 and $\mathrm{Sr}-90$ will be required when the contents of some tanks are processed, because of expected concentration variabilities among the tanks. Alternatively, the time of reaching the Class A limit could be established as being a few hundred years in the future to take advantage of the decay of these radionuclides (the half-lives of Ni-63 and Sr-90 are 100 and 29 years, respectively). 
In the current flowsheet, where nickel removal is not included, Ni-63 contributes nearly all of the $0.31 \mathrm{MCi}$ total radionuclide content of the SST LLW content. This total content is a factor of $\sim 200$ lower than in the untreated SST wastes. Addition of a $99 \%$ efficient nickel removal step would decrease the total radionuclide content to $0.013 \mathrm{MCi}$, which is lower by another factor of $\sim 20$.

If the total DST wastes were also processed by the same flowsheet, an additional $0.025 \mathrm{MCi}$ of total radioactivity ( $\sim 80 \%$ of it from $\mathrm{Ni}-63$ ) would be added to the LLW inventory (and the overall average DST LLW would contain $\sim 35 \%$ of the Sr-90 allowed by the Class A limit). Thus, the LLW from processing the combined SST and DST wastes by the example clean option flowsheet (no Ni-63 removal) would contain $\sim 0.34 \mathrm{MCi}$. This $L L W$ radionuclide content is a factor of $\sim 50$ lower than the $\sim 18 \mathrm{MCi}$ value (with daughter activity subtracted) given in the reference case (Figure 1.1). 


\subsection{References}

10 CFR 61. 1988. U.S. Nuclear Regulatory Commission, "Licensing Requirements for Land Disposal of Radioactive Waste." U.S. Code of Federal Regulations.

Beard, S. J., and H. L. Caudill. 1964. Technetium Recovery and Storage at B-Plant. HW-83348, General Electric Co., Richland, Washington.

Bibler, J. P., and R. M. Wallace. 1987. Preparation and Properties of a Cesium Specific

Resorcinol - Formaldehyde Ion Exchange Resin. DPST-87-647, Savannah River Laboratory, Aiken, South Carolina.

Bibler, N. E., J. E. Hoisington, and E. W. Holtzcheiter. 1981. Technical Data Summary Decomposition of Oxalic Acid by the Manganese Catalyzed Nitric Acid Reaction. DPSTD-80-36, Savannah River Laboratory, Aiken, South Carolina.

Bond, W. D. 1990. "The Thorex Process." In Science and Technology of Tributyl Phosphate. W. W. Schulz, L. L. Burger, and J. D. Navratil, eds., Volume III. CRC Press, Inc., Boca Raton, Florida.

Bray, L. A., R. J. Elovich, and K. J. Carson. 1990. Cesium Recovery Using Savannah River Laboratory Resorcinol-Formaldehyde Ion Exchange Resin. PNL-7273, Pacific Northwest Laboratory, Richland, Washington.

Bray, L. A., L. F. Lust, R. L. Moore, F. P. Roberts, F. M. Smith, H. H. Van Tuyl, and E. J. Wheelwright. 1964. "Recovery and Purification of Multikilocurie Quantities of Fission Product Strontium by Cation Exchange." Chemical Engineering Progress Symposium Series 47, Volume 60, pp. 9-19.

Buck, J. W., et al. 1991. Preliminary Recommendations on the Design of the Characterization Program for the Hanford Site Single-Shell Tanks--A System Analysis. PNL-7573, Vol. 2, Pacific Northwest Laboratory, Richland, Washington.

Buckingham, J. S., et al. 1967. Waste Management Technical Manual. ISO-100 DEL, Isochem, Inc., Richland, Washington.

Campbell, D. O., and D. D. Lee. 1991. Treatment Options and Flowsheets for ORNL Low-Level Liquid Waste Supernate. ORNL/TM-11800, Oak Ridge National Laboratory, Oak Ridge, Tennessee.

Delegard, C. H. 1985. Solubility of $\mathrm{PuO}_{2} \times \mathrm{H}_{2} \mathrm{O}$ in Alkaline Hanford High-Level Waste Solution. RHO-RE-SA-75P, Rockwell Hanford Operations, Richland, Washington.

Droppo, J. G., Jr., et al. 1991. Single-Shell Tank Constituent Rankings for Use in Preparing Waste Characterization Plans. PNL-7572, Pacific Northwest Laboratory, Richland, Washington. 
Faubel, W., and S. A. Ali. 1986. "Separation of Cesium from Acid ILW-PUREX Solutions by Sorption on Inorganic Ion Exchangers." Radiochimica Acta 40:49-56.

General Electric. 1964. Quarterly Progress Report - A Study of Tungsten-Technetium Alloys, April 1, 1964 - July 1, 1964. HW-83550, General Electric Co., Richland, Washington.

Grygiel, M. L., et al. 1991. Tank Waste Disposal Program Redefinition. WHC-EP-0475, Rev. 0, Westinghouse Hanford Company, Richland, Washington.

Horwitz, E. P. 1993. "Combining Extractant Systems for the Simultaneous Extraction of Transuranic Elements and Selected Fission Products." In Proceedings of the First Hanford Separation Science Workshop, July 23-25, 1991, Richland, Washington. PNL-SA-21775, Pacific Northwest Laboratory, Richland, Washington.

Horwitz, E. P., M. L. Dietz, and D. E. Fisher. 1991. "SREX. A New Process for the Extraction and Recovery of Strontium from Acidic Nuclear Waste Streams." Solvent Extraction and Ion Exchange 9:1-25.

Horwitz, E. P., H. Diamond, R. C. Gatrone, K. L. Nash, and P. G. Rickert. 1990. "TUCS: A New Class of Aqueous Complexing Agents for Use in Solvent Extraction Processes." Presented at the International Solvent Extraction Conference, ISEC-90, July 20, 1990, Kyoto, Japan.

Horwitz, E. P., D. G. Kalina, H. Diamond, G. F. Vandegrift, and W. W. Schulz. 1985. "The TRUEX Process - A Process for the Extraction of the Transuranic Elements from Nitric Acid Wastes Utilizing Modified PUREX Solvent." Solvent Extraction and Ion Exchange 3:75-109.

Jantzen, C. M. 1990. "Formation of Zeolite During Caustic Dissolution of Fiberglass: Implications for Studies of the Kaolinite-to-Mullite Transformation." J. Am. Ceram. Soc. 73(12): 3708-3711.

Koch, G. 1969. Recovery of By-Product Actinides from Power Reactor Fuels. KFK-976, Gesellschaft fur Kernforschung, Karlsruhe, Germany.

Kolarik, Z. 1991. Separation of Actinides and Long-Lived Fission Products from High-Level Radioactive Waste (A Review). KfK 4945, Kernforschungszentrum Karlsruhe, Karlsruhe, Germany.

Lumetta, G. J., and J. L. Swanson. 1993. Pretreatment of Plutonium Finishing Plant (PFP) Sludge: Report for the Period October 1990-March 1992. PNL-8601, Pacific Northwest Laboratory, Richland, Washington.

Lumetta, G. J., M. J. Wagner, N. G. Colton, and E. O. Jones, 1993. Underground Storage Tank Integrated Demonstration, Evaluation of Pretreatment Options for Hanford Tank Wastes. PNL-8537, Pacific Northwest Laboratory, Richland, Washington.

Marsh, S. F., and S. J. Yarbro. 1988. Comparative Evaluation of DHDECMP and CMPO as Extractants for Recovering Actinides from Nitric Acid Waste Streams. LA-11191, Los Alamos National Laboratory, Los Alamos, New Mexico. 
Roberts, F. P., F. M. Smith, and E. J. Wheelwright. 1963. Recovery of Technetium from Hanford Waste. HW-SA-2851, General Electric Co., Richland, Washington.

Schulz, W. W. 1980. Removal of Radionuclides from Hanford Defense Waste Solutions.

RHO-SA-51, Rockwell Hanford Operations, Richland, Washington.

Smith, H. D., D. B. Mackey, K. H. Pool, and E. B. Schwenk. 1992. "Corrosion Resistance of Stainless Steels and High Ni-Cr Alloys to Acid Fluoride Wastes." In Proceedings of the Third International Conference on High Level Radioactive Waste Management, April 12-16, 1992. Las Vegas, Nevada.

Straalsund, J. L., J. L. Swanson, E. G. Baker, J. J. Holmes, E. O. Jones and W. L. Kuhn. 1992. Clean Option: An Alternative Strategy for Hanford Tank Waste Remediation, Volume 1. Overview. PNL-8388 Vol. 1, Pacific Northwest Laboratory, Richland, Washington.

Thompson, G. H., E. L. Childs, R. L. Kochen, R. J. Schmunk, C. M. Smith. 1979. Actinide Recovery from Combustible Waste: The $\mathrm{Ce}(I \mathrm{~V})-\mathrm{HNO}_{3}$ System Final Report. RFP-2907, Rocky Flats Plant, Golden, Colorado.

U.S. Department of Energy (DOE). 1987. Final Environmental Impact Statement - Disposal of Hanford Defense High-Level, Transuranic, and Tank Wastes, DOE/EIS-0113, Richland, Washington.

Vialard, E., and M. Germain. 1986. "Technetium Behavior Control in the Purex Process." ISEC ' 86 International Solvent Extraction Conference Preprints, p. 1-137. DECHEMA, Frankfurt am Main, Germany.

Wheelwright, E. J., L. A. Bray, H. H. Van Tuyl, and H. T. Fullam. 1974. Flowsheet for Recovery of Curium from Power Reactor Fuel Reprocessing Waste. BNWL-1831, Pacific Northwest Laboratory, Richland, Washington. 


\section{Distribution}

No. of

Coplea

OFrsite

12 DOE/Office of Scientific and Technical Information

J. C. Tseng

U.S. Department of Energy

EM-36, Trevion II Bldg.

12800 Middlebrook Road

Germantown, MD 20874

M. Attrep, Jr.

Los Alamos National Laboratory

P.O. Box 1663

SM30, MS-J514

Los Alamos, MM 87545

J. T. Bell

Oak Ridge National Laboratory

Bldg. 4501, MS-6223

P.O. Box 2008

Oak Ridge, TN 37831-6223

A. L. Blancett

Westinghouse Savannah River Company

Savannah River Technology Center

Alken, SC 29808

W. D. Bond

Oak Ridge National Laboratory

P.O. Box 2008, MS-6385

Oak Ridge, TN 37831-6223

N. E. Brown

Sandia National Laboratory

Albuquerque, NM 87185

D. O. Campbell

102 Windham Road

Oak Ridge, TN 37830
No. of

Coples

D. J. Chaiko

Argonne Natlonal Laboratory

9700 South Cass Avenue

Argonne, IL 60439

O. R. Choppin

Department of Chemistry, B-164

Florida State University

Tallahussee, FL 32306

E. D. Collins

Oak Ridge National Laboratory

P.O. Box 2008, MS-6385

Oak Ridge, TN 37831.6223

M. Coops

Lawrence Livermore National Laboratory

P.O. Box 808, MS L.352

Livermore, CA 94550

H. J. Dewey

Los Alamos National Laboratory

P.O. Box 1663

TA3, SM30, MS-H854

Los Alamos, NM 87545

T. Fryberger

U.S. Department of Energy

Trevion II Bldg.

12800 Middlebrook Road

Germantown, MD 20874

S. M. Gibson

U.S. Department of Energy

Trevion II Bldg.

12800 Middlebrook Road

Germantown, MD 20874

Distr. I 
No. of

Coples

M. T. Cordon

Department of Ecology

P. O. Box 47600

Olympia, WA 98504-7600

E. P. Horwitz

Argonne National Laboratory

9700 South Cass Avenue

Argonne, IL. 60439

A. L. Olson

Weatinghouse Idatio Nuclear Company

P.O. Box 4000

Idaho Falls, ID 83415

D. A. Orth

124 Vivion Dr.

Alken, SC 29803

D. O. Provout

Department of Ecology

P. O. Box 47600

Olympla, WA 98504-7600

W. W. Schulz

7200 Montgomery Blvd, N.E.

Box 127

Albuquerque, NM 87109

K. W. Thomas

Los Alamos National Laboratory

P.O. Box 1663, MS-J514

Los Alamos, NM 87545

M. C. Thompson

Westinghouse Savannah River Company

Savannah River Technology Center

Aiken, SC 29808

T. A. Todd

Westinghouse Idaho Nuclear Company

P.O. Box 4000

Idaho Falls, ID 83415
No. of

Copien.

O. F. Vandegrifit

Argonne National Laboratory

Bullding 205

9700 South Cass Avenue

Argonne, IL. 60439

S. M. Wolf

U.S. Department of Energy

BM-542. Trevion II Blds.

12800 Middlebrook Roud

Germantown. MD 20874

S. L. Yarbro

Los Almos National Laboratory

P.O. Box 1663

MS-ESO1

Los Alamos, NM 87545

\section{ONSITE}

3 DOE Richland Oparation Offlce

S. T. Burnum, R3-74

P. E. Lamont, R3-74

J. C. Peschong, R3.74

17 Watinghoure Hanford Company

J. N. Appel, S4-58

S. A. Barker, S4-55

K. D. Boomer, H5-49

A. L. Boldt, RI-20

S. A. Colby, L.5-31

R. G. Cowan, L5-31

R. L. Gllchrist, L5-63

H. D. Harmon, R2.52

J. J. Holmes, L5-55

C. Jansen, Jr., LO.14

B. J. Knutson, L0-14

M. J. Kupfer, H5-49

W. C. Miller, S4-55

D. J. Newland, B1-58

R. M. Orme, S4-58 
PNL.8388 Vol.2

UC. 721

No. of

No. of

Coples

\section{Coplew}

J. P. Sloughter, T6-07

L. Laverhass, P8.38

J. A. Voogd, H5-49

O. J. Lumetta, P7.25

O. B. Mellinger, K1-78

50 Badfla Northyeat Luborntory

E. O. Baker, P8-38

L. A. Bray, P7.25

C. H. Bryan, P7.25

C. D. Carlson, P7.25

N. O. Colton, P8-38

R. J. Hall, K8.28

M. S. Hanson, K1-S1

L. K. Holton, P7-43

B. M. Johnson, K1-78

E. O. Jones, P8-38

W. L. Kuhn, P8-38

D. E. Kurath, P7-43

R. J. Orth, P8-38

R. K. Quinn, K2-50

L. J. Sealock, Jr., K2-10

E. A. Schmieman, K8-37

L. J. Silva, P8-38

L. J. Snowden-Swan, P8-38

R. D. Scheele, P7.25

J. D. Spencer, K1-40

J. L. Straalsund (10), K1.79

J. L. Swanson (20), P7.25

W. O. Richmond, P7-41

Publishing Coordination

Technical Report Files (5)

Distr. 3 

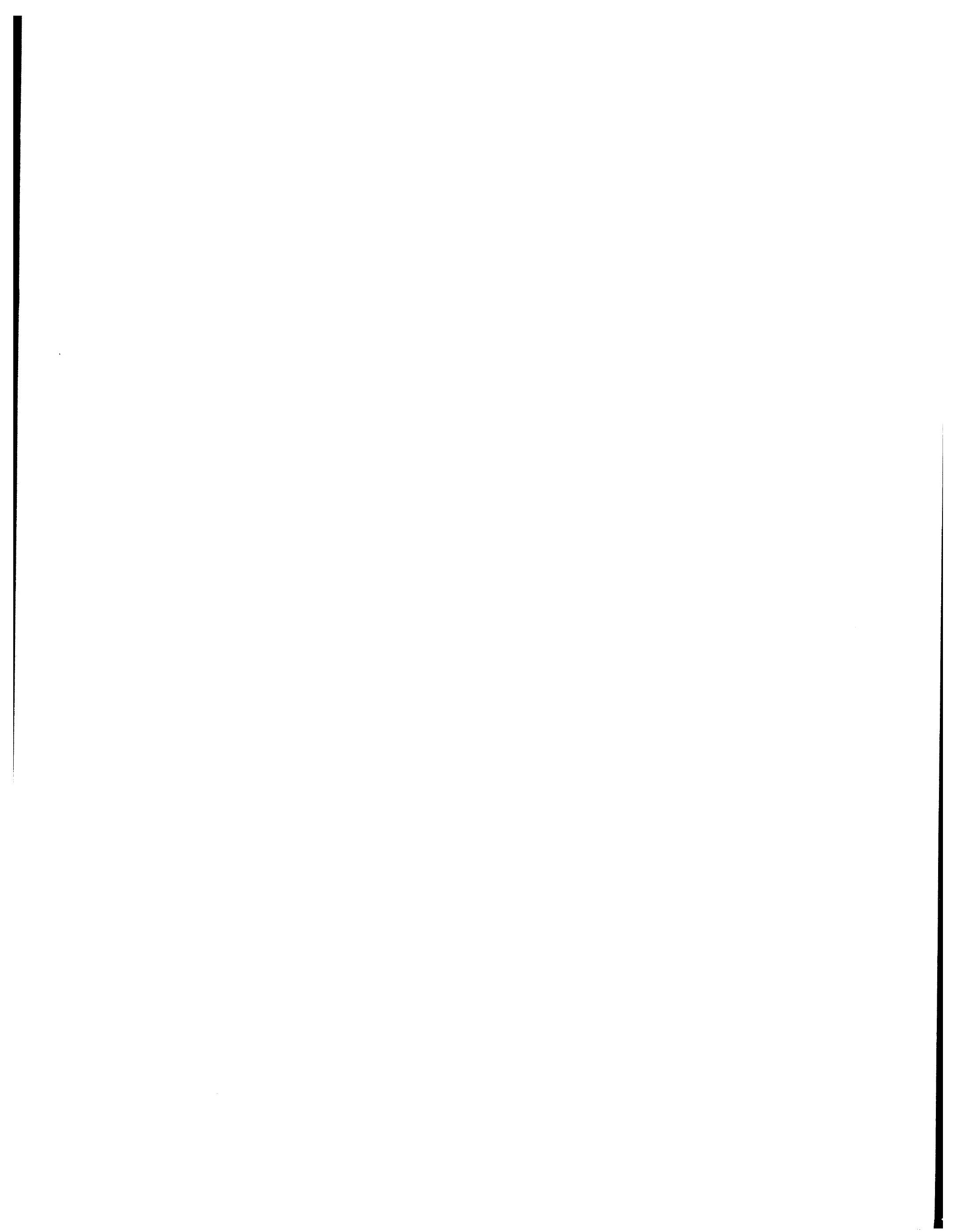